\title{
Review
}

Mehrdad Alizadeh, Yalda Vasebi, Naser Safaie*

\section{Microbial antagonists against plant pathogens in Iran: A review}

https://doi.org/10.1515/opag-2020-0031

received October 27, 2019; accepted May 18, 2020

\begin{abstract}
The purpose of this article was to give a comprehensive review of the published research works on biological control of different fungal, bacterial, and nematode plant diseases in Iran from 1992 to 2018. Plant pathogens cause economical loss in many agricultural products in Iran. In an attempt to prevent these serious losses, chemical control measures have usually been applied to reduce diseases in farms, gardens, and greenhouses. In recent decades, using the biological control against plant diseases has been considered as a beneficial and alternative method to chemical control due to its potential in integrated plant disease management as well as the increasing yield in an eco-friendly manner. Based on the reported studies, various species of Trichoderma, Pseudomonas, and Bacillus were the most common biocontrol agents with the ability to control the wide range of plant pathogens in Iran from lab to the greenhouse and field conditions.
\end{abstract}

Keywords: biological control, Trichoderma, Pseudomonas, Bacillus

\section{Introduction}

Increasing human population in the world demands more food (70 to 100\%) by 2050 to supply human needs (Godfray et al. 2010). Furthermore, different pests and diseases cause annual economic losses (20 to 40\%) in agricultural products by decreasing the crop yield, destroying the quality, and pollution of products with toxic chemicals

\footnotetext{
* Corresponding author: Naser Safaie, Department of Plant Pathology, Faculty of Agriculture, Tarbiat Modares University, Tehran, Iran, e-mail: nsafaie@modares.ac.ir Mehrdad Alizadeh: Department of Plant Pathology, Faculty of Agriculture, Tarbiat Modares University, Tehran, Iran Yalda Vasebi: Department of Plant Protection, Faculty of Agriculture, Tabriz University, Tabriz, Iran.
}

(Guo et al. 2013). Therefore, growers have generally concentrated on the intensive use of chemicals for the management of pests and diseases which induce several problems, including resistance to pesticides, hazardous effects on human health, loss of beneficial soil microorganisms, entrance of residual toxic material in the food chain, and reduction in macro-microorganism biodiversity (Sindhu et al. 2016). These problems make enhanced attempts for developing ecofriendly microbe-based pesticides or biopesticides which use biological control agents (BCAs) as active ingredients and basically act different from common chemical pesticides (Sindhu et al. 2009).

Biological control, which attracted broad considerations in the past few decades, is defined as a bioeffector strategy that uses other living organisms for controlling insects, mites, weeds, and phytopathogens (Flint et al. 1998). Biocontrol agents either with antagonistic activities, or modifying effects on plant physiology and anatomy, mostly reduce the negative effects of pathogens. The advantages of beneficial microbes for associated plants are establishment of antagonistic microorganisms, prevention of phytopathogens, overall improvement of plant health, plant growth promotion, enhanced nutrient availability and uptake, and increased resistance to both biotic and abiotic stresses in the hosts (Vinale et al. 2014).

The first published studies on biological control of plant pathogens in Iran were presented in 1992. Trichoderma spp. and Gliocladium spp. were the first biocontrol agents applied against Athelia rolfsii (Sclerotium rolfsii), Rhizoctonia solani, and Fusarium solani, the causal agents of diseases on groundnut, bean, and apple, respectively (Asghari and Myee 1992; Bazgir et al. 1992; Karampour and Okhovat 1992). In the twenty-first century, with the improvement of biological control of plant pathogens throughout Iran, different biocontrol agents have been applied against the various pathogens in vitro, in greenhouse and field conditions. A large number of fungal and bacterial biocontrol agents have been found as the most important agents for plant disease management with identification of their role in plant pathogen management (Ramadan et al. 2016). Trichoderma, Pseudomonas, and Bacillus species have mostly been used for biological control of phytopathogens in Iran (Peyghami 
and Nishabouri 1998; Shahiri Tabarestani et al. 2000; Mostofizadeh-Ghalamfarsa et al. 2002; Niknejad-Kazempour et al. 2004a,b; Golzary et al. 2008b; Peighami-Ashnaei et al. 2009a,b; Ojaghian et al. 2010; Khalighi and Khodakaramian 2012; Naeimi and Zare 2013; Azizpour and Rouhrazi 2016; Karimi et al. 2016; Khaledi and Taheri 2016; Abdoli et al. 2018; Hosini et al. 2018; Zeynadini-Riseh et al. 2018). Furthermore, because of increasing the stability of biological agents, the bioformulation progress has recently been evaluated in Iran (Karimi and Sadeghi 2015). The current study is a comprehensive review of applying fungal and bacterial antagonists for biological control of various plant diseases caused by fungal, bacterial, and nematodes in Iran during a period of 26 years.

\section{Mechanisms of biocontrol agents for the management of phytopathogens}

A key factor for attaining an effective prevention of phytopathogens in their hosts is the knowledge about their mechanism of action. Understanding the mechanisms in the biological control process can allow the establishment of favorable conditions in the interaction between phytopathogen and biocontrol agent that is important in performing a successful biological control strategy in a specific pathosystem (Handelsman and Stabb 1996). The microorganisms operating for biocontrol of phytopathogens have different modes of action (Nega 2014). In the present study, the most common mechanisms of interspecies antagonisms include direct antagonism, mixed-path antagonism, and indirect antagonism ( $\mathrm{Pal}$ and McSpadden 2006; Parveen et al. 2016), which lead to biological control of plant pathogens, have been addressed. Microbial biocontrol agents take care of plants against pathogens via different modes. These agents could induce resistance or initial enhanced resistance against pathogens without direct confrontation with the phytopathogen. Also, competitions for nutrients and spaces are additional indirect interactions with phytopathogens (Köhl et al. 2019). These agents might directly interact with the pathogens using hyperparasitism (Ghorbanpour et al. 2018) or antibiosis (Raaijmakers and Mazzola 2012). Without these agents in soil and tissues of plants, the pathogens easily attack plants and could weaken or kill considered hosts (Figure 1). These modes will be discussed in the following sentences.

\subsection{Parasitism}

Mycoparasitism, direct parasitism or hyperparasitism, is the ability of fungal antagonistic agents to parasite other fungi

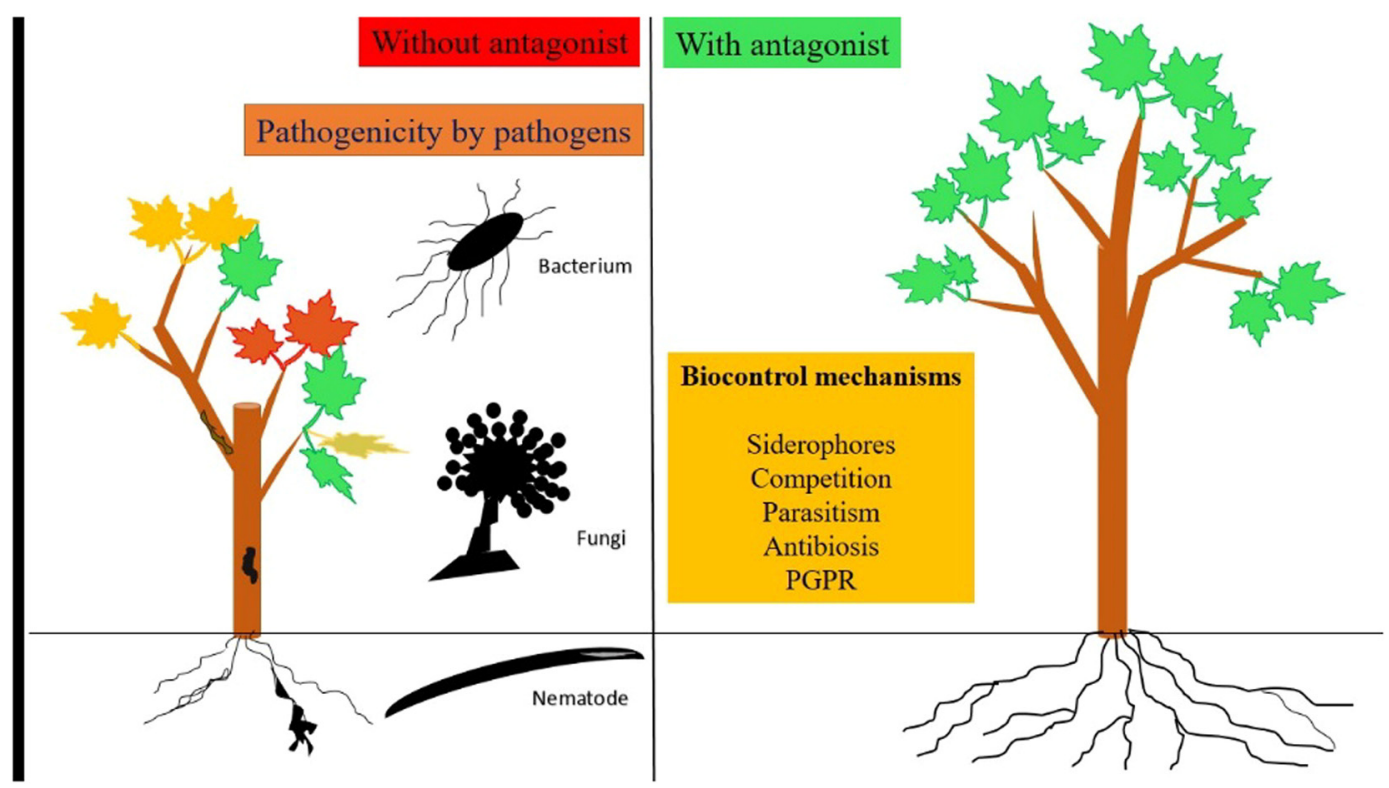

Figure 1: Left: in the absence of antagonists, different pathogens especially fungi, bacteria, and nematodes can cause losses in plants. Over time, affected plants will show the weakness in the development and symptoms of diseases. Right: in the presence of antagonists with different biocontrol mechanisms, such as competition, parasitism, and antibiosis, the pathogens will not be able to progress in the host, and thus, the plant can grow and develop well rather than the absence of antagonists in soil and tissues of hosts. 
for utilizing them as food. Mycoparasitism causes either complete death of fungal propagules or destruction and lysis of their structure (Maloy 1993). Mycoparasitism depends upon the sequential occurrence of the following events: coming into close contact with fungal pathogen, mutual recognition between antagonist and pathogen, lytic enzyme secretion by antagonist, penetration into the host, active growth of antagonist into the host, and exit (Spadaro and Gullino 2004; Talibi et al. 2014). Various chemical compounds can be implicated in these processes, such as lectins, during the initial contact and recognition and cell wall-degrading enzymes (CWDEs), such as $\beta$-1,3-glucanases, chitinases, proteinases, and lipases, during the penetration process (Vos et al. 2015). Wisniewski et al. (1991) who studied biological control of Botrytis cinerea by yeast antagonist Meyerozyma guilliermondii (Pichia guilliermondii) demonstrated that lectin-like interaction resulted in firm attachment of antagonist's cell to $B$. cinerea. Lysis of fungal cell wall also occurred due to the action of extracellular $\beta$-1,3-glucanase enzyme secreted by the antagonistic yeast. Trichoderma species are specific mycoparasitic fungi with the species of $T$. atroviride, T. virens, and $T$. reesei confirming that mycoparasitism is their ancestral lifestyle (Kubicek et al. 2011).

One of the main components in mycoparasitism event is CWDEs including endochitinases, $\beta-1,3$-glucanases, and proteases that are extracellular enzymes secreted by Trichoderma (Vos et al. 2015). After initial pathogen recognition by Trichoderma, hyphae wind around the pathogen's hyphae by forming hook, the appressorium permeates into the pathogen cell, and chitin is broken down by enzymes such as chitinase and glucanase (Ghorbanpour et al. 2018). Subsequently, mycoparasitic's hyphae release antibiotic compounds which penetrate the affected pathogen's hyphae and resynthesize the host cell wall inhibited by these compounds (Toghueoa et al. 2016).

\subsection{Antibiotic}

Antibiotic is a secreting secondary metabolite with low molecular weight that is deleterious to the other microorganisms at low concentrations (Fravel 1988). The antibiotic produced by biocontrol agents decreases the disease symptoms as a main contributing mechanism particularly under soil conditions (Haas and Défago 2005). Some soilborne microorganisms, such as different strains of fluorescent Pseudomonas and Bacillus (Weller 1988) and Trichoderma species (Benítez et al. 2004), have appropriate features for biocontrol abilities. Furthermore, several strains of these species are able to promote plant growth and development as well as the disease prevention (Fernando et al. 2006; Arseneault and Filion 2017). The antibiotics at subinhibitory concentrations may inhibit the release of extracellular virulence factors and adherence mechanisms in bacteria (Kumar et al. 2008). Secondary metabolites can impress the community of soil microbial ecosystems in a variety of ways and levels (Abawi and Widmer 2000). The antibiotic production has been confirmed to be an important mechanism applied by microorganisms to manage a wide range of plant pathogens (McSpadden and Fravel 2002). Even at subinhibitory concentrations, antibiotics can create physiological changes in organisms. For instance, in Pseudomonas aeruginosa quinolone and macrolide antibiotics can block cell signaling and production of virulence factors (Ulloa-Ogaz et al. 2015). Bacillus spp. produce enzymes, exotoxins, and metabolites with nematicidal activity (Engelbrecht et al. 2018). Although several rhizobacteria such as Pasteuria, Pseudomonas, and Streptomyces have nematicidal efficacy, the largest decrease in the hatching of Meloidogyne javanica eggs was found in Bacillus (74\%) and Pseudomonas (54.77\%) (Turatto et al. 2017). Furthermore, Bacillus spp. with antibiotic production are applied as antifungal antagonists for controlling postharvest diseases. Pyrrolnitrin antibiotic produced by Burkholderia cepacia has been used against Penicillium digitatum, $B$. cinerea, and Penicillium expansum pathogens. Similarly, syringomycin produced by Pseudomonas syringae was utilized to prevent citrus green mold and apple grey mold (Dukare et al. 2019). Alongside these beneficial microorganisms, Streptomyces spp. can help plants with antibiotic production against phytopathogens (Olanrewaju and Babalola 2019).

\subsection{Cell wall degradation enzymes}

Microorganisms which produce enzymes are able to hydrolyze chitin, proteins, cellulose, and hemicellulose and also may play a role in the suppression of plant pathogens. Chitin and $\beta$-1,3-glucans are major constituents of many fungal cell walls (Lam and Gaffney 1993). Trichoderma strains with antagonistic potential have been mainly characterized by their ability to secrete enzymes such as chitinases, glucanases, and proteases that hydrolyze the cell walls of pathogens (López-Mondéjar et al. 2011). Geraldine et al. (2013) reported that $N$ - $\beta$-acetylglucosaminidase and $\beta-1,3-$ glucanase are the key components of Trichoderma species action in biocontrol of Sclerotinia sclerotionum in the field. Serratia marcescens which produces chitinases was found to 
suppress the growth of Botrytis spp., R. solani, and Fusarium oxysporum (Ningaraju 2006).

\subsection{Competition for available resources}

Microorganisms' challenge for available resources is named competition. For instance, when pine stumps were inoculated by spores Phlebiopsis gigantea (Phlebia gigantea), the spores prevent from Heterobasidion annosum infections. Considering that the pathogen is non-established on the pine, the severity of root rot disease could be decreased by the biocontrol agent (Cook and Baker 1983). Despite the possibility of existing antagonistic relationship (e.g., antibiosis) between the two fungi, the achievement of available resource sites may be the first mechanism in competition (Maloy 1993). Carbon sources such as glucose and fructose are one of the important action modes in yeasts Papiliotrema laurentii (Cryptococcus laurentii) and Sporobolomyces roseus, which can control $B$. cinerea in decreasing its colonization and sporulation (Ghorbanpour et al. 2018). In the biological control of $P$. digitatum by Debaryomyces hansenii, competition plays an important role in obtaining nutrients in occupied sites (Droby et al. 1998). Furthermore, arbuscular mycorrhiza due to the creation of physiological and anatomical modifications can limit the progression of pathogen. These changes involve root lignification, creation of a thick cell wall using pectin, chitinase activation, and transfer of pathogenesis-related protein-1a to the infected area of root (Malik et al. 2016).

\subsection{Siderophore}

Low-molecular weight chelators with a very high and specific affinity for Fe(III) are called siderophores (Barbeau et al. 2002). Aerobic and facultative anaerobic microorganisms with the ability of siderophore production may have an important role in microorganism interactions (Haggag and Mohamed 2007). Siderophores have been known to play a significant role in phytopathogen prevention by several bacteria as BCAs which prevent the growth, development, and metabolic activity of phytopathogens by iron chelation (Haggag Wafaa et al. 2000). Different species of Trichoderma as biocontrol antagonists release more effective siderophores that chelate iron $\left(\mathrm{Fe}^{3+}\right)$ and prevent growth and development of other fungal pathogens (Naher et al. 2014). Iron competition can be a limiting factor in alkaline soils for microbial growth and development (Leong and Expert 1989). Siderophores produced by some bacteria, such as fluorescent pseudomonads, have very high dependency for iron, as a result, sequestering these limited resources from other microflora can inhibit their growth and development (Loper and Buyer 1991). In several studies, it has been reported that Pseudomonas fluorescens with siderophore biosynthesis plays an important role in the prevention of pathogen (Costa and Loper 1994). Rahnella aquatilis with siderophore production can inhibit $B$. cinerea and $P$. expansum postharvest pathogens (Calvo et al. 2007). The siderophore pulcherrimin produced by Metschnikowia pulcherrima and Monilinia fructicola yeasts was applied for biological control of postharvest apple pathogens B. cinerea, Alternaria alternata, and P. expansum (Saravanakumar et al. 2008). In particular, several species of Streptomyces detach iron by siderophore production in a way that some pathogens, owing to a lack of siderophore production, cannot take these ions for growth (Kloepper et al. 1980).

\subsection{Induction of host resistance}

Plant growth promoting rhizobacteria can protect plants against pathogens using induction of systemic resistance (ISR) (Sikora 1992). P. fluorescens with stimulating ISR can prevent the early penetration of Heterodera schachtii to roots (Oostendorp and Sikora 1989). The ISR stimulation by Bacillus subtilis leads to the protection of cotton plants against Meloidogyne incognita and Meloidogyne arenaria. The ISR stimulation by Pseudomonas putida and $S$. marcescens inhibited cucumber Fusarium wilt caused by F. oxysporum f.sp. cucumerinum. The application of Pseudomonas sp. in plants leads to systematic protection against F. oxysporum f.sp. dianthi (David et al. 2018). Flavimonas oryzihabitans, S. marcescens, and Bacillus pumilus have developed ISR against $P$. syringae pv. lachrymans (David et al. 2018).

The direct promotion of plant growth by plant growth promoting bacteria through the production of phytohormones has been called phytostimulation (Bloemberg and Lugtenberg 2001). The enzyme 1-aminocyclopropane-1carboxylate (ACC) deaminase is a phytostimulation that is the most studied one. Some bacterial endophytes producing ACC deaminase have been shown to enhance plant growth, such as Arthrobacter spp., Bacillus spp., P. putida, Rhodococcus spp. (Belimov et al. 2001; Sziderics et al. 2007), and Streptomyces spp. (Palaniyandi et al. 2014; Jaemsaeng et al. 2018). The bacterial strains producing 
other plant hormones, including indole-3-acetic acid (IAA), jasmonates, and abscisic acid, may also contribute to plant growth stimulation (Patten and Glick 2002; Forchetti et al. 2007). IAA is synthesized by different species of Streptomyces, such as $S$. violaceus, $S$. griseus, $S$. exfoliate, S. coelicolor, and S. lividans (Manulis et al. 1994). Also, IAA in $S$. atrovirens activates growth promoting bacteria in groundnut and several crops (Reddy et al. 2016).

\section{Reduction in the population of biocontrol agents}

Phytopathogens may significantly alleviate the growth of biocontrol agents by using the nutrition resources within their occupied spaces more rapidly as well as by modifying their efficacy. This was found in several fungal root pathogens which can colonize the wheat rhizosphere despite the presence of $P$. fluorescens biocontrol agent (Mazzola and Cook 1991). Decline in the population of $P$. fluorescens occurs in the existence of some Pythium species. In this instance, infection by Pythium species leads to the limitation of the root surface which is available for $P$. fluorescens colonization and to the reduction of population of potential antagonists. Fedi et al. (1997) reported that a plant pathogenic $P$. ultimum with modification of gene expression of $P$. fluorescens tends to decrease biocontrol agent population. The competition in the rhizosphere for nutrients released from root wounds caused by $P$. ultimum was limited by the reduction of population size. Because of the importance of microbial community in number and diversity, competition and microorganism-microorganism interactions may also happen in phyllosphere (Vorholt 2012). On the other hand, existence of these microbial communities may also impress the efficacy of BCAs. Understanding the rhizosphere, phyllosphere, and endosphere microbial community structure and their interactions in these niches can contribute to the betterment of biocontrol (Bardin et al. 2015).

\section{Improving the biocontrol agent effects}

The use of combinations of BCAs may be a better method for developing biocontrol positive effects
(Duffy and Weller 1995). Combined biocontrol agents with high level of biocontrol protection have been investigated for better efficacy and prevention of several phytopathogens (Mihajlović et al. 2017). It has been confirmed that natural prevention of Fusarium wilt in France (Châteaurenard soil) was related to the different mechanisms in which multiple microorganisms singly or together restricted the pathogen activation (Alabouvette et al. 1998). However, given that the application of biological control against soilborne pathogens will not be a good replacement of methyl bromide fumigation, these two methods could act together in integrated pest management (Akrami et al. 2011).

\section{Biological control in Iran}

A complete list of all pathogens and the antagonists used against them is provided in Table 1. Results showed that most studies were conducted in vitro and in greenhouse conditions, and a few cases were carried out in the farm condition in Iran. Bacterial strains belonging to 24 genera, Achromobacter, Acinetobacter, Azotobacter, Bacillus, Beauveria, Bradyrhizobium, Brochothrix, Burkholderia, Enterobacter, Erwinia, Escherichia, Flavobacterium, Lactobacillus, Mesorhizobium, Paenibacillus, Pantoea, Pasteuria, Pseudomonas, Rhizobium, Serratia, Sphingomonas, Sporolactobacillus, Stenotrophomonas, and Streptomyces, have been used in various studies. Also, fungal strains belonging to 27 genera, Acremonium, Alternaria, Arthrinium, Arthrobotrys, Aspergillus, Chaetomium, Cladobotryum, Coniothyrium, Embellisia, Fusarium, Gliocladium, Glomus, Hypsizygus, Lecythophora, Metarhizium, Paecilomyces, Penicillium, Periconia, Piriformospora, Pleurotus, Pythium, Scopulariopsis, Sebacina, Talaromyces, Trichoderma, Trichothecium, and Verticillium, have been applied in Iranian studies against different plant pathogens. Also, strains of ten genera, Candida, Galactomyces, Hanseniaspora, Metschnikowia, Meyerozyma, Pichia, Rhodotorula, Saccharomyces, Torulaspora, and Zygoascus, which belong to the yeast have been used for controlling the phytopathogens in Iran. The bacterial strains related to different species of Pseudomonas and Bacillus and fungal strains related to Trichoderma species had the greatest efficiency in biological control of different plant pathogens in Iran. These antagonists have been mostly used for biological control of fungi, bacteria, and nematodes, respectively. 
Table 1: List of pathogens, hosts, and antagonists with procedures based on published research works in Iran from 1992 to 2018

\begin{tabular}{|c|c|c|c|c|}
\hline Pathogens & Host & Antagonists & Procedure & Ref. \\
\hline Rhizoctonia solani & Bean & Gliocladium sp. & $\begin{array}{l}\text { In vitro and } \\
\text { greenhouse }\end{array}$ & Bazgir et al. (1992) \\
\hline Athelia rolfsii (Sclerotium rolfsii) & Groundnut & Trichoderma harzianum & Greenhouse & Asghari and Myee (1992) \\
\hline Fusarium solani & Apple & $\begin{array}{l}\text { T. koningii, } T . \text { viride, } \\
\text { T. harzianum, and } T . \text { virens } \\
\text { (Gliocladium virens) }\end{array}$ & Greenhouse & $\begin{array}{l}\text { Karampour and } \\
\text { Okhovat (1992) }\end{array}$ \\
\hline Colletotrichum coccodes & Potato & Trichoderma spp. & In vitro & Okhovat et al. (1994) \\
\hline R. solani & Rice & $\begin{array}{l}\text { T. koningii, T. viride, } \\
\text { T. harzianum, and T. virens }\end{array}$ & Field & $\begin{array}{l}\text { Izadyar and } \\
\text { Padasht (1994) }\end{array}$ \\
\hline R. solani & Rice & Trichoderma sp. & In vitro & $\begin{array}{l}\text { Pourabdullah and } \\
\text { Binesh (1994) }\end{array}$ \\
\hline Phytophthora erythroseptica & Potato & $\begin{array}{l}\text { T. harzianum, T. viride, and } \\
\text { T. koningii }\end{array}$ & In vitro & Zafari et al. (1994) \\
\hline R. solani & Bean & $\begin{array}{l}T . \text { viride, } T . \text { harzianum, and } \\
T . \text { virens }\end{array}$ & Greenhouse & Bazgir et al. (1994a) \\
\hline R. solani & Bean & $\begin{array}{l}T . \text { viride, } T \text {. harzianum, and } \\
T . \text { virens }\end{array}$ & Field & Bazgir et al. (1994b) \\
\hline Scelotinia sclerotiorum & Eggplant & $\begin{array}{l}\text { T. reesei, } T . \text { hamatum, } \\
T . \text { longibrachiatum, } T . \text { koningii, } \\
T . \text { viride, } T . \text { virens, and } \\
\text { Gliocladium } \mathrm{sp.}\end{array}$ & In vitro & Amir-Sadeghi et al. (1994) \\
\hline $\begin{array}{l}\text { Macrophomina sp. and } \\
\text { Rhizoctonia sp. }\end{array}$ & Soybean & Bacillus subtilis & $\begin{array}{l}\text { In vitro and } \\
\text { greenhouse }\end{array}$ & Sanei and Ghobadi (1995) \\
\hline Heterodera schachtii & Sugar beet & Paecilomyces farinosus & In vitro & Ahmadi et al. (1995a) \\
\hline H. schachtii & Sugar beet & F. solani & In vitro & Ahmadi et al. (1995b) \\
\hline H. schachtii & Sugar beet & $\begin{array}{l}\text { Acremonium spp., Embellisia } \\
\text { chlamydospora, Fusarium spp., } \\
\text { P. lilacinus, Scopulariopsis } \\
\text { brevicaulis, Verticillium } \\
\text { chlamydosporium, and } \\
\text { Verticillium lecanii }\end{array}$ & In vitro & $\begin{array}{l}\text { Hojjat Jalali and } \\
\text { Coosemans (1995) }\end{array}$ \\
\hline Tilletia laevis & Cucumber & T. viride & Greenhouse & $\begin{array}{l}\text { Peyghami and } \\
\text { Babadoost (1996) }\end{array}$ \\
\hline T. controversa & Wheat & T. viride & Greenhouse & $\begin{array}{l}\text { Peyghami and } \\
\text { Babadoost (1996) }\end{array}$ \\
\hline F. solani & Chickpea & $\begin{array}{l}\text { T. koningii, } T \text {. viride, } \\
T . \text { harzianum, and } T \text {. virens }\end{array}$ & Greenhouse & $\begin{array}{l}\text { Okhowat and } \\
\text { Karampour (1996) }\end{array}$ \\
\hline M. javanica & - & Pasteuria penetrans & Greenhouse & Damadzadeh et al. (1996) \\
\hline $\begin{array}{l}\text { M. javanica, } M . \text { incognita, and } \\
\text { M. arenaria }\end{array}$ & - & P. penetrans & In vitro & Ameri et al. (1996) \\
\hline $\begin{array}{l}\text { Macrophomina phaseolina and } \\
\text { R. solani }\end{array}$ & Soybean & B. subtilis & In vitro & $\begin{array}{l}\text { Sanei and } \\
\text { Ghobadi (1996) }\end{array}$ \\
\hline H. schachtii & Sugar beet & $\begin{array}{l}\text { E. chlamydospora, Acremonium } \\
\text { spp., S. brevicaulis, P. lilacinus, } \\
\text { Fusarium spp., V. } \\
\text { chlamydosporium, and V. lecanii }\end{array}$ & In vitro & $\begin{array}{l}\text { Hojjat-Jalali and } \\
\text { Coosemans (1995) }\end{array}$ \\
\hline Pythium ultimum & Chickpea & $T$. viride and $T$. virens & Field & Shahriary et al. (1996) \\
\hline M. javanica & Tomato & P. lilacinus & Greenhouse & Fatemy (1996) \\
\hline H. schachtii & Sugar beet & P. farinosus & In vitro & Ahmadi et al. (1996a) \\
\hline H. schachtii & Sugar beet & F. solani & In vitro & Ahmadi et al. (1996b) \\
\hline $\begin{array}{l}\text { R. solani, Colletotrichum } \\
\text { coccodes, and Phytophthora } \\
\text { drechsleri }\end{array}$ & - & $\begin{array}{l}\text { Trichoderma spp. and } \\
\text { Gliocladium sp. }\end{array}$ & In vitro & Okhovat (1997) \\
\hline H. schachtii & Beet & Paecilomyces fumosoroseus & Greenhouse & $\begin{array}{l}\text { Fatemy and Ahmadian } \\
\text { Yazdi (1997) }\end{array}$ \\
\hline F. o. f.sp. cucumerinum & Cucumber & T. harzianum & Greenhouse & $\begin{array}{l}\text { Peyghami and } \\
\text { Nishabouri (1998) }\end{array}$ \\
\hline
\end{tabular}


Table 1: continued

\begin{tabular}{|c|c|c|c|c|}
\hline Pathogens & Host & Antagonists & Procedure & Ref. \\
\hline A. rolfsii (S. rolfsii) & Groundnut & $\begin{array}{l}\text { T. aureoviride, } T . \text { hamatum, } \\
T . \text { longibrachiatum, } \\
T . \text { harzianum, } T . \text { virens }\end{array}$ & In vitro & Mirhosaini et al. (1998) \\
\hline $\begin{array}{l}\text { R. solani, Bipolaris sorokiniana, } \\
\text { and Fusarium culmorum }\end{array}$ & Wheat & Penicillium polonicum & Greenhouse & Mansoori (1998) \\
\hline Ph. capsici & Pepper & $\begin{array}{l}\text { Trichoderma sp. and } \\
\text { Gliocladium sp. }\end{array}$ & In vitro & Behboodi et al. (1998) \\
\hline P. ultimum & - & Pythium oligandrum & In vitro & Rahnama and Cooke (1998) \\
\hline Pythium butleri & - & Aspergillus niger & In vitro & Rouhani and Safari 1998 \\
\hline Mauginiella scaettae & Date palm & T. koningii and $T$. viride & Field & $\begin{array}{l}\text { Shetab-Booshehri } \\
\text { et al. (1998) }\end{array}$ \\
\hline $\begin{array}{l}\text { Xanthomonas translucens pv. } \\
\text { cerealis }\end{array}$ & Wheat & $\begin{array}{l}\text { Pantoea agglomerans and } \\
\text { Pseudomonas fluorescens }\end{array}$ & Greenhouse & $\begin{array}{l}\text { Marefat and Rand } \\
\text { Rahimian (1998) }\end{array}$ \\
\hline F. o. f.sp. lycopersici & Tomato & T. harzianum and $T$. viride & Greenhouse & Niknejad et al. (2000) \\
\hline Erwinia amylovora & Pear & $\begin{array}{l}\text { Erwinia herbicola and } \\
P . \text { fluorescens }\end{array}$ & $\begin{array}{l}\text { In vitro, } \\
\text { greenhouse, } \\
\text { and field }\end{array}$ & Ahmadi et al. (2000) \\
\hline S. sclerotiorum & Aubergine & $\begin{array}{l}\text { T. harzianum, T. virens, } \\
\text { T. koningii, Trichoderma } \\
\text { pseudokoningii, and Gliocladium } \\
\text { deliquescens }\end{array}$ & $\begin{array}{l}\text { In vitro and } \\
\text { greenhouse }\end{array}$ & Omrani et al. (2000) \\
\hline M. phaseolina & Soybean & $\begin{array}{l}T . \text { viride, } T . \text { koningii, and } \\
T . \text { harzianum }\end{array}$ & In vitro & Ghaffarian et al. (2000) \\
\hline R. solani & Rice & $\begin{array}{l}\text { T. viride, } T \text {. koningii, and } \\
\text { T. harzianum }\end{array}$ & Field & Izadyar et al. (2000a) \\
\hline Verticillium dahliae & Cotton & Talaromyces flavus & $\begin{array}{l}\text { In vitro and } \\
\text { greenhouse }\end{array}$ & Naraghi et al. (2000) \\
\hline V. dahliae & Cotton & $\begin{array}{l}\text { Pseudomonas sp. and } \\
\text { Bacillus sp. }\end{array}$ & In vitro & Azad Disfani et al. (2000) \\
\hline R. solani & Sugar beet & $\begin{array}{l}\text { T. harzianum, } T \text {. viride, and } \\
\text { T. virens }\end{array}$ & $\begin{array}{l}\text { In vitro and } \\
\text { greenhouse }\end{array}$ & $\begin{array}{l}\text { Shahiri Tabarestani } \\
\text { et al. }(2000)\end{array}$ \\
\hline R. solani & Rice & $\begin{array}{l}T . \text { harzianum, } T . \text { viride, } \\
T . \text { koningii, and } T . \text { virens }\end{array}$ & In vitro & Izadyar et al. (2000b) \\
\hline R. solani & Rice & $\begin{array}{l}T . \text { harzianum, } T . \text { viride, and } \\
T . \text { virens }\end{array}$ & $\begin{array}{l}\text { In vitro and } \\
\text { greenhouse }\end{array}$ & $\begin{array}{l}\text { Niknejad-Kazempour } \\
\text { et al. }(2000)\end{array}$ \\
\hline Neofusicoccum mangiferae & Citrus & $\begin{array}{l}\text { T. harzianum, } T . \text { virens, } \\
T . \text { koningii, and } \\
T . \text { longibrachiatum }\end{array}$ & In vitro & Taheri et al. (2000) \\
\hline S. sclerotiorum & Mulberry & $\begin{array}{l}\text { T. harzianum, T. viride, } \\
\text { T. aureoviride, T. koningii, } \\
\text { T. saturniporum, } \\
\text { T. pseudokoningii, and } \\
\text { T. longibrachiatum }\end{array}$ & In vitro & Merat et al. (2000) \\
\hline $\begin{array}{l}\text { Fusarium spp., Sclerotium } \\
\text { cepivorum, Pythium spp., and } \\
\text { R. solani }\end{array}$ & Onion & T. harzianum and $T$. viride & Greenhouse & Peyghami (2001) \\
\hline R. solani & Rice & $\begin{array}{l}\text { T. harzianum, } T \text {. viride, and } \\
T \text {. virens }\end{array}$ & $\begin{array}{l}\text { In vitro and } \\
\text { greenhouse }\end{array}$ & $\begin{array}{l}\text { Niknejad Kazempour } \\
\text { et al. (2002) }\end{array}$ \\
\hline $\begin{array}{l}\text { Gaeumannomyces graminis var. } \\
\text { tritici }\end{array}$ & Wheat & $T$. harzianum and $T$. viride & Greenhouse & Foroutan et al. (2002) \\
\hline $\begin{array}{l}\text { F. avenaceum, F. graminearum, } \\
\text { F. culmorum, F. moniliforme, } \\
\text { F. oxysporum, F. solani, } \\
\text { F. semitectum, F. sambucinum, } \\
\text { F. proliferatum, and } F \text {. tricinctum }\end{array}$ & Wheat & $\begin{array}{l}P . \text { fluorescens, } P \text {. syringae, } \\
P . \text { putida, } P \text {. cichorii, } \\
P . \text { aeruginosa, } P \text {. aureofaciens, } \\
\text { and } P . \text { viridiflava }\end{array}$ & In vitro & $\begin{array}{l}\text { Mostofizadeh- } \\
\text { Ghalamfarsa et al. (2002) }\end{array}$ \\
\hline
\end{tabular}


Table 1: continued

\begin{tabular}{|c|c|c|c|c|}
\hline Pathogens & Host & Antagonists & Procedure & Ref. \\
\hline G. graminis var. tritici & Wheat & Pseudomonas spp. & $\begin{array}{l}\text { In vitro and } \\
\text { greenhouse }\end{array}$ & Sedaghatfar et al. (2002) \\
\hline G. graminis var. tritici & Wheat & T. harzianum and T. viride & $\begin{array}{l}\text { In vitro and } \\
\text { greenhouse }\end{array}$ & Foroutan et al. (2002) \\
\hline $\begin{array}{l}\text { F. graminearum, F. moniliforme, } \\
\text { F. nygamai, F. oxysporum, } \\
\text { F. proliferatum, F. sambucinum, } \\
\text { F. semitectum, F. solani, and } \\
\text { F. tricinctum }\end{array}$ & Wheat & Pseudomonas spp. & In vitro & $\begin{array}{l}\text { Mostofizadeh- } \\
\text { Ghalamfarsa et al. (2002) }\end{array}$ \\
\hline F. o. f.sp. melonis & Melon & $\begin{array}{l}\text { Streptomyces sp., } T \text {. harzianum, } \\
T . \text { virens, and } T . \text { viride }\end{array}$ & $\begin{array}{l}\text { In vitro and } \\
\text { greenhouse }\end{array}$ & Ashrafizadeh et al. (2002) \\
\hline M. javanica & Tomato & P. lilacinus & Greenhouse & $\begin{array}{l}\text { Pakniat and } \\
\text { Banihashemi (2002) }\end{array}$ \\
\hline Ph. drechsleri & Cucurbit & Streptomyces sp. & In vitro & $\begin{array}{l}\text { Heidari Faroughi } \\
\text { et al. (2002) }\end{array}$ \\
\hline F. graminearum & Wheat & $\begin{array}{l}\text { Streptomyces sp., Pseudomonas } \\
\text { sp., and Bacillus sp. }\end{array}$ & In vitro & Norouzian et al. (2002) \\
\hline Sclerotinia minor & Sunflower & $\begin{array}{l}T . \text { harzianum, } T . \text { viride, and } \\
T . \text { virens }\end{array}$ & In vitro & $\begin{array}{l}\text { Abdollahzadeh } \\
\text { et al. (2003) }\end{array}$ \\
\hline Ph. drechsleri & Cantaloupe & $\begin{array}{l}\text { T. harzianum, } T \text {. viride, and } \\
T . \text { virens }\end{array}$ & Greenhouse & $\begin{array}{l}\text { Heidari Faroughi } \\
\text { et al. (2004) }\end{array}$ \\
\hline Tilletia indica & Wheat & $\begin{array}{l}T . \text { longibrachiatum, } \\
T . \text { harzianum, and } T . \text { viride }\end{array}$ & Greenhouse & $\begin{array}{l}\text { Beeazar and } \\
\text { Torabi }(2004)\end{array}$ \\
\hline F. o. f.sp. ciceri & Chickpea & T. longibrachiatum & Greenhouse & Karimi et al. (2004a) \\
\hline F. o. f.sp. ciceri & Chickpea & Bacillus sp. & In vitro & Karimi et al. (2004b) \\
\hline F. o. f.sp. dianthi & Carnation & P. fluorescens and Bacillus sp. & Greenhouse & Karimi et al. (2004c) \\
\hline R. solani & Chickpea & $\begin{array}{l}T . \text { harzianum, } T . \text { viride, and } \\
T . \text { virens }\end{array}$ & Greenhouse & Mohammadi et al. (2004) \\
\hline B. sorokiniana & Wheat & $\begin{array}{l}\text { B. subtilis, } P \text {. fluorescens, and } \\
\text { Bacillus pumilus }\end{array}$ & Greenhouse & Mohammadi et al. (2004) \\
\hline M. phaseolina & Soybean & T. harzianum & Greenhouse & Barari et al. (2004) \\
\hline Armillaria mellea & - & $\begin{array}{l}\text { Cladobotryum polypore, } \\
\text { C. varium, C. dendroides, and } \\
\text { C. verticillatum }\end{array}$ & In vitro & $\begin{array}{l}\text { Asef and Mohammadi- } \\
\text { Gholtapeh (2004) }\end{array}$ \\
\hline T. laevis & Wheat & B. subtilis & Greenhouse & Khodaygan et al. (2004) \\
\hline B. sorokiniana & Wheat & $\begin{array}{l}\text { Trichoderma sp. and } \\
\text { Streptomyces sp. }\end{array}$ & Greenhouse & Salehpour et al. (2004) \\
\hline R. solani & Rice & P. fluorescens & $\begin{array}{l}\text { Field and } \\
\text { greenhouse }\end{array}$ & $\begin{array}{l}\text { Niknejad- } \\
\text { Kazempour (2004) }\end{array}$ \\
\hline F. moniliforme & Rice & P. fluorescens & In vitro & $\begin{array}{l}\text { Niknejad-Kazempour } \\
\text { et al. (2004) }\end{array}$ \\
\hline R. solani & Rice & $\begin{array}{l}\text { Bacillus cereus and } \\
\text { P. fluorescens }\end{array}$ & In vitro & Sajjadi et al. (2004) \\
\hline Pyricularia grisea & Rice & $\begin{array}{l}\text { Bacillus megaterium, B. subtilis, } \\
\text { Bacillus circulans, and } \\
\text { P. fluorescens }\end{array}$ & Field & $\begin{array}{l}\text { Padasht-Dehkaei } \\
\text { et al. (2004) }\end{array}$ \\
\hline F. oxysporum & Onion & $\begin{array}{l}\text { B. cereus, B. subtilis, and } \\
\text { P. fluorescens }\end{array}$ & Field & Saberi-Riseh et al. (2004) \\
\hline Ph. citrophthora & Pistachio & P. fluorescens & Field & Saberi-Riseh et al. (2004) \\
\hline P. ultimum & Cucumber & $\begin{array}{l}\text { B. subtilis, Trichoderma sp., and } \\
\text { P. fluorescens }\end{array}$ & Greenhouse & Taghinasab et al. (2004) \\
\hline F. oxysporum & Basal & $B$. cereus and $P$. fluorescens & $\begin{array}{l}\text { Greenhouse } \\
\text { and field }\end{array}$ & $\begin{array}{l}\text { Ramezani-Baghmishezad } \\
\text { et al. (2004) }\end{array}$ \\
\hline
\end{tabular}


Table 1: continued

\begin{tabular}{|c|c|c|c|c|}
\hline Pathogens & Host & Antagonists & Procedure & Ref. \\
\hline S. sclerotiorum & Rapeseed & Bacillus spp. & In vitro & $\begin{array}{l}\text { Akbari-Kiarodi } \\
\text { et al. (2004) }\end{array}$ \\
\hline R. solani & Cotton & Bacillus sp. and $P$. fluorescens & $\begin{array}{l}\text { In vitro and } \\
\text { greenhouse }\end{array}$ & Heydari et al. (2004) \\
\hline Gibberella fujikuroi & Rice & $\begin{array}{l}\text { T. virens, T. harzianum, Bacillus } \\
\text { sp., B. subtilis, and B. circulans }\end{array}$ & $\begin{array}{l}\text { In vitro and } \\
\text { greenhouse }\end{array}$ & $\begin{array}{l}\text { Padasht Dehkaei } \\
\text { et al. (2004) }\end{array}$ \\
\hline Xanthomonas axonopodis pv. citri & Citrus & $P$. fluorescens and $P$. putida & $\begin{array}{l}\text { In vitro and } \\
\text { greenhouse }\end{array}$ & Khodakaramian (2004) \\
\hline F. oxysporum & Chickpea & B. subtilis and $P$. fluorescens & $\begin{array}{l}\text { Greenhouse } \\
\text { and field }\end{array}$ & Jamali et al. (2004) \\
\hline R. solani & Sugar beet & B. subtilis & $\begin{array}{l}\text { In vitro and } \\
\text { greenhouse }\end{array}$ & Shahiri et al. (2005) \\
\hline B. sorokiniana & Wheat & B. subtilis and P. fluorescens & $\begin{array}{l}\text { In vitro and } \\
\text { greenhouse }\end{array}$ & Mohammadi et al. (2005) \\
\hline Ph. capsici & Pepper & $\begin{array}{l}\text { T. viride, } T \text {. koningii, } \\
T . \text { harzianum, and } T . \text { virens }\end{array}$ & $\begin{array}{l}\text { In vitro and } \\
\text { greenhouse }\end{array}$ & Behboudi et al. (2005) \\
\hline S. sclerotiorum & Rapeseed & $\begin{array}{l}\text { B. cereus, B. subtilis, and } \\
\text { P. fluorescens }\end{array}$ & In vitro & Akbari et al. $(2005 a, b)$ \\
\hline F. graminearum & Wheat & $\begin{array}{l}\text { P. aeruginosa, B. subtilis, and } \\
\text { P. fluorescens }\end{array}$ & Greenhouse & Foroutan et al. (2005) \\
\hline V. dahliae & - & $\begin{array}{l}\text { Streptomyces plicatus and } \\
\text { Frankia sp. }\end{array}$ & In vitro & $\begin{array}{l}\text { Shahidi Bonjar and } \\
\text { Aghighi (2005) }\end{array}$ \\
\hline Pseudomonas tolaasii & $\begin{array}{l}\text { Agaricus } \\
\text { bisporus }\end{array}$ & P. fluorescens & $\begin{array}{l}\text { In vitro and } \\
\text { greenhouse }\end{array}$ & $\begin{array}{l}\text { Khabbaz Jolfaei } \\
\text { et al. (2005) }\end{array}$ \\
\hline $\begin{array}{l}R . \text { solani, F. oxysporum, F. solani, } \\
\text { and } C . \text { coccodes }\end{array}$ & Potato & T. harzianum & $\begin{array}{l}\text { Greenhouse } \\
\text { and field }\end{array}$ & Soltani et al. (2006) \\
\hline S. sclerotiorum & Sunflower & $\begin{array}{l}\text { T. harzianum, } T \text {. viride, and } \\
\text { T. virens }\end{array}$ & In vitro & $\begin{array}{l}\text { Abdollahzadeh } \\
\text { et al. (2006) }\end{array}$ \\
\hline M. javanica and $M$. incognita & Pistachio & P. penetrans & Greenhouse & $\begin{array}{l}\text { Karimipourfard and } \\
\text { Damadzadeh (2006) }\end{array}$ \\
\hline $\begin{array}{l}\text { R. solani, F. oxysporum, F. solani } \\
\text { and Lasiodiplodia sp. }\end{array}$ & Mulberry & P. fluorescens and Bacillus spp. & In vitro & $\begin{array}{l}\text { Niknejad-Kazempour } \\
\text { et al. (2006) }\end{array}$ \\
\hline Ph. cactorum & Apple & P. fluorescens and B. subtilis & Greenhouse & Farzaneh et al. (2006) \\
\hline F. o. f.sp. tuberosi & Potato & P. fluorescens & Greenhouse & $\begin{array}{l}\text { Khorasani-Aghazadeh } \\
\text { et al. (2006) }\end{array}$ \\
\hline R. solani & Common bean & Burkholderia cepacia & Greenhouse & $\begin{array}{l}\text { Ahmadzadeh et al. } \\
(2006 \mathrm{~b})\end{array}$ \\
\hline Ascochyta rabiei & Chickpea & T. harzianum & Greenhouse & Bahrami et al. (2006) \\
\hline F. graminearum & Wheat & $\begin{array}{l}\text { Streptomyces sp., P. fluorescens, } \\
\text { and B. subtilis }\end{array}$ & $\begin{array}{l}\text { In vitro and } \\
\text { greenhouse }\end{array}$ & Nourozian et al. (2006) \\
\hline Bipolaris spicifera & Wheat & Bacillus sp. and $P$. fluorescens & Greenhouse & Behdani et al. (2006) \\
\hline R. solani & Bean & P. fluorescens & Greenhouse & $\begin{array}{l}\text { Afsharmanesh et } \\
\text { al. (2006) }\end{array}$ \\
\hline $\begin{array}{l}\text { M. phaseolina, } R . \text { solani, Ph. } \\
\text { nicotianae var. parasitica, } \\
\text { Pythium sp., and Fusarium sp. }\end{array}$ & $\begin{array}{l}\text { Soybean, } \\
\text { pistachio, bean, } \\
\text { pepper, and } \\
\text { cucumber }\end{array}$ & Pseudomonas spp. & In vitro & $\begin{array}{l}\text { Ahmadzadeh et al. } \\
(2006 a)\end{array}$ \\
\hline V. dahliae & Cucumber & $\begin{array}{l}\text { B. subtilis, } P \text {. fluorescens, and } \\
\text { B. pumilus }\end{array}$ & Greenhouse & Ahmadifar et al. (2006) \\
\hline R. solani & Rice & P. fluorescens & In vitro & Kazemzadeh et al. (2006) \\
\hline T. laevis & Wheat & P. putida and $P$. fluorescens & Greenhouse & Khodaygan et al. (2006) \\
\hline Ph. sojae & Soybean & Pseudomonas spp. & Greenhouse & Zebarjad et al. (2006) \\
\hline R. solani & Rice & $\begin{array}{l}\text { B. cereus, B. subtilis, and } \\
\text { P. fluorescens }\end{array}$ & Greenhouse & Sajadi et al. (2006) \\
\hline
\end{tabular}


Table 1: continued

\begin{tabular}{|c|c|c|c|c|}
\hline Pathogens & Host & Antagonists & Procedure & Ref. \\
\hline M. phaseolina & Melon & T. harzianum and T. virens & $\begin{array}{l}\text { In vitro and } \\
\text { glasshouse }\end{array}$ & Etebarian (2006) \\
\hline F. graminearum & Wheat & $\begin{array}{l}\text { B. cereus, B. subtilis, } \\
\text { P. fluorescens, and E. herbicola }\end{array}$ & $\begin{array}{l}\text { Greenhouse } \\
\text { and field }\end{array}$ & Alimi et al. (2006) \\
\hline $\begin{array}{l}\text { Ralstonia solanacearum and } \\
\text { Pectobacterium carotovorum } \\
\text { subsp. carotovorum }\end{array}$ & $\begin{array}{l}\text { Pistachio, olive, } \\
\text { potato, and } \\
\text { cotton }\end{array}$ & S. plicatus and Frankia sp. & In vitro & $\begin{array}{l}\text { Shahidi Bonjar } \\
\text { et al. (2006) }\end{array}$ \\
\hline V. dahliae & $\begin{array}{l}\text { Pistachio, olive, } \\
\text { potato, and } \\
\text { cotton }\end{array}$ & S. plicatus and Frankia sp. & In vitro & Aghighi et al. (2006) \\
\hline Sclerotinia sclerotiorum & Sunflower & Coniothyrium minitans & In vitro & $\begin{array}{l}\text { Pourmehdi Alamdarlou } \\
\text { et al. (2006) }\end{array}$ \\
\hline Ustilago hordei & Barley & $\begin{array}{l}\text { Bacillus licheniformis, B. cereus, } \\
\text { and } P \text {. fluorescens }\end{array}$ & Field & Etebarian et al. (2007) \\
\hline S. sclerotiorum & Canola & $P$. fluorescens & $\begin{array}{l}\text { In vitro and } \\
\text { greenhouse }\end{array}$ & Behnam et al. (2007) \\
\hline Ophiostoma novo-ulmi & Elm & $T$. harzianum and $T$. virens & In vitro & Iraqi et al. (2007) \\
\hline G. graminis var. tritici & Wheat & $\begin{array}{l}T . \text { virens, } T . \text { koningiopsis, } \\
T . \text { koningii, and } T . \text { viridescens }\end{array}$ & $\begin{array}{l}\text { In vitro and } \\
\text { greenhouse }\end{array}$ & $\begin{array}{l}\text { Mehrabi Koshki } \\
\text { et al. }(2007)\end{array}$ \\
\hline R. solani & Bean & B. subtilis and $P$. fluorescens & Greenhouse & $\begin{array}{l}\text { Peighamy-Ashnaei } \\
\text { et al. (2007) }\end{array}$ \\
\hline R. solani & Rape & B. cepacia & In vitro & $\begin{array}{l}\text { Sharifi-Tehrani } \\
\text { et al. (2007) }\end{array}$ \\
\hline Ph. cactorum & Apple & P. fluorescens & $\begin{array}{l}\text { In vitro and } \\
\text { greenhouse }\end{array}$ & Farzaneh et al. (2007) \\
\hline P. grisea & Rice & $\begin{array}{l}\text { B. circulans, B. megaterium, } \\
\text { B. subtilis, and } P \text {. fluorescens }\end{array}$ & Field & $\begin{array}{l}\text { Padasht and } \\
\text { Izadyar (2007) }\end{array}$ \\
\hline F. o. f.sp. dianthi & Carnation & $\begin{array}{l}\text { B. cereus, B. subtilis, and } \\
\text { P. fluorescens }\end{array}$ & $\begin{array}{l}\text { In vitro and } \\
\text { greenhouse }\end{array}$ & Karimi et al. (2007) \\
\hline R. solani & Colza & P. fluorescens & $\begin{array}{l}\text { In vitro and } \\
\text { greenhouse }\end{array}$ & Sarani et al. (2008b) \\
\hline S. sclerotiorum & Tobacco & $\begin{array}{l}\text { T. citrinoviride, T. harzianum, } \\
T . \text { atroviride, } T . \text { virens, } \\
T . \text { koningii, } T . \text { ghanense, and } \\
\text { T. longibrachiatum }\end{array}$ & $\begin{array}{l}\text { In vitro and } \\
\text { greenhouse }\end{array}$ & Sajadi and Asemi (2008) \\
\hline M. phaseolina & Eggplant & $\begin{array}{l}\text { T. hamatum, } T . \text { harzianum, } \\
T . \text { polysporum, and } T . \text { viride }\end{array}$ & In vitro and field & Ramezani (2008) \\
\hline M. javanica & Tomato & T. harzianum & In vitro & Golzary et al. (2008b) \\
\hline A. mellea & Fruit trees & T. harzianum and T. virens & In vitro & Asef et al. (2008) \\
\hline Penicillium digitatum & Orange & Pseudomonas spp. & In vitro & Zamani et al. (2008a) \\
\hline P. digitatum & Orange & P. agglomerans & Greenhouse & Zamani et al. (2008b) \\
\hline F. o. f.sp. tuberose & Potato & $\begin{array}{l}\text { Brevibacillus brevis, B. subtilis, } \\
\text { and } P \text {. fluorescens }\end{array}$ & Greenhouse & Khorasani et al. (2008) \\
\hline Colletotrichum gloeosporioides & Citrus & B. subtilis & In vitro & Salari et al. (2008a) \\
\hline Penicillium expansum & Apple & T. virens & Greenhouse & $\begin{array}{l}\text { Tabe-Bordbar et al. } \\
(2008 \text { b) }\end{array}$ \\
\hline Aspergillus flavus & Pistachio & $\begin{array}{l}\text { B. subtilis, B. licheniformis, } \\
B . \text { cereus, and } P \text {. fluorescens }\end{array}$ & In vitro & Haghdel et al. (2008a,b) \\
\hline M. javanica & Tomato & P. fluorescens & Greenhouse & Mokhtari et al. (2008) \\
\hline M. javanica & Tomato & P. fluorescens & In vitro & Golzary et al. (2008a) \\
\hline Magnaporthe salvini & Rice & P. fluorescens & In vitro & Ahmaddeh et al. (2008) \\
\hline F. oxysporum & Potato & $\begin{array}{l}\text { P. putida, } P \text {. fluorescens, and } \\
\text { P. aeruginosa }\end{array}$ & Field & Ommati et al. (2008) \\
\hline P. digitatum & Citrus & $\begin{array}{l}\text { T. viride, } P \text {. fluorescens, and } \\
\text { B. subtilis }\end{array}$ & In vitro & Zamani et al. (2008c) \\
\hline
\end{tabular}


Table 1: continued

\begin{tabular}{|c|c|c|c|c|}
\hline Pathogens & Host & Antagonists & Procedure & Ref. \\
\hline F. solani and $P$. ultimum & - & B. subtilis & In vitro & $\begin{array}{l}\text { Selselehzakeri } \\
\text { et al. (2008) }\end{array}$ \\
\hline R. solani & Sugar beet & T. harzianum and $T$. viride & Field & Safaee et al. (2008) \\
\hline R. solani & Sugar beet & P. oligandrum & $\begin{array}{l}\text { In vitro and } \\
\text { greenhouse }\end{array}$ & Salari et al. (2008b) \\
\hline R. solani & Canola & $\begin{array}{l}\text { P. fluorescens, B. cepacia, } \\
\text { B. subtilis, and Streptomyces sp. }\end{array}$ & $\begin{array}{l}\text { In vitro and } \\
\text { greenhouse }\end{array}$ & Sarani et al. (2008a) \\
\hline Penicillium solitum & Apple & $T$. viride and $T$. virens & Greenhouse & $\begin{array}{l}\text { Tabe Bordbar et al. } \\
(2008 \mathrm{a})\end{array}$ \\
\hline O. novo-ulmi & Elm & B. subtilis & In vitro & Iragi et al. 2008 \\
\hline R. solani & Rice & $\begin{array}{l}\text { T. atroviride, } T \text {. harzianum, and } \\
\text { T. virens }\end{array}$ & In vitro & $\begin{array}{l}\text { Khalili and } \\
\text { Sadravi (2008) }\end{array}$ \\
\hline Botrytis mali & Apple & Candida membranifaciens & Greenhouse & Alavifard et al. (2008a) \\
\hline Botrytis cinerea & Apple & $\begin{array}{l}\text { C. membranifaciens, Rhodotorula } \\
\text { mucilaginosa, and Meyerozyma } \\
\text { guilliermondii (Pichia } \\
\text { guilliermondii) }\end{array}$ & $\begin{array}{l}\text { In vitro and } \\
\text { greenhouse }\end{array}$ & Alavifard et al. (2008b) \\
\hline P. expansum & Apple & C. membranifaciens & $\begin{array}{l}\text { In vitro and } \\
\text { greenhouse }\end{array}$ & $\begin{array}{l}\text { Gholamnejad } \\
\text { et al. (2008) }\end{array}$ \\
\hline S. sclerotiorum & Potato & $\begin{array}{l}T . \text { ceramicum , } T . \text { koningii, } \\
T . \text { koningiopsis, } T . \text { virens, } \\
T . \text { viridescens, } T . \text { orientalis, and } \\
T . \text { atroviride }\end{array}$ & $\begin{array}{l}\text { In vitro and } \\
\text { greenhouse }\end{array}$ & Ojaghian et al. (2008) \\
\hline G. graminis and $M$. phaseolina & - & $\begin{array}{l}\text { Piriformospora indica and } \\
\text { Sebacina vermifera }\end{array}$ & In vitro & $\begin{array}{l}\text { Abbaszadeh and } \\
\text { Mohammadi Goltapeh } \\
(2008 a)\end{array}$ \\
\hline M. phaseolina & Soybean & $\begin{array}{l}\text { T. harzianum, } T \text {. viride, } P \text {. indica, } \\
\text { and S. vermifera }\end{array}$ & $\begin{array}{l}\text { In vitro and } \\
\text { greenhouse } \\
\text { and field }\end{array}$ & $\begin{array}{l}\text { Abbaszadeh and } \\
\text { Mohammadi Goltapeh } \\
(2008 \mathrm{~b})\end{array}$ \\
\hline Pyricularia oryzae & Rice & Streptomyces spp. & $\begin{array}{l}\text { In vitro and } \\
\text { greenhouse }\end{array}$ & $\begin{array}{l}\text { Ebrahimi-Zarandi } \\
\text { et al. (2008) }\end{array}$ \\
\hline P. expansum & Apple & P. fluorescens & $\begin{array}{l}\text { In vitro and } \\
\text { greenhouse }\end{array}$ & Khazaee et al. (2008) \\
\hline Ph. nicotianae & - & P. fluorescens & $\begin{array}{l}\text { In vitro and } \\
\text { greenhouse }\end{array}$ & Nazerian et al. (2008) \\
\hline S. sclerotiorum & Canola & B. subtilis & In vitro & $\begin{array}{l}\text { Nasrolah Nejad and } \\
\text { Rahnama (2008) }\end{array}$ \\
\hline P. syringae pv. tomato & Tomato & P. fluorescens & In vitro & Mousavi et al. (2008a) \\
\hline $\begin{array}{l}\text { Clavibacter michiganensis subsp. } \\
\text { michiganensis }\end{array}$ & Tomato & P. fluorescens & In vitro & Mousavi et al. (2008b) \\
\hline E. amylovora & Pear & P. fluorescens and Pantoea sp. & In vitro & Mirzaie et al. (2008) \\
\hline M. phaseolina & Soybean & T. harzianum & In vitro & Montazernia et al. (2008) \\
\hline S. sclerotiorum & Canola & P. fluorescens and B. subtilis & $\begin{array}{l}\text { In vitro and } \\
\text { greenhouse }\end{array}$ & $\begin{array}{l}\text { Mansouripour } \\
\text { et al. }(2008)\end{array}$ \\
\hline G. graminis var. tritici & Wheat & Azotobacter isolates & In vitro & Maghsodloo et al. (2008) \\
\hline B. cinerea & Apple & $\begin{array}{l}\text { B. subtilis, Pichia } \\
\text { membraniciens, and Candida } \\
\text { guilliermondii }\end{array}$ & $\begin{array}{l}\text { In vitro and } \\
\text { greenhouse }\end{array}$ & Zangoie et al. (2008) \\
\hline$X$. axonopodis pv. citri & Citrus & P. fluorescens & Greenhouse & $\begin{array}{l}\text { Khodakaramian } \\
\text { et al. (2008) }\end{array}$ \\
\hline
\end{tabular}


Table 1: continued

\begin{tabular}{|c|c|c|c|c|}
\hline Pathogens & Host & Antagonists & Procedure & Ref. \\
\hline $\begin{array}{l}\text { F. graminearum, } R \text {. solani AG4, } \\
\text { R. solani AG5, M. phaseolina, and } \\
\text { Ph. cactorum }\end{array}$ & $\begin{array}{l}\text { Wheat, sugar } \\
\text { beet, potato, } \\
\text { soyabean, and } \\
\text { apple }\end{array}$ & $\begin{array}{l}\text { T. hamatum, T. harzianum, } \\
T . \text { virens, and Trichoderma sp. }\end{array}$ & In vitro & Hajieghrari et al. (2008) \\
\hline G. graminis var. tritici & Wheat & $\begin{array}{l}\text { T. koningiopsis, } \\
T . \text { brevicompactum, and } \\
\text { T. viridescens }\end{array}$ & Greenhouse & Zafari et al. (2008) \\
\hline M. javanica & Tomato & T. harzianum & $\begin{array}{l}\text { In vitro and } \\
\text { greenhouse }\end{array}$ & $\begin{array}{l}\text { Maleki Ziyarati } \\
\text { et al. (2009) }\end{array}$ \\
\hline M. phaseolina & Melon & $P$. fluorescens and $P$. putida & $\begin{array}{l}\text { In vitro and } \\
\text { greenhouse }\end{array}$ & Kheiri et al. (2009) \\
\hline H. schachtii & Sugar beet & T. harzianum and $T$. virens & $\begin{array}{l}\text { In vitro and } \\
\text { greenhouse }\end{array}$ & $\begin{array}{l}\text { Mahdikhani Moghadam } \\
\text { et al. (2009) }\end{array}$ \\
\hline S. sclerotiorum & Canola & T. harzianum and $T$. virens & In vitro & $\begin{array}{l}\text { Nasrolah Nejad } \\
\text { et al. }(2009)\end{array}$ \\
\hline M. javanica & Tomato & T. harzianum & Greenhouse & Ziarati et al. (2009) \\
\hline T. laevis & Wheat & $\begin{array}{l}T . \text { koningii, } T . \text { brevicompactum, } \\
T . \text { harzianum, and } T . \text { virens }\end{array}$ & Field & $\begin{array}{l}\text { Mehrabi Koshki } \\
\text { et al. (2009) }\end{array}$ \\
\hline R. solani & Common bean & P. fluorescens & Greenhouse & $\begin{array}{l}\text { Ahmadzadeh and } \\
\text { Tehrani (2009) }\end{array}$ \\
\hline B. cinerea & Apple & P. fluorescens and B. subtilis & Greenhouse & $\begin{array}{l}\text { Peighami-Ashnaei et al. } \\
\text { (2009a) }\end{array}$ \\
\hline S. sclerotiorum & Sunflower & P. fluorescens & Greenhouse & Ashofteh et al. (2009) \\
\hline $\begin{array}{l}\text { Xanthomonas campestris pv. } \\
\text { malvacearum }\end{array}$ & Cotton & $P$. aeruginosa & Greenhouse & $\begin{array}{l}\text { Fallahzadeh-Mamaghani } \\
\text { et al. (2009) }\end{array}$ \\
\hline R. solani & Bean & B. subtilis and $P$. fluorescens & In vitro & $\begin{array}{l}\text { Peighami-Ashnaei et al. } \\
\text { (2009b) }\end{array}$ \\
\hline R. solani & Common bean & B. cepacia & $\begin{array}{l}\text { In vitro and } \\
\text { greenhouse }\end{array}$ & $\begin{array}{l}\text { Ahmadzadeh } \\
\text { et al. (2009) }\end{array}$ \\
\hline P. expansum & Apple & Saccharomyces cerevisiae & In vitro & $\begin{array}{l}\text { Gholamnejad } \\
\text { et al. (2009) }\end{array}$ \\
\hline H. schachtii & Sugar beet & $\begin{array}{l}\text { Pleurotus ostreatus, } P . \text { sajor- } \\
\text { caju, P. florida, P. flabellatus, } \\
\text { P. eryngii, and Hypsizygus } \\
\text { ulmarius }\end{array}$ & $\begin{array}{l}\text { In vitro and } \\
\text { greenhouse }\end{array}$ & Palizi et al. (2009) \\
\hline P. expansum & Apple & $\begin{array}{l}\text { R. mucilaginosa and } \\
\text { M. guilliermondii }\end{array}$ & In vitro & $\begin{array}{l}\text { Gholamnejad } \\
\text { et al. (2009) }\end{array}$ \\
\hline V. dahliae & Cotton & $\begin{array}{l}\text { Glomus etunicatum, } \\
\text { G. intraradices, and } \\
\text { G. versiforme }\end{array}$ & Greenhouse & Norouzi et al. (2009) \\
\hline Meloidogyne spp. & - & Paecilomyces lilacinus & Greenhouse & Boromand et al. (2010) \\
\hline $\begin{array}{l}\text { F. oxysporum, R. solani, } M . \\
\text { phaseolina, and Pythium sp. }\end{array}$ & Faba bean & Pseudomonas sp. & $\begin{array}{l}\text { In vitro and } \\
\text { greenhouse }\end{array}$ & Golpayegani et al. (2010) \\
\hline R. solani & Rice & $\begin{array}{l}T . \text { harzianum, } T . \text { atroviride, and } \\
T . \text { virens }\end{array}$ & $\begin{array}{l}\text { In vitro, } \\
\text { greenhouse, } \\
\text { and field }\end{array}$ & Naeimi et al. (2010) \\
\hline Phytophthora sojae & - & $\begin{array}{l}T . \text { virens, } T . \text { orientalis, } \\
T . \text { brevicompactum, } T . \text { atroviride, } \\
T . \text { ceramicum and } T . \text { asperellum }\end{array}$ & In vitro & Ayoubi et al. (2010) \\
\hline B. sorokiniana & Wheat & P. fluorescens & $\begin{array}{l}\text { In vitro and } \\
\text { greenhouse }\end{array}$ & $\begin{array}{l}\text { Ranjbar Sistani } \\
\text { et al. (2010) }\end{array}$ \\
\hline G. fujikuroi & Rice & T. harzianum and $T$. virens & $\begin{array}{l}\text { In vitro and } \\
\text { greenhouse }\end{array}$ & Roodgar et al. (2010) \\
\hline Pythium aphanidermatum & Cucumber & B. subtilis and $B$. licheniformis & $\begin{array}{l}\text { In vitro and } \\
\text { greenhouse }\end{array}$ & Safari Asl et al. (2010) \\
\hline
\end{tabular}


Table 1: continued

\begin{tabular}{|c|c|c|c|c|}
\hline Pathogens & Host & Antagonists & Procedure & Ref. \\
\hline B. cinerea & Tomato & $\begin{array}{l}\text { T. harzianum, T. arundinaceum, } \\
T . \text { viridescens, } T . \text { atroviride, and } \\
T . \text { koningii }\end{array}$ & $\begin{array}{l}\text { In vitro and } \\
\text { greenhouse }\end{array}$ & Eivazi et al. (2010) \\
\hline P. expansum & Apple & B. subtilis & $\begin{array}{l}\text { In vitro and } \\
\text { greenhouse }\end{array}$ & Emadi et al. (2010) \\
\hline Phytophthora drechsleri & Cantaloupe & $\begin{array}{l}\text { Pseudomonas fluorescens, } \\
P . \text { putida and } P \text {. aeruginosa }\end{array}$ & $\begin{array}{l}\text { In vitro and } \\
\text { greenhouse }\end{array}$ & Tabarraie et al. (2010) \\
\hline P. expansum & Apple & R. mucilaginosa & $\begin{array}{l}\text { In vitro and } \\
\text { greenhouse }\end{array}$ & Golamnejad et al. (2010) \\
\hline Penicillium italicum & Orange & M. guilliermondii & $\begin{array}{l}\text { In vitro and } \\
\text { greenhouse }\end{array}$ & $\begin{array}{l}\text { Ghasemi Sardareh } \\
\text { et al. (2010) }\end{array}$ \\
\hline Verticillium albo-atrum & Tomato & T. flavus & $\begin{array}{l}\text { In vitro and } \\
\text { greenhouse }\end{array}$ & Naraghi et al. (2010) \\
\hline F. o. f.sp. ciceri & Chickpea & $\begin{array}{l}\text { B. subtilis, } P \text {. aeruginos } a \text {, and } \\
\text { P. putida }\end{array}$ & In vitro & $\begin{array}{l}\text { Karimik Amini } \\
\text { et al. (2010) }\end{array}$ \\
\hline B. sorokiniana & Wheat & $\begin{array}{l}\text { Glomus fasciculatum and } \\
\text { B. subtilis }\end{array}$ & Greenhouse & $\begin{array}{l}\text { Hashemi Alizade } \\
\text { et al. (2010) }\end{array}$ \\
\hline F. o. f.sp. radicis-cucumerinum & Cucumber & B. subtilis & Greenhouse & Yousefi et al. (2010) \\
\hline S. sclerotiorum & Potato & $\begin{array}{l}T . \text { ceramicum, } T . \text { koningii, } \\
T . \text { koningiopsis, } T . \text { viridescens, } \\
T . \text { virens, and Coniothyrium } \\
\text { minitans }\end{array}$ & In vitro & Ojaghian et al. (2010) \\
\hline Sclerotinia sclerotiorum & Sunflower & Pseudomonas fluorescens & $\begin{array}{l}\text { In vitro and } \\
\text { greenhouse }\end{array}$ & Khezri et al. (2010) \\
\hline Sclerotium cepivorum & Garlic & Bacillus spp. & In vitro & Babaei Nasir et al. (2010) \\
\hline $\begin{array}{l}\text { Fusarium oxysporum f.sp. gladioli } \\
\text { Gladiolus }\end{array}$ & Garlic & Trichoderma spp. & In vitro & Bagheri et al. (2010) \\
\hline F. oxysporum and $F$. solani & Chickpea & T. harzianum and $T$. asprellum & $\begin{array}{l}\text { In vitro and } \\
\text { greenhouse }\end{array}$ & $\begin{array}{l}\text { Akrami and } \\
\text { Ibrahime (2010) }\end{array}$ \\
\hline M. phaseolina & Sunflower & B. subtilis & $\begin{array}{l}\text { In vitro and } \\
\text { greenhouse }\end{array}$ & Iraqi and Rahnama (2011) \\
\hline R. solani & Canola & B. серасіа & $\begin{array}{l}\text { In vitro and } \\
\text { greenhouse }\end{array}$ & Sarani et al. (2010) \\
\hline P. carotovorum & Potato & $\begin{array}{l}\text { P. putida, } P \text {. aeruginosa, and } \\
P . \text { fluorescens }\end{array}$ & Field & $\begin{array}{l}\text { Khodakaramian and } \\
\text { Zafari }(2010)\end{array}$ \\
\hline X. axonopodis pv. citri & Citrus & $\begin{array}{l}\text { P. fluorescens, } P \text {. viridiflava, and } \\
\text { P. syringae }\end{array}$ & In vitro & Montakhabi et al. (2010) \\
\hline G. graminis var. tritici & Wheat & $\begin{array}{l}\text { B. subtilis, } B . \text { pumilus, } \\
\text { P. fluorescens, } P \text {. putida, } \\
\text { P. aeruginosa, and } \\
\text { Chromobacteria } \mathrm{sp} \text {. }\end{array}$ & $\begin{array}{l}\text { In vitro and } \\
\text { greenhouse }\end{array}$ & Babaeipoor et al. (2011) \\
\hline Phoma lingam & Rapeseed & B. subtilis and $T$. koningii & $\begin{array}{l}\text { In vitro and } \\
\text { greenhouse }\end{array}$ & Panjehkeh et al. (2011) \\
\hline H. schachtii & Sugar beet & $\begin{array}{l}\text { T. harzianum, T. virens, and } \\
\text { B. subtilis }\end{array}$ & Field & $\begin{array}{l}\text { Mahdikhani Moghadam } \\
\text { and Rouhani (2011) }\end{array}$ \\
\hline F. oxysporum & Lentil & $P$. fluorescens & Greenhouse & Akrami et al. (2011) \\
\hline F. culmorum & - & B. subtilis & Greenhouse & Khezri et al. (2011) \\
\hline S. sclerotiorum & Sunflower & P. fluorescens & Greenhouse & $\begin{array}{l}\text { Heidari-Tajabadi } \\
\text { et al. (2011) }\end{array}$ \\
\hline$P$. italicum and $P$. digitatum & Citrus & P. syringae and Candida famata & Greenhouse & $\begin{array}{l}\text { Nasrollahi Omran } \\
\text { et al. (2011) }\end{array}$ \\
\hline G. graminis var. tritici & Wheat & P. fluorescens & Greenhouse & Bagheri et al. (2011) \\
\hline P. expansum & Apple & R. mucilaginosa & In vitro & Gholamnejad et al. (2011) \\
\hline $\begin{array}{l}\text { Phytophthora parasitica and } P h \text {. } \\
\text { citrophthora }\end{array}$ & Pistachio & Streptomyces sp. & $\begin{array}{l}\text { In vitro and } \\
\text { greenhouse }\end{array}$ & Salari et al. (2011) \\
\hline
\end{tabular}


Table 1: continued

\begin{tabular}{|c|c|c|c|c|}
\hline Pathogens & Host & Antagonists & Procedure & Ref. \\
\hline Ph. drechsleri & Sugar beet & $\begin{array}{l}\text { T. asperellum, } T . \text { atroviride, } \\
T . \text { harzianum, and } T . \text { virens }\end{array}$ & Greenhouse & $\begin{array}{l}\text { Moayedi and } \\
\text { Mostowfizadeh- } \\
\text { Ghalamfarsa (2011) }\end{array}$ \\
\hline M. javanica & Olive & $P$. fluorescens and $P$. putida & Greenhouse & $\begin{array}{l}\text { Khalighi and } \\
\text { Khodakaramian (2012) }\end{array}$ \\
\hline Fusarium solani & Potato & $\begin{array}{l}T . \text { brevicompactum, } \\
T . \text { longibrachiatum } \\
\text { and } T . \text { asperellum }\end{array}$ & $\begin{array}{l}\text { In vitro and } \\
\text { greenhouse }\end{array}$ & Ommati and Zaker (2012) \\
\hline M. javanica & Tomato & T. harzianum & Greenhouse & Naserinasab et al. (2012) \\
\hline P. carotovorum & Potato & Pseudomonas spp. & $\begin{array}{l}\text { In vitro and } \\
\text { greenhouse }\end{array}$ & Ghods-Alavi et al. (2012) \\
\hline P. grisea & Rice & T. harzianum & Greenhouse & Raeesi et al. (2012a) \\
\hline B. cinerea & - & T. harzianum & $\begin{array}{l}\text { In vitro and } \\
\text { greenhouse }\end{array}$ & Raeesi et al. (2012b) \\
\hline R. solani & Rice & $P$. fluorescens and $P$. aeruginosa & $\begin{array}{l}\text { In vitro and } \\
\text { greenhouse }\end{array}$ & Kazemzadeh et al. (2012) \\
\hline Ph. sojae & Soybean & $\begin{array}{l}\text { Bradyrhizobium japonicum, } \\
T . \text { spirale, } T \text {. orientale and } \\
T . \text { brevicompactum }\end{array}$ & $\begin{array}{l}\text { In vitro and } \\
\text { greenhouse }\end{array}$ & Ayoubi et al. (2012) \\
\hline P. aphanidermatum & Cucumber & $\begin{array}{l}\text { T. longibrachiatum and } \\
\text { T. atroviride }\end{array}$ & Greenhouse & Ale Aghaee et al. (2012) \\
\hline Ph. parasitica & Citrus & Streptomyces sp. & $\begin{array}{l}\text { In vitro and } \\
\text { greenhouse }\end{array}$ & Sadeghi (2012) \\
\hline F. o. f.sp. lycopersici & Tomato & Streptomyces sp. & In vitro & Fadaei et al. (2012) \\
\hline F. solani f.sp. pisi & Chickpea & T. harzianum and $T$. viride & $\begin{array}{l}\text { In vitro and } \\
\text { greenhouse }\end{array}$ & Afrousheh et al. (2012a) \\
\hline Fusarium subglutinans & Cucumber & Streptomyces spp. & In vitro & $\begin{array}{l}\text { Sadeghi and } \\
\text { Hatami (2012) }\end{array}$ \\
\hline F. solani f.sp. pisi & Pea & T. harzianum and $T$. viride & $\begin{array}{l}\text { In vitro and } \\
\text { greenhouse }\end{array}$ & Afrousheh et al. (2012b) \\
\hline Phytophthora sojae & Soybean & $\begin{array}{l}T . \text { orientals, } T . \text { brevicompactum } \\
\text { and } T . \text { spirale and } \\
\text { Bradyrhizobium japonicum }\end{array}$ & $\begin{array}{l}\text { In vitro and } \\
\text { greenhouse }\end{array}$ & Najmeh et al. (2012) \\
\hline Rosellinia necatrix & - & $T$. flavus & In vitro & $\begin{array}{l}\text { Masudi and } \\
\text { Shahidi (2012) }\end{array}$ \\
\hline P. aphanidermatum & Cucumber & $\begin{array}{l}T . \text { virens, } T . \text { harzianum, and } \\
T . \text { atroviride }\end{array}$ & $\begin{array}{l}\text { In vitro and } \\
\text { greenhouse }\end{array}$ & Hosseyni et al. (2012a) \\
\hline $\begin{array}{l}\text { R. solani, M. phaseolina, } \\
\text { F. graminearum, and } \\
\text { S. sclerotiorum }\end{array}$ & - & T. viride & In vitro & Soofi et al. (2012) \\
\hline $\begin{array}{l}\text { Bipolaris australiensis and } B . \\
\text { cinerea }\end{array}$ & Saffron & $\begin{array}{l}T . \text { virens, } T \text {. harzianum, and } \\
T \text {. koningii }\end{array}$ & In vitro & Roohabadi et al. (2012) \\
\hline F. graminearum & Wheat & $T$. harzianum and $T$. virens & Field & Baghani et al. (2012) \\
\hline F. o. f.sp. radicis-cucumerinum & Cucumber & T. harzianum & $\begin{array}{l}\text { In vitro and } \\
\text { greenhouse }\end{array}$ & $\begin{array}{l}\text { Javanshir Javid } \\
\text { et al. (2012) }\end{array}$ \\
\hline Monosporascus cannonballus & Muskmelon & $\begin{array}{l}T . \text { atroviride, } T . \text { harzianum, and } \\
T . \text { virens }\end{array}$ & $\begin{array}{l}\text { In vitro and } \\
\text { greenhouse }\end{array}$ & Keshavarzi et al. (2012a) \\
\hline F. graminearum & Wheat & $T$. harzianum and $T$. virens & Field & Baghani et al. (2012) \\
\hline $\begin{array}{l}\text { R. solani and } F \text {. solani f.sp. } \\
\text { tuberose }\end{array}$ & Sugar beet & P. putida & In vitro & Nazari et al. (2012) \\
\hline Alternaria alternata & Potato & $\begin{array}{l}\text { T. viride, } T . \text { orientalis, } \\
\text { T. arundinaceum, and } \\
\text { T. harzianum }\end{array}$ & $\begin{array}{l}\text { In vitro and } \\
\text { greenhouse }\end{array}$ & Nasiri et al. (2012) \\
\hline P. aphanidermatum & Cucumber & Bacillus sp. and B. subtilis & Greenhouse & Hosseyni et al. (2012b) \\
\hline
\end{tabular}


Table 1: continued

\begin{tabular}{|c|c|c|c|c|}
\hline Pathogens & Host & Antagonists & Procedure & Ref. \\
\hline F. solani and $R$. solani & - & Streptomyces sp. & In vitro & $\begin{array}{l}\text { Vasebi and } \\
\text { Dehnad (2012) }\end{array}$ \\
\hline B. cinerea & Apple & Hanseniaspora occidentalis & In vitro & Azadrooh et al. (2012) \\
\hline A. flavus & Pistachio & $\begin{array}{l}\text { T. harzianum and } \\
\text { T. longibrachiatum }\end{array}$ & In vitro & Chegini et al. (2012) \\
\hline M. cannonballus & Cucumis melon & $\begin{array}{l}\text { T. harzianum, T. virens, } \\
\text { T. atroviride, and Chaetomium } \\
\text { globosum }\end{array}$ & In vitro & Keshavarzi et al. (2012b) \\
\hline M. javanica & - & $\begin{array}{l}\text { Penicillium griseofulvum, } \\
\text { Penicillium chrysogenum, and } \\
\text { Penicillium coprophilum }\end{array}$ & In vitro & Karkhaneh et al. (2012) \\
\hline $\begin{array}{l}\text { V. albo-atrum, } F \text {. oxysporum, and } \\
\text { R. solani }\end{array}$ & Potato & T. flavus & In vitro & Naraghi et al. (2012a) \\
\hline R. solani & Common bean & Streptomyces microflavus & $\begin{array}{l}\text { In vitro and } \\
\text { greenhouse }\end{array}$ & Moazenian et al. (2012b) \\
\hline A. flavus & Pistachio & T. harzianum and $T$. koningii & In vitro & Kahnooji et al. (2012) \\
\hline Ph. drechsleri & Pistachio & $\begin{array}{l}\text { T. longibrachiatum and } \\
\text { T. harzianum }\end{array}$ & In vitro & Mirkhani et al. (2012) \\
\hline Ph. drechsleri & Pistachio & T. harzianum & Greenhouse & $\begin{array}{l}\text { Alipoor Moghadam } \\
\text { et al. (2012) }\end{array}$ \\
\hline Paecilomyces variotii & Pistachio & Streptomyces spp. & In vitro & Ansari et al. (2012) \\
\hline$P$. tolaasii & A. bisporus & $\begin{array}{l}\text { Pseudomonas reactants, Bacillus } \\
\text { sp., and } P \text {. fluorescens }\end{array}$ & In vitro & Tajalipour et al. (2012) \\
\hline V. albo-atrum & Potato & T. flavus & Greenhouse & Naraghi et al. (2012b) \\
\hline B. oryzae & Rice & $\begin{array}{l}T . \text { harzianum, } T \text {. atroviride, and } \\
\text { T. virens }\end{array}$ & Greenhouse & Khalili et al. (2012) \\
\hline F. solani & Bean & $T$. harzianum and $T$. viride & $\begin{array}{l}\text { In vitro and } \\
\text { greenhouse }\end{array}$ & Khodaei et al. (2012) \\
\hline $\begin{array}{l}\text { F. solani, } R \text {. solani, F. oxysporum, } \\
\text { Pestalotiopsis spp., C. } \\
\text { gloeosporioides, and P. digitatum }\end{array}$ & Citrus & Streptomyces sp. & In vitro & Noorizadeh et al. (2012) \\
\hline P. italicum & Orange & Pichia kluyveri & In vitro & $\begin{array}{l}\text { Ghasemi Sardareh } \\
\text { et al. (2012) }\end{array}$ \\
\hline R. solani & Sugar beet & T. harzianum & In vitro & Ghanbari et al. (2012) \\
\hline P. expansum & Apple & Torulaspora delbrueckii & In vitro & Ebrahimi et al. (2012a,b) \\
\hline Magnaporthe oryzae & Rice & $\begin{array}{l}\text { T. harzianum, T. atroviride, and } \\
\text { T. virens }\end{array}$ & In vitro & Javadi et al. (2012) \\
\hline F. graminearum & Wheat & $\begin{array}{l}P . \text { fluorescens, } E \text {. herbicola, } \\
B . \text { subtilis, and } B . \text { cereus }\end{array}$ & $\begin{array}{l}\text { In vitro and } \\
\text { greenhouse }\end{array}$ & Alimi et al. (2012) \\
\hline S. sclerotiorum & Bean & $\begin{array}{l}\text { B. subtilis subsp. spizizenii and } \\
\text { Streptomyces acrimycini }\end{array}$ & $\begin{array}{l}\text { In vitro and } \\
\text { greenhouse }\end{array}$ & Gholami et al. (2012) \\
\hline S. sclerotiorum & Cucumber & Bacillus sp. & In vitro & Rostami et al. (2012) \\
\hline G. graminis var. tritici & Wheat & P. fluorescens & $\begin{array}{l}\text { In vitro and } \\
\text { greenhouse }\end{array}$ & Lagzian et al. (2012) \\
\hline F. oxysporum & Cucurbit & $\begin{array}{l}\text { T. harzianum and } \\
\text { T. longibrachiatum }\end{array}$ & In vitro & $\begin{array}{l}\text { Abdolahy and } \\
\text { Parsaiyan (2012) }\end{array}$ \\
\hline F. solani & Cucurbit & T. koningii & In vitro & $\begin{array}{l}\text { Abdolahy and } \\
\text { Parsaiyan (2012) }\end{array}$ \\
\hline V. dahliae & Pistachio & T. harzianum and T. koningii & In vitro & Jamdar et al. (2012) \\
\hline Pratylenchus loosi & Tea & B. subtilis & In vitro & Rahanandeh et al. (2012) \\
\hline M. javanica & Cucumber & $\begin{array}{l}\text { P. fluorescens, B. subtilis, and } \\
\text { Pantoea sp. }\end{array}$ & Greenhouse & Majzoob et al. (2012) \\
\hline Meloidogyne javanica & Tomato & $\begin{array}{l}\text { Arthrobotrys oligospora and } \\
\text { Paecilomyces lilacinus }\end{array}$ & Greenhouse & $\begin{array}{l}\text { Jamshidnejad } \\
\text { et al. (2012) }\end{array}$ \\
\hline B. cinerea & Strawberry & Trichoderma spp. & $\begin{array}{l}\text { In vitro and } \\
\text { greenhouse }\end{array}$ & Naeimi and Zare (2013) \\
\hline
\end{tabular}


Table 1: continued

\begin{tabular}{|c|c|c|c|c|}
\hline Pathogens & Host & Antagonists & Procedure & Ref. \\
\hline P. aphanidermatum & Sugar beet & $\begin{array}{l}\text { Trichoderma erinaceum, } \\
T . \text { koningii, } T . \text { longibrachiatum, } \\
\text { and } T . \text { harzianum }\end{array}$ & Greenhouse & Abdollahi et al. (2013) \\
\hline $\begin{array}{l}\text { Fusarium oxysporum f. sp. } \\
\text { tuberosi }\end{array}$ & Potato & $\begin{array}{l}\text { Trichoderma virens and } \\
\text { Trichoderma asperellum }\end{array}$ & $\begin{array}{l}\text { In vitro and } \\
\text { greenhouse }\end{array}$ & Ommati et al. (2013) \\
\hline B. sorokiniana & Wheat & $\begin{array}{l}\text { G. fasciculatum and } \\
\text { P. fluorescens }\end{array}$ & Greenhouse & $\begin{array}{l}\text { Hashemi Alizadeh } \\
\text { et al. (2013) }\end{array}$ \\
\hline Tylenchulus semipenetrans & Citrus & $\begin{array}{l}\text { F. solani, F. oxysporum, } \\
\text { P. lilacinus, Cladosporium } \\
\text { cladosporioides, and } \\
\text { Acremonium strictum }\end{array}$ & Greenhouse & $\begin{array}{l}\text { Chavoshisani } \\
\text { et al. (2013) }\end{array}$ \\
\hline Aspergillus flavus & Pistachio & $\begin{array}{l}\text { Trichoderma harzianum and } \\
\text { Trichoderma longibrachiatum }\end{array}$ & In vitro & Chegini et al. (2013) \\
\hline M. javanica & Tomato & $\begin{array}{l}\text { Glomus mosseae and } \\
\text { G. intraradices }\end{array}$ & Greenhouse & Golzari et al. (2013) \\
\hline A. flavus & Pistachio & B. subtilis & In vitro & $\begin{array}{l}\text { Afsharmanesh } \\
\text { et al. (2013) }\end{array}$ \\
\hline Colletotrichum lindemuthianum & Bean & $\begin{array}{l}\text { B. subtilis subsp. subtilis, } \\
\text { B. atrophaeus, B. tequilensis, } \\
\text { B. subtilis subsp. spizizenii, } \\
\text { Streptomyces cyaneofuscatus, } \\
\text { S. flavofuscus, S. parvus, and } \\
\text { S. acrimycini }\end{array}$ & $\begin{array}{l}\text { In vitro and } \\
\text { greenhouse }\end{array}$ & Gholami et al. (2013) \\
\hline P. aphanidermatum & Tarragon & T. asperelloides & In vitro & Pakdaman et al. (2013) \\
\hline E. amylovora & $\begin{array}{l}\text { Apple, pear, and } \\
\text { quince }\end{array}$ & $\begin{array}{l}\text { P. fluorescens, } P \text {. agglomerans, } \\
\text { P. putida, and Serratia } \\
\text { marcescens }\end{array}$ & Field & Gerami et al. (2013) \\
\hline F. culmorum & Wheat & Pseudomonas spp. & Greenhouse & Madloo et al. (2013) \\
\hline P. loosi & Tea & P. fluorescens & In vitro & Rahanandeh et al. (2013) \\
\hline V. dahliae & Cotton & $\begin{array}{l}\text { B. subtilis, Bacillus coagulans, } \\
\text { Bacillus polymyxa, and } \\
\text { P. fluorescens }\end{array}$ & Greenhouse & Mansoori et al. (2013) \\
\hline F. graminearum & Wheat & T. harzianum and $T$. viride & Field & Foroutan (2013) \\
\hline M. phaseolina & Soybean & $\begin{array}{l}\text { P. agglomerans, Bacillus sp., } \\
\text { and } T \text {. harzianum }\end{array}$ & $\begin{array}{l}\text { In vitro and } \\
\text { greenhouse }\end{array}$ & Vasebi et al. (2013) \\
\hline Ph. drechsleri & Cucumber & P. fluorescens & $\begin{array}{l}\text { In vitro and } \\
\text { greenhouse }\end{array}$ & Ghafelebashi et al. (2014) \\
\hline B. cinerea & Apple & $\begin{array}{l}\text { B. subtilis, C. membranifaciens } \\
\text { and } M . \text { guilliermondii }\end{array}$ & $\begin{array}{l}\text { In vitro and } \\
\text { greenhouse }\end{array}$ & Zanguei et al. (2014) \\
\hline M. oryzae & Rice & $\begin{array}{l}\text { T. harzianum, T. atroviride, and } \\
\text { T. virens }\end{array}$ & $\begin{array}{l}\text { In vitro and } \\
\text { greenhouse }\end{array}$ & Javadi et al. (2014) \\
\hline F. solani f.sp. pisi & Pea & G. mosseae and G. intraradices & Greenhouse & Soharabi et al. (2014) \\
\hline F. o. f.sp. lycopersici & Tomato & $T$. harzianum and $T$. virens & Greenhouse & Jalali (2014) \\
\hline P. tolaasii & Mushroom & $\begin{array}{l}\text { P. reactants, } P \text {. putida, } \\
P \text {. fluorescens, and } B \text {. subtilis }\end{array}$ & Greenhouse & Tajalipour et al. (2014) \\
\hline M. javanica & Tomato & $P$. fluorescens & In vitro & Bagheri et al. (2014) \\
\hline A. flavus & Pistachio & B. subtilis & In vitro & $\begin{array}{l}\text { Afsharmanesh } \\
\text { et al. (2014) }\end{array}$ \\
\hline P. digitatum & Citrus & $\begin{array}{l}\text { B. subtilis, Rhizobium rubi, and } \\
\text { P. digitatum }\end{array}$ & In vitro & Mohammadi et al. (2014) \\
\hline Cercospora beticola & Sugar beet & $\begin{array}{l}\text { Bacillus sp., Enterobacter sp., } \\
\text { and Enterobacter sp. }\end{array}$ & $\begin{array}{l}\text { In vitro and } \\
\text { greenhouse }\end{array}$ & Mousavi Mirak (2014) \\
\hline
\end{tabular}


Table 1: continued

\begin{tabular}{|c|c|c|c|c|}
\hline Pathogens & Host & Antagonists & Procedure & Ref. \\
\hline M. phaseolina & Soybean & T. harzianum & $\begin{array}{l}\text { In vitro and } \\
\text { greenhouse }\end{array}$ & Khaledi and Taheri (2014) \\
\hline R. solanacearum & Potato & Paenibacillus polymyxa & $\begin{array}{l}\text { In vitro and } \\
\text { greenhouse }\end{array}$ & Dadjoo et al. (2014) \\
\hline F. o. f.sp. melonis & Cantaloupe & B. subtilis & In vitro & $\begin{array}{l}\text { Hosseini Haji Abdal et al. } \\
\text { (2014b) }\end{array}$ \\
\hline F. o. f.sp. melonis & Cantaloupe & T. atroviride and $T$. harzianum & $\begin{array}{l}\text { In vitro and } \\
\text { greenhouse }\end{array}$ & $\begin{array}{l}\text { Hosseini Haji Abdal et al. } \\
(2014 a)\end{array}$ \\
\hline M. incognita & Tea & $P$. aeruginosa and $P$. fluorescens & In vitro & $\begin{array}{l}\text { Rahanandeh and } \\
\text { Moshaiedy (2014) }\end{array}$ \\
\hline P. chrysogenum and B. cinerea & - & Streptomyces griseus & In vitro & Danaei et al. (2014) \\
\hline R. solani & Cotton & $\begin{array}{l}\text { P. aureofaciens and } \\
\text { P. fluorescens }\end{array}$ & Greenhouse & Samavat et al. (2014) \\
\hline M. phaseolina & Soybean & T. harzianum & Field & Barari et al. (2014) \\
\hline $\begin{array}{l}\text { F. sambucinum, Fusarium } \\
\text { subglutinans, Phoma glomerata, } \\
\text { and } N \text {. mangiferae }\end{array}$ & Cucumber & Streptomyces sp. & In vitro & $\begin{array}{l}\text { Sadeghi and } \\
\text { Hatami (2014) }\end{array}$ \\
\hline M. phaseolina & Soybean & P. agglomerans & $\begin{array}{l}\text { In vitro and } \\
\text { greenhouse }\end{array}$ & Vasebi et al. (2015) \\
\hline M. javanica & Tomato & Trichoderma spp. & $\begin{array}{l}\text { In vitro and } \\
\text { greenhouse }\end{array}$ & Kavari et al. (2015) \\
\hline Ph. drechsleri & Cucumber & T. harzianum & Greenhouse & $\begin{array}{l}\text { Delkhah and } \\
\text { Behboudi (2015) }\end{array}$ \\
\hline M. javanica & Tomato & T. harzianum and $P$. fluorescens & Greenhouse & Mokhtari et al. (2015) \\
\hline M. javanica & Tomato & $\begin{array}{l}\text { Metarhizium anisopliae and } \\
\text { T. harzianum }\end{array}$ & Greenhouse & Khosravi et al. (2015) \\
\hline F. graminearum & Wheat & P. fluorescens & Greenhouse & Shahbazi et al. (2015) \\
\hline P. aphanidermatum & Cucumber & P. fluorescens & Greenhouse & $\begin{array}{l}\text { Akbari-Moghadam } \\
\text { et al. (2015) }\end{array}$ \\
\hline G. graminis var. tritici & Wheat & Trichoderma spp. and T. flavus & In vitro & $\begin{array}{l}\text { Mohammadi and } \\
\text { Ghanbari (2015) }\end{array}$ \\
\hline S. cepivorum & Garlic & $\begin{array}{l}\text { T. asperellum, T. harzianum, and } \\
\text { T. flavus }\end{array}$ & Greenhouse & $\begin{array}{l}\text { Mahdizadehnaraghi } \\
\text { et al. (2015) }\end{array}$ \\
\hline $\begin{array}{l}\text { F. solani, } R . \text { solani, and } \\
\text { F. oxysporum }\end{array}$ & Bean & $\begin{array}{l}\text { Pseudomonas sp. and } \\
\text { Bacillus sp. }\end{array}$ & $\begin{array}{l}\text { In vitro and } \\
\text { greenhouse }\end{array}$ & Faraji et al. (2015) \\
\hline R. solani & Cotton & P. fluorescens & Greenhouse & $\begin{array}{l}\text { Abdollahipuor } \\
\text { et al. (2015) }\end{array}$ \\
\hline F. o. f.sp. lycopersici & Tomato & B. pumilus & Greenhouse & $\begin{array}{l}\text { Heidarzadeh and } \\
\text { Baghaee-Ravari (2015) }\end{array}$ \\
\hline Meloidogyne spp. & Kiwifruit & $\begin{array}{l}\text { Pseudomonas chlororaphis } \\
\text { subsp. aureofaciens and } \\
\text { P. fluorescens }\end{array}$ & Greenhouse & Bashiri et al. (2015) \\
\hline $\begin{array}{l}\text { Fusarium solani, Rhizoctonia } \\
\text { solani, and Fusarium oxysporum }\end{array}$ & Bean & $\begin{array}{l}\text { Pseudomonas sp. and } \\
\text { Bacillus sp. }\end{array}$ & $\begin{array}{l}\text { In vitro and } \\
\text { greenhouse }\end{array}$ & Faraji et al. (2015) \\
\hline V. dahliae & Pistachio & T. harzianum & Greenhouse & Fotoohiyan et al. (2015) \\
\hline P. aphanidermatum & Cucumber & G. mosseae & Greenhouse & Hosseini et al. (2016) \\
\hline F. oxysporum & Tomato & P. fluorescens & Greenhouse & Jamali et al. (2016) \\
\hline $\begin{array}{l}\text { B. cinerea, C. cladosporioides, } \\
\text { and Aspergillus tubingensis }\end{array}$ & Grape & T. harzianum and T. hamatum & In vitro & Davari and Ezazi (2016) \\
\hline B. cinerea & Strawberry & B. subtilis and B. licheniformis & Greenhouse & Amini et al. (2016) \\
\hline Mycosphaerella rabiei & Chickpea & $\begin{array}{l}\text { T. atroviride, } T \text {. virens, and } \\
\text { T. atroviride }\end{array}$ & Greenhouse & Naghed et al. (2016) \\
\hline $\begin{array}{l}\text { A. alternata, Alternaria dumosa, } \\
\text { Alternaria tenuissima, Alternaria } \\
\text { mimicula, Alternaria tomaticola, } \\
\text { and } C \text {. cladosporioides }\end{array}$ & Tomato & T. harzianum and $T$. virens & Greenhouse & Beydaghi et al. (2016) \\
\hline
\end{tabular}


Table 1: continued

\begin{tabular}{|c|c|c|c|c|}
\hline Pathogens & Host & Antagonists & Procedure & Ref. \\
\hline M. javanica & Tomato & G. mosseae & Greenhouse & $\begin{array}{l}\text { Azami-Sardooie } \\
\text { et al. (2016) }\end{array}$ \\
\hline F. o. f.sp. lycopersici & Tomato & T. harzianum & $\begin{array}{l}\text { In vitro and } \\
\text { greenhouse }\end{array}$ & Barari (2016) \\
\hline $\begin{array}{l}\text { M. phaseolina, } R \text {. solani, } \\
\text { S. sclerotiorum, and } \\
\text { F. graminearum }\end{array}$ & $\begin{array}{l}\text { Melon, melon, } \\
\text { canola, and } \\
\text { wheat }\end{array}$ & T. harzianum & In vitro & Abbasi et al. (2016) \\
\hline M. phaseolina & Soybean & T. harzianum & Greenhouse & Khalili et al. (2016) \\
\hline F. solani f.sp. pisi & Chickpea & Streptomyces antibioticus & Greenhouse & Soltanzadeh et al. (2016) \\
\hline A. rabiei & Chickpea & $\begin{array}{l}\text { P. putida, P. fluorescens, } \\
\text { Mesorhizobium ciceri, and } \\
\text { Burkholderia multivorans }\end{array}$ & In vitro & $\begin{array}{l}\text { Azizpour and } \\
\text { Rouhrazi (2016) }\end{array}$ \\
\hline R. solani & Sugar beet & $\begin{array}{l}\text { Bacillus amyloliquefaciens, } \\
\text { B. pumilus, and Bacillus } \\
\text { siamensis }\end{array}$ & Greenhouse & Karimi et al. (2016) \\
\hline F. o. f.sp. lycopersici & Tomato & B. subtilis and $P$. fluorescens & $\begin{array}{l}\text { In vitro and } \\
\text { greenhouse }\end{array}$ & Jalali et al. (2016) \\
\hline A. flavus & Pistachio & B. subtilis & In vitro & Farzaneh et al. (2016) \\
\hline $\begin{array}{l}\text { Penicillium crustosum and } \\
\text { A. tubingensis }\end{array}$ & Grape & Pichia membranaefaciens & $\begin{array}{l}\text { In vitro and } \\
\text { greenhouse }\end{array}$ & $\begin{array}{l}\text { Ranjbar Chaharborj } \\
\text { et al. (2016) }\end{array}$ \\
\hline $\begin{array}{l}\text { S. sclerotiorum and } \\
\text { P. aphanidermatum }\end{array}$ & Cucumber & $\begin{array}{l}\text { Pseudomonas spp., } \\
\text { Stenotrophomonas spp., and } \\
\text { Flavobacterium spp. }\end{array}$ & $\begin{array}{l}\text { In vitro and } \\
\text { greenhouse }\end{array}$ & Bagheri et al. (2016) \\
\hline X. translucens pv. cerealis & Wheat & Pseudomonas spp. & $\begin{array}{l}\text { Greenhouse and } \\
\text { in vitro }\end{array}$ & $\begin{array}{l}\text { Fallahzadeh-Mamaghani } \\
\text { et al. (2016) }\end{array}$ \\
\hline F. o. f.sp. cucumerinum & Cucumber & T. flavus & Greenhouse & Shahriari et al. (2016) \\
\hline M. javanica & Tomato & T. harzianum & Greenhouse & Heidari and Olia (2016) \\
\hline Agrobacterium tumefaciens & Tobacco & B. subtilis & Greenhouse & Nazari et al. (2016) \\
\hline R. solanacearum & Potato & P. fluorescens & $\begin{array}{l}\text { In vitro and } \\
\text { greenhouse }\end{array}$ & $\begin{array}{l}\text { Hasani and } \\
\text { Khodakaramian (2016) }\end{array}$ \\
\hline G. graminis var. tritici & Wheat & B. subtilis & $\begin{array}{l}\text { In vitro and } \\
\text { greenhouse }\end{array}$ & $\begin{array}{l}\text { Khezri and Manafi } \\
\text { Shabestari (2016) }\end{array}$ \\
\hline F. solani f.sp. phaseoli & Bean & T. hamatum and $P$. fluorescens & $\begin{array}{l}\text { In vitro and } \\
\text { greenhouse }\end{array}$ & $\begin{array}{l}\text { Khosro-Anjom } \\
\text { et al. }(2016)\end{array}$ \\
\hline V. dahliae & Tomato & $\begin{array}{l}\text { B. subtilis, B. pumilus, } \\
\text { B. atrophaeus, and Bacillus } \\
\text { thuringiensis }\end{array}$ & $\begin{array}{l}\text { In vitro and } \\
\text { greenhouse }\end{array}$ & $\begin{array}{l}\text { Safdarpour and } \\
\text { Khodakaramian (2016) }\end{array}$ \\
\hline E. amylovora & Apple & P. agglomerans & In vitro & $\begin{array}{l}\text { Firouzian Bandpey and } \\
\text { Rahimian (2016) }\end{array}$ \\
\hline F. oxysporum & - & $\begin{array}{l}\text { T. harzianum, T. koningii, and } \\
\text { T. virens }\end{array}$ & In vitro & $\begin{array}{l}\text { Habibi and } \\
\text { Rahnama (2016) }\end{array}$ \\
\hline $\begin{array}{l}\text { F. oxysporum f.sp. lycopersici and } \\
\text { M. javanica }\end{array}$ & Tomato & G. mosseae & Greenhouse & Amirafzali et al. (2016) \\
\hline Diplodia bulgarica & Apple & $\begin{array}{l}\text { Arthrinium arundinis, Arthrinium } \\
\text { saccharicola, Periconia sp., } \\
\text { Penicillium sp., Aspergillus } \\
\text { persii, C. globosum, Chaetomium } \\
\text { sp., Trichothecium roseum, } \\
\text { A. tenuissima, and Alternaria } \\
\text { infectoria }\end{array}$ & In vitro & Alijani et al. (2016) \\
\hline R. necatrix & Apple & B. siamensis and B. pumilus & In vitro & Binandeh et al. (2016) \\
\hline F. oxysporum & Cucumber & T. harzianum & In vitro & Akhlaghi et al. (2016) \\
\hline P. aphanidermatum & Cucumber & $\begin{array}{l}\text { B. cereus, B. licheniformis, and } \\
\text { Bacillus endophyticus }\end{array}$ & In vitro & Rezaei et al. (2016) \\
\hline
\end{tabular}


Table 1: continued

\begin{tabular}{|c|c|c|c|c|}
\hline Pathogens & Host & Antagonists & Procedure & Ref. \\
\hline R. solani & Wheat & T. citrinoviride & $\begin{array}{l}\text { In vitro and } \\
\text { greenhouse }\end{array}$ & Sharify et al. (2016a) \\
\hline R. solani & Wheat & T. asperellum & $\begin{array}{l}\text { In vitro and } \\
\text { greenhouse }\end{array}$ & Sharify et al. (2016b) \\
\hline P. tolaasii & A. bisporus & $\begin{array}{l}\text { Brochothrix thermosphacta and } \\
\text { Bacillus mycoides }\end{array}$ & In vitro & Aslani et al. (2016) \\
\hline B. cinerea & Grape & $\begin{array}{l}\text { T. harzianum and } \\
\text { C. membranifaciens }\end{array}$ & In vitro & Kasfi et al. (2016a) \\
\hline A. niger & Grape & $\begin{array}{l}\text { T. harzianum and } \\
\text { C. membranifaciens }\end{array}$ & In vitro & Kasfi et al. (2016b) \\
\hline H. schachtii & Sugar beet & $\begin{array}{l}\text { T. harzianum, Thalaromyces } \\
\text { flavus, F. solani, and } \\
\text { V. chlamydosporium }\end{array}$ & Greenhouse & Shirazi et al. (2016) \\
\hline M. phaseolina & Mungbean & $\begin{array}{l}\text { T. harzianum, T. reesei, A. niger, } \\
\text { and B. subtilis }\end{array}$ & Greenhouse & Shahid and Khan (2016) \\
\hline $\begin{array}{l}\text { Curvularia lunata and Bipolaris } \\
\text { sorokiniana }\end{array}$ & Wheat & Achromobacter xylosoxidans & In vitro & $\begin{array}{l}\text { Bagheri and } \\
\text { Ahmadzadeh (2016) }\end{array}$ \\
\hline$R$. solani & Tomato & Beauveria bassiana & Greenhouse & Azadi et al. (2016) \\
\hline Bipolaris victoriae & Rice & $\begin{array}{l}\text { T. harzianum, } A \text {. tenuissima, } \\
\text { Fusarium verticillioides, } \\
\text { Alternaria citri, } A \text {. infectoria, and } \\
\text { Preussia sp. }\end{array}$ & Greenhouse & $\begin{array}{l}\text { Safari Motlagh and } \\
\text { Mohammadian (2016) }\end{array}$ \\
\hline M. javanica & Tomato & $P$. fluorescens & Greenhouse & Tanha et al. (2016) \\
\hline M. javanica & Tomato & $\begin{array}{l}\text { Talaromyces flavus and } \\
\text { T. harzianum }\end{array}$ & Greenhouse & $\begin{array}{l}\text { Abootorabi and } \\
\text { Naraghi }(2016)\end{array}$ \\
\hline F. solani and $F$. oxysporum & Chickpea & $\begin{array}{l}\text { T. harzianum, T. asperellum, and } \\
\text { T. virens }\end{array}$ & Field & Khomeini et al. (2016) \\
\hline M. phaseolina & Soybean & T. harzianum & Greenhouse & Khaledi and Taheri (2016) \\
\hline C. beticola & Sugar beet & $\begin{array}{l}\text { Bacillus sp., Paenibacillus sp., } \\
\text { Pseudomonas sp., and } \\
\text { Enterobacter sp. }\end{array}$ & $\begin{array}{l}\text { In vitro and } \\
\text { greenhouse }\end{array}$ & Arzanlou et al. (2016) \\
\hline M. phaseolina & Soybean & $\begin{array}{l}\text { T. harzianum, T. asperellum, and } \\
\text { Trichoderma virens }\end{array}$ & Greenhouse & $\begin{array}{l}\text { Barari and } \\
\text { Foroutan (2016) }\end{array}$ \\
\hline M. phaseolina & Soybean & $T$. harzianum and $T$. atroviride & $\begin{array}{l}\text { In vitro and } \\
\text { greenhouse }\end{array}$ & Kia and Rahnama (2016) \\
\hline F. o. f.sp. dianthi & Carnation & T. harzianum & In vitro & Kermajany et al. (2017) \\
\hline V. dahliae & Pistachio & T. harzianum & Greenhouse & Fotoohiyan et al. (2017) \\
\hline $\begin{array}{l}\text { F. verticillioides, } \\
\text { P. aphanidermatum, } \\
\text { Penicillium sp., and V. dahliae }\end{array}$ & - & $\begin{array}{l}\text { Lactobacillus fermentum, } \\
\text { Lactobacillus plantarum, } \\
\text { Lactobacillus paralimentaris, } \\
\text { Lactobacillus pentosus, } \\
\text { Lactobacillus buchneri, and } \\
\text { Sporolactobacillus terrae }\end{array}$ & In vitro and field & Kharazian et al. (2017) \\
\hline Rhizoctonia solani & Suger beet & Bacillus subtilis & $\begin{array}{l}\text { In vitro and } \\
\text { greenhouse }\end{array}$ & Ahmadzadeh et al. (2017) \\
\hline Macrophomina phaseolina & Soybean & $\begin{array}{l}\text { Trichoderma harzianum, } \\
\text { Tricchoderma reesei and } \\
\text { Trichoderma atroviride }\end{array}$ & $\begin{array}{l}\text { In vitro and } \\
\text { greenhouse }\end{array}$ & Alamdarlou et al. (2017) \\
\hline $\begin{array}{l}\text { F. oxysporum, } X \text {. campestris, and } \\
\text { E. amylovora }\end{array}$ & - & Streptomyces sp. & In vitro & $\begin{array}{l}\text { Shams and } \\
\text { Shahnavaz (2017) }\end{array}$ \\
\hline M. javanica & Cucumber & $\begin{array}{l}\text { Pseudomonas rhodesiae and } \\
\text { Acinetobacter sp. }\end{array}$ & $\begin{array}{l}\text { In vitro and } \\
\text { greenhouse }\end{array}$ & Amini et al. (2017) \\
\hline
\end{tabular}


Table 1: continued

\begin{tabular}{|c|c|c|c|c|}
\hline Pathogens & Host & Antagonists & Procedure & Ref. \\
\hline $\begin{array}{l}\text { C. michiganensis subsp. } \\
\text { insidiosus }\end{array}$ & Alfalfa & $\begin{array}{l}\text { B. subtilis, Pseudomonas sp., } \\
\text { Escherichia coli, Sphingomonas } \\
\text { paucimobilis, and Paenibacillus } \\
\text { glycanilyticus }\end{array}$ & $\begin{array}{l}\text { In vitro and } \\
\text { greenhouse }\end{array}$ & $\begin{array}{l}\text { Omidi Nasab and } \\
\text { Khodakaramian (2017) }\end{array}$ \\
\hline P. loosi & Tea & P. lilacinus & Greenhouse & Yahyavi Azad et al. (2017) \\
\hline P. syringae pv. syringae & Oak & $\begin{array}{l}\text { Pseudomonas protegens, } \\
\text { Stenotrophomonas maltophilia, } \\
\text { and Bacillus firmus }\end{array}$ & In vitro & $\begin{array}{l}\text { Tashi-Oshnoei } \\
\text { et al. (2017) }\end{array}$ \\
\hline F. o. f.sp. radicis lycopersici & Tomato & Streptomyces carpaticus & $\begin{array}{l}\text { In vitro and } \\
\text { greenhouse }\end{array}$ & $\begin{array}{l}\text { Zahed and } \\
\text { Behbudi (2017) }\end{array}$ \\
\hline A. niger and $A$. flavus & - & B. cereus & In vitro & Motamedi et al. (2017) \\
\hline Xanthomonas oryzae pv. oryzae & Rice & $\begin{array}{l}\text { Bacillus sp., B. subtilis, } \\
\text { P. putida, and Enterobacter sp. }\end{array}$ & Greenhouse & Yousefi et al. (2018) \\
\hline R. solani & Common bean & $\begin{array}{l}\text { B. pumilus, } T \text {. harzianum, and } \\
\text { Rhizophagus intraradices }\end{array}$ & Greenhouse & $\begin{array}{l}\text { Nasir Hussein } \\
\text { et al. (2018) }\end{array}$ \\
\hline $\begin{array}{l}\text { P. syringae pv. syringae and } \\
\text { P. tolaasii }\end{array}$ & Pistachio & $\begin{array}{l}\text { Pantoea brenneri, } P \text {. protegens, } \\
\text { S. maltophilia, Bacillus } \\
\text { anthracis, } B \text {. pumilus, and } \\
\text { Serratia plymuthica }\end{array}$ & Greenhouse & $\begin{array}{l}\text { Etminani and } \\
\text { Harighi (2018) }\end{array}$ \\
\hline M. incognita & Pistachio & $\begin{array}{l}\text { P. fluorescens, B. cereus, and } \\
\text { B. subtilis }\end{array}$ & Greenhouse & $\begin{array}{l}\text { Zeynadini-Riseh } \\
\text { et al. (2018) }\end{array}$ \\
\hline Fusarium pseudograminearum & Wheat & $\begin{array}{l}\text { P. fluorescens, B. subtilis, and } \\
\text { Streptomyces sp. }\end{array}$ & $\begin{array}{l}\text { In vitro and } \\
\text { greenhouse }\end{array}$ & Norouzian et al. (2018) \\
\hline V. dahliae & Tomato & $\begin{array}{l}\text { Bacillus spp., Pseudomonas } \\
\text { spp., and Enterobacter spp. }\end{array}$ & In vitro & Zendehdel et al. (2018) \\
\hline H. schachtii & Sugar beet & $\begin{array}{l}\text { T. harzianum, Talaromyces } \\
\text { flavus, F. solani, and Pochonia } \\
\text { chlamydosporium }\end{array}$ & Greenhouse & Hosini et al. (2018) \\
\hline F. oxysporum & Cucumber & T. harzianum and $T$. atroviride & In vitro & Nosrati (2018) \\
\hline $\begin{array}{l}P . \text { carotovorum subsp. } \\
\text { carotovorum }\end{array}$ & Potato & Bacillus spp. & In vitro & Abdoli et al. (2018) \\
\hline S. sclerotiorum & Cucumber & Streptomyces albidoflavus & $\begin{array}{l}\text { In vitro and } \\
\text { greenhouse }\end{array}$ & Eini et al. (2018) \\
\hline P. loosi & Tea & $\begin{array}{l}P . \text { lilacinus and Clonostachys } \\
\text { rosea }\end{array}$ & Greenhouse & Yahyavi Azad et al. (2018) \\
\hline M. phaseolina & Melon & B. amyloliquefaciens & Greenhouse & Bakhshi et al. (2018) \\
\hline S. sclerotiorum & Cucumber & S. albidoflavus & $\begin{array}{l}\text { In vitro and } \\
\text { greenhouse }\end{array}$ & $\begin{array}{l}\text { Zahed and } \\
\text { Behbudi (2018) }\end{array}$ \\
\hline F. o. f.sp. radices lycopersici & Tomato & Streptomyces spp. & $\begin{array}{l}\text { In vitro and } \\
\text { greenhouse }\end{array}$ & Vafaie et al. (2018) \\
\hline F. oxysporum & Cucumber & P. fluorescens & Greenhouse & $\begin{array}{l}\text { Saberi-Riseh and } \\
\text { Fathi }(2018)\end{array}$ \\
\hline B. cinerea & & $\begin{array}{l}\text { Pichia galeiformis, Galactomyces } \\
\text { candidum, M. guilliermondii, } \\
\text { S. cerevisiae, Zygoascus } \\
\text { meyerae, Pichia sp., Candida } \\
\text { parapsilosis, Metschnikowia sp., } \\
\text { Candida boidinii, Lecythophora } \\
\text { sp., and Candida catenulata }\end{array}$ & In vitro & Gharaei et al. (2018) \\
\hline
\end{tabular}




\section{Future perspectives}

The climate changes and the growing human population with enhancing food demands have been considered as risks to food security in Iran. Different beneficial population of microbes can positively affect agricultural farms, such as pollutant degradation, productivity, and decrease in disease and pest. Maintaining and improving the performance of these microbes can increase agricultural products in different geographical area of Iran with various climates. More studies are needed to reach these aims in Iran. We need to engineer microbes in different parts and various population of plants. We can use beneficial microbes as bioformulation or other methods of treatments on plants. Since the roots are in contact with soil and rhizosphere has high biodiversity, these are the most important parts in plants for engineering the microbes. Therefore, soil improvement with beneficial microorganisms will be able to help farmers and agricultural ecosystems in the future years.

Conflict of interest: Authors declare no conflict of interest.

\section{References}

[1] Abawi GS, Widmer TL. Impact of soil health management practices on soilborne pathogens, nematodes and root disease of vegetable crops. Appl Soil Ecol. 2000;15: 37-47.

[2] Abbasi S, Safaie N, Shams-bakhsh M, Shahbazi S. Biocontrol activities of gamma induced mutants of Trichoderma harzianum against some soilborne fungal pathogens and their DNA fingerprinting. Iran J Biotechnol. 2016;14(4):260-9.

[3] Abbaszadeh F, Mohammadi-Goltapeh E. Biocontrol of the charcoal rot of soybean (Macrophomina phaseolina) by members of the Sebacinales and Trichoderma species under greenhouse and field conditions. 18th Iranian Plant Protection Congress; 2008a. p. 267.

[4] Abbaszadeh F, Mohammadi-Goltapeh E. Determination of suitable conditions for the axenic culture mycorrhizal fungi (Piriformospora indica and Sebacina vermifera) and to study the antagonistic ability of these fungi in vitro condition, 18th Iranian Plant Protection Congress; 2008b. p. 362.

[5] Abdolahy M, Parsaiyan M. Study on antagonistic efficacy of Trichoderma isolates on cucurbit root rot. 20th Iranian Plant Protection Congress; 2012. p. 338.

[6] Abdoli F, Fallahzadeh Mamaghani V, Shirzad A. Screening of biofilm forming rhizobacteria of field crops for biological control of Pectobacterium carotovorum subsp. carotovorum the causal agent of potato soft rot. Biol Control Pests Plant Dis. 2018;7(1):75-84.
[7] Abdollahi M, Ommati F, Zaker M. Efficacy of some native Trichoderma isolates in biological control of Pythium aphanidermatum the causal agent of sugar beet root rot under greenhouse condition. Biocontrol Plant Prot. 2013;1(1):41-52.

[8] Abdollahipuor FZ, Akbar Shirzad A, Hamid Mohammadi H. Evaluation of biocontrol of Rhizoctonia solani in cotton by Pseudomonas fluorescens isolates. Biol Control Pests Plant Dis. 2015;4(1).

[9] Abdollahzadeh J, Mohammadi Goltapeh E, Rouhani H. Evaluation of antagonistic effect of Trichoderma species in biological control of causal agent of crown and root rot of sunflower (Sclerotinia minor) in vitro. J Agric Sci. 2003;13(2):13-23.

[10] Abdollahzadeh J, Mohammadi GE, Rouhani H. Investigation on biocontrol of crown and root rot of sunflower (Sclerotinia sclerotiorum) by Trichoderma species in laboratory condition. J Agric Sci. 2006;12(1):43-56.

[11] Abootorabi E, Naraghi L. Biological control of tomato root knot nematode Meloidogyne javanica By Talaromyces flavus and Trichoderma harzianum in the greenhouse conditions. Biocontrol Plant Prot. 2016;4(2):1-9.

[12] Afrousheh M, Mohammadi H, Shokoohi E. Effect of Trichoderma viride and Trichoderma harzianum on chickpea root rot caused by Fusarium solani f. sp pisi. 20th Iranian Plant Protection Congress; 2012a. p. 286.

[13] Afrousheh M, Mohammadi H, Shokoohi E. Evaluation of Trichoderma viride and Trichoderma harzianum as biocontrol agents against pea root rot disease caused by Fusarium solani f sp pisi. 20th Iranian Plant Protection Congress; 2012b. p. 255.

[14] Afsharmanesh H, Ahmadzadeh M, Sharifi-Tehrani A. Biocontrol of Rhizoctonia solani the causal agent of bean damping-off by fluorescent pseudomonads. Commun Agric Appl Biol Sci. 2006;71(3):1021-29.

[15] Afsharmanesh H, Ahmadzadeh M, Javan-Nikkhah M, Behboudi K. Improvement in biocontrol activity of Bacillus subtilis UTB1 against Aspergillus flavus using gammairradiation. Crop Prot. 2014;60:83-92.

[16] Afsharmanesh H, Ahmadzadeh M, Majdabadi A, Motamedi F, Behboudi K, Javan-Nikkhah M. Enhancement of biosurfactants and biofilm production after gamma irradiationinduced mutagenesis of Bacillus subtilis UTB1 a biocontrol agent of Aspergillus flavus. Arch Phytopathol Plant Prot. 2013;46(15):1874-84.

[17] Aghighi S, Shahidi Bonjar GH, Naghizadeh M, Rashid Farrokhi P, Banihashemi Z, Heydarnejad J, et al. Bioactivity of Iranian native strains of Streptomyces plicatus and Frankia sp. against pistachio olive potato and cotton isolates of Verticillium dahliae. 17th Iranian Plant Protection Congress; 2006. p. 468.

[18] Ahmadzadeh M, Shahrokhi A, Rahimian H, Behboodi K. Isolation of Bacillus subtilis strains from Iran and their biocontrol effect against Rhizoctonia solani AG2-2 damping off of sugar beet in vitro and greenhouse Scinzer. J Agric Biol Sci. 2017;3(1):5-10.

[19] Ahmadzadeh M, Farzaneh M, Javan-Nikkhah M. Biological control of Magnaporthe salvini the causal agent of stem rot of rice by fluorescent Pseudomonads. 18th Iranian Plant Protection Congress; 2008. p. 291. 
[20] Ahmadi A, Sedaghat M, Saroukhani E, Khoshkam S. The evaluation of efficacy of biocontrol strains of Erwinia herbicola and Pseudomonas fluorescens against pear fire blight disease. 14th Iranian Plant Protection Congress; 2000. p. 140.

[21] Ahmadi AR, Hedjaroude CA, Sharifi-Tehrani A, Kheiri A, Akiyani A. First report on isolation and identification of Paecilomyces farinosus from Heterodera schachtii and its antagonistic effects on the eggs in Iran. 12th Iranian Plant Protection Congress; 1996a. p. 354.

[22] Ahmadi AR, Hedjaroude CA, Sharifi-Tehrani A, Kheiri A, Akiyani A Isolation of Fusarium solani from the sugar beet cyst nematode (Heterodera schachtii) and antagonistic evaluation on the eggs in vitro. 12th Iranian Plant Protection Congress; 1996b. p. 355.

[23] Ahmadifar F, Roustaei A, Shahriari D. Biological control of cucumber wilt disease caused by Verticillium dahliae by using isolates of Bacillus and Pseudomonas. Agric Res. 2006;6(1):65-78.

[24] Ahmadzadeh M, Sharifi-Tehrani A, Nabizadeh M. Biological control of Rhizoctonia solani Kuhn casual agent of common bean damping-off through Burkholderia cepacia (ex Burk) Yabuchi. Iran J Plant Prot Sci. 2009;39(1):81-90.

[25] Ahmadzadeh M, Tehrani AS. Evaluation of fluorescent pseudomonads for plant growth promotion antifungal activity against Rhizoctonia solani on common bean and biocontrol potential. Biol Control. 2009;48(2):101-7.

[26] Ahmadzadeh M, Afsharmanesh H, Javan-Nikkhah M, SharifiTehrani A. Identification of some molecular traits in fluorescent pseudomonads with antifungal activity. Iran J Biotechnol. 2006a;4(4):245-53.

[27] Ahmadzadeh M, Sharifi-Tehrani A, Naizadeh M. Biological control of Rhizoctonia solani causal agent of common bean damping-off Burkholderia cepacia. 17th Iranian Plant Protection Congress; 2006b. p. 144.

[28] Akbari KS, Niknejad KM, Elahinia SA, Khodaparast SA. Effect of antagonistic bacteria on Sclerotinia sclerotiorum the causal agent of white mold in oilseed rape. Iran J Plant Pathol. 2005a;41(3):307-28.

[29] Akbari KS, Niknezhad KM, Elahinia SA, Khodaparast SA. Effect of antagonistic bacteria on Sclerotinia sclerotiorum the causal agent of white mold in oilseed rape. Plant Dis. 2005b;41:307-28.

[30] Akbari-Kiarodi SL, Niknejad-Kazampor M, elahinia SS. Antagonistic effects of four Bacillus spp. isolates on lysis and inhibition of germination of Sclerotinia sclerotiorum the causal agents of oilseed rape white mold disease. 16th Iranian Plant Protection Congress; 2004. p. 288.

[31] Akbari-Moghadam E, Saberi-Riseh R, Khodaygan P, Alaei H. Evaluate the control ability of Pseudomonas fluorescens strains on cucumber root rot disease. Biol Control Pests Plant Dis. 2015;4(2):77-88.

[32] Akhlaghi M, Moradzadeh Eskandari M, Rouhani H, Mahdikhani Moghaddam E. Evaluation of some native and commercial isolates of Trichoderma to control of cucumber Fusarium wilt. 22th Iranian Plant Protection Congress; 2016. p. 350.

[33] Akrami M, Golzary H, Ahmadzadeh M. Evaluation of different combinations of Trichoderma species for controlling Fusarium rot of lentil. Afr J Biotechnol. 2011;10(14):2653-58.
[34] Akrami M, Ibrahimev A. Evaluation of different combination of Trichoderma species for controlling Fusarium rot of chickpea. J Crop Ecophysiology. 2010;4(2-1):75-83.

[35] Alabouvette C, Schippers B, Lemanceau P, Bakker PAHM. Biological control of Fusarium wilts. In: Boland GJ, Kuykendall LD, editors. Plant-microbe interactions and biological control. New York NY: Marcel Dekker; 1998. p. $15-36$.

[36] Alamdarlou RM, Idin Hasanzadeh I, Mirabadi AZ, Foroozan F. Evaluation of the efficacy of Trichoderma isolates in the biological control of soybean charcoal rot disease in the laboratory and greenhouse conditions. Biocontrol Plant Prot. 2017;5(1):71-80.

[37] Alavifard FS, Etebarian HR, Sahebany N, Aminian H. Biological control of grey mould of apple by isolates Candida membranifaciens, Rhodotorula mucilaginosa and Pichia guilliermondii. 18th Iranian Plant Protection Congress; 2008a. p. 339.

[38] Alavifard F, Etebarian HR, Sahebany N, Aminian H. Control of grey mould of apple by Candida membranifaciens and induction of defense responses at $20^{\circ} \mathrm{C}$. 18th Iranian Plant Protection Congress; 2008b. p. 338.

[39] Ale Aghaee SH, Shahriari D, Torabi M. Evaluation of the effect of Trichoderma spp. isolates on biological control of Pythium aphanidermatum the causal agent of cucumber damping-off and seed rot in laboratory and greenhouse. 20th Iranian Plant Protection Congress; 2012. p. 252.

[40] Alijani N, Manafi Shabestari M, Ghosta Y. Biocontrol effects of endophytic fungi isolated from apple trees against Diplodia bulgarica the causal agent of apple canker disease. 22th Iranian Plant Protection Congress; 2016. p. 339.

[41] Alimi M, Soleimani MJ, Taghinasab Darzi M. Characterization and application of microbial antagonists for control of Fusarium head blight of wheat caused by Fusarium graminearum using single and mixture strain of antagonistic bacteria on resistance and susceptible cultivars African. J Microbiol Res. 2012;6(2):326-33.

[42] Alimi M, Soleymani M, Rahimian H, Mohajer A. Application of antagonistic bacteria for controlling Fusarium head blight of wheat caused by Fusarium graminearum on semi-resistance and susceptible cultivars in greenhouse and field conditions. J Agric Sci Nat Resour. 2006;13(5):102-1014.

[43] Alipoor Moghadam M, Moradi M, Sedaghati E, Khodaygan P. Identification of Trichoderma species and investigation on their effects on the crown and root rot of pistachio seedlings in Kerman province. 20th Iranian Plant Protection Congress; 2012. p. 295.

[44] Ameri M, Kheiri A, Damadzadeh M, Rahimian H. An investigation on the efficiency of Pasteuria penetrans for control of root-knot nematodes (Meloidogyne javanica). 12th Iranian Plant Protection Congress; 1996. p. 379.

[45] Amini J, Faizi S, Mirzaei S. Biological control of gray mold of three cultivar of strawberry using Bacillus strains. Biol Control Pests Plant iseasesD. 2016;5(1):13-23.

[46] Amini F, Mahdikhani-Moghaddam E, Baghaee-Ravari S. Efficiency of cucumber endophytic bacteria on Meloidogyne javanica control under lab and greenhouse conditions. Biol Control Pests Plant esDiseas. 2017;6(1):83-92.

[47] Amirafzali M, Fekrat F, Azami-Sardooei Z. Investigation of the effects of vermi- compost and Glomus mosseae on Fusarium 
oxysporum f.sp. lycopersici and Meloidogyne javanica. 22th Iranian Plant Protection Congress; 2016. p. 329.

[48] Amir-Sadeghi S, Sharifi-Tehrani A, Hejaroud DHA, Okhovat M, Rouhani H. Investigation on antagonistic properties of Trichoderma spp. Against Sclerotinia sclerotiorum (Lib) deBary the causal agent of Sclerotinia disease of eggplant. 11th Protection Congress Plant Iranian; 1994. p. 151.

[49] Ansari LGH, Shahedi SA, Ayatollahi M, Deghat S. Tracking for Streptomyces antagonists of Paecilomyces variotii causal of die-back disorder and verification and study on some physiological properties of the antagonists. 20th Iranian Plant Protection Congress; 2012. p. 293.

[50] Arseneault T, Filion M. Biocontrol through antibiosis: exploring the role played by subinhibitory concentrations of antibiotics in soil and their impact on plant pathogens. Can J Plant Pathol. 2017;39(3):267-74.

[51] Arzanlou M, Mousavi S, Bakhshi M, Khakvar R, Bandehagh A. Inhibitory effects of antagonistic bacteria inhabiting the rhizosphere of the sugarbeet plants on Cercospora beticola Sacc the causal agent of Cercospora leaf spot disease on sugar beet. J Plant Prot Res. 2016;56(1):6-14.

[52] Asef MR, Mohammadi-Gholtapeh E. Antagonistic effects of Cladobotryum species on the rhizomorph of Armillaria mellea. 16th Iranian Plant Protection Congress; 2004. p. 500 .

[53] Asef M, Goltapeh E, Danesh Y. Antagonistic effects of Trichoderma species in biocontrol of Armillaria mellea in fruit trees in Iran. J Plant Prot Res. 2008;48(2):213-22.

[54] Asghari MR, Myee CD. Comparative efficiency of management practices on stem and pod rot of groundnut. 10th Iranian Plant Protection Congress; 1992. p. 100.

[55] Ashofteh F, Ahmadzadeh M, Fallahzadeh-Mamaghani V. Effect of mineral components of the medium used to grow biocontrol strain UTPF61 of Pseudomonas fluorescens on its antagonistic activity against Sclerotinia wilt of sunflower and its survival during and after the formulation process. J Plant Pathol. 2009;91(3):607-13.

[56] Ashrafizadeh A, Etebarian HR, Zamanizadeh HR. Evaluation of Streptomyces and Trichoderma isolates for biological control of Fusarium wilt of melon. 15th Iranian Plant Protection Congress; 2002. p. 105.

[57] Aslani MA, Harighi B, Abdollahzadeh J. Biological control of brown blotch disease of white button mushroom (Agaricus bisporus) using antagonistic bacteria. 22th Iranian Plant Protection Congress; 2016. p. 372.

[58] Ayoubi N, Mirabolfathy M, Zafari D. The control of soybean root and crown rot (Phytophthora sojae) by Trichoderma at greenhouse conditions. 19th Iranian Plant Protection Congress; 2010. p. 783.

[59] Ayoubi N, Zafari D, Mirabolfathy M. Combination of Trichoderma species and Bradyrhizobium japonicum in control of Phytophthora sojae and soybean growth. J Crop Prot. 2012;1(1):67-79.

[60] Azad Disfani F, Sharifi-Tehrani A, Hedjaroude GA, Mohammadi M, Rohani H. Study on antagonistic properties of Bacillus and Pseudomonas isolates against Verticillium dahliae the causal agent of cotton wilt. 14th Iranian Plant Protection Congress; 2000. p. 57.

[61] Azadi N, Shirzad A, Mohammadi H. A study of some biocontrol mechanisms of Beauveria bassiana against
Rhizoctonia disease on tomato. Acta Biol Szeged.

2016;60(2):119-27.

[62] Azadrooh M, Aminian H, Erebarian HR, Sahebani N. Studies on effect of combination sodium carbonate and yeast Hanseniaspora occidentalis M46 in control of Apple fruit gray mold caused by Botrytis cinerea. 20th Iranian Plant Protection Congress; 2012. p. 273.

[63] Azami-Sardooie Z, Nasirpour R, Fekrat F, Alizadeh H. Use of Brassica oleracea tissue and Glomus mosseae for controlling of Meloidogyne javanica on tomato plant. Biol Control Pests Plant Dis. 2016;6(1):41-51.

[64] Azizpour N, Rouhrazi K. Isolation and Characterization of Rhizosphere Bacteria for the Biocontrol of the Ascochyta rabiei in Iran. Adv Plants Agric Res. 2016;3(4):104.

[65] Babaei Nasir S, Amini J, Soleimani Pari MJ, Harighi B. Biocontrol of garlic white rot disease (Sclerotium cepivorum) by using bacterial antagonistic strains of Bacillus species in In Vitro. 19th Iranian Plant Protection Congress; 2010. p. 809.

[66] Babaeipoor E, Mirzaei S, Danesh YR, Arjm A, Chaichi M. Evaluation of some antagonistic bacteria in biological control of Gaeumannomyces graminis var. tritici causal agent of wheat take-all disease in Iran. Afr J Microbiol Res. 2011;5(29):5165-73.

[67] Baghani F, Rahnama K, Aghajani MA, Dehghan MA. Parasitization of Fusarium graminearum by Trichoderma isolates after spraying wheat spikes in the field conditions. 20th Iranian Plant Protection Congress; 2012. p. 268.

[68] Bagheri F, Rohani H, Felahati Rastegar M, Saberi Riseh RA. Investigation on Phase Variation Phenomenon in Fluorescent Pseudomonads and their Effect on Control of Gaeumannomyces graminis var. tritici Causal Agent of Takeall Disease. Iran J Plant Prot Sci. 2011;42(2):199-208.

[69] Bagheri N, Ahmadzadeh M. First report of Achromobacter xylosoxidans on wheat rhizosphere in Iran and its biocontrol activity. Sci Agriculturae. 2016;16(1):36-42.

[70] Bagheri N, Ahmadzadeh M, Heydari R. Effects of Pseudomonas fluorescens strain UTPF5 on the mobility mortality and hatching of root-knot nematode Meloidogyne javanica. Arch Phytopathol Plant Prot. 2014;47(6):744-52.

[71] Bagheri S, Alizadeh H, Azadvar H, Amirmijani A. Evaluation of biocontrol characteristics of antagonistic bacteria isolated from cucumber rhizosphere against Sclerotinia sclerotiorum and Pythium aphanidermatum. Iran J Plant Prot Sci. 2016;47(2):325-40.

[72] Bagheri J, Elahinia SA, Niknejad M, Pedramfar H, Bayar H. Biological control of vascular wilt and corm rot of gladiola (Fusarium oxysporum f.sp. gladioli) with Trichoderma isolates in vitro. 19th Iranian Plant Protection Congress; 2010. p. 812.

[73] Bahrami B, Afshari-Azad H, Hassanzadeh N. Possibility of biological control of Ascochyta rabiei the causal agent of chickpea blight disease using antagonistic microorganisms. 17th Iranian Plant Protection Congress; 2006. p. 126.

[74] Bakhshi E, Safaie N, Shamsbakhsh M. Bacillus amyloliquefaciens as a biocontrol agent improves the management of charcoal root rot in melon. J Agric Sci Technol. 2018;20(3):597-607.

[75] Barari H. Biocontrol of tomato Fusarium wilt by Trichoderma species under in vitro and in vivo Conditions. Cercetari Agronomice Moldova. 2016;49(1):91-98. 
[76] Barari H, Foroutan A. Biocontrol of soybean charcoal root rot disease by using Trichoderma spp. Cercetari Agronomice Moldova. 2016;49(2):41-51.

[77] Barari H, Alani V, Foroutan A, Dalili A. Biocontrol of soybean charcoal rot disease using antagonistic fungi in laboratory and greenhouse. 16th Iranian Plant Protection Congress; 2004. p. 282.

[78] Barari H, Rayatpanah S, Dalili A, Oladi M. Study of the efficiency of three strains of Trichoderma harzianum on charcoal rot of soybean in field conditions in Mazandaran province. 21th Iranian Plant Protection Congress; 2014. p. 113.

[79] Barbeau K, Zhang G, Live DH, Butler A. Petrobactin, a photoreactive siderophore produced by the oil-degrading marine bacterium Marinobacter hydrocarbonoclasticus. J Am Chem Soc. 2002;124(3):378-9.

[80] Bardin M, Ajouz S, Comby M, Lopez-Ferber M, Graillot B, Siegwart $M$, et al. Is the efficacy of biological control against plant diseases likely to be more durable than that of chemical pesticides. Front Plant Sci. 2015;27(6):566.

[81] Bashiri S, Llop P, Davino M, Golmohammadi M, Scuderi G. Efficacy of Pseudomonas chlororaphis subsp. aureofaciens $\mathrm{SH} 2$ and Pseudomonas fluorescens RH43 isolates against root-knot nematodes (Meloidogyne spp.) in kiwifruit XJENZA; 2015. p. 8.

[82] Bazgir A, Rouhani H, Okhovat $M$. The investigation of Gliocladium sp. effect on Rhizoctonia solani the causal agent of seedling death and bean seed rot. 10th Iranian Plant Protection Congress; 1992. p. 108.

[83] Bazgir E, Rouhani H, Okhovat M, Karimi A. Comparative efficiency of chemical vs biological control of Rhizoctonia disease of bean under field conditions. 11th Iranian Plant Protection Congress; 1994a. p. 141.

[84] Bazgir E, Okhovat M, Sharifi A, Rouhani H. A comparative of chemical and biological control of Rhizoctonia disease in bean in greenhouse. 11th Iranian Plant Protection Congress; 1994b. p. 140.

[85] Beeazar A, Torabi M. Study of the effectiveness of antagonistic Trichoderma in biological control of wheat carnal bunt (Tilletia indica) in vitro and in vivo. 16th Iranian Plant Protection Congress; 2004. p. 32.

[86] Behboodi K, Sharifi-Tehrani A, Hedjaroude GA, Zad J. Study on antagonistic properties of Trichoderma virens against Phytophthora capsici the causal agent of pepper dampingoff. 13th Iranian Plant Protection Congress; 1998. p. 180.

[87] Behboudi K, Sharifi TA, Hejaroud GA, Zad S. Antagonistic effects of Trichoderma species on Phytophthora capsici the causal agent of pepper root and crown rot. Plant iseasesD. 2005;41:342-65.

[88] Behdani M, Roustaee A, Etebarian HR, Khodakaramian. Biological control of root rot of wheat (Bipolaris spicifera) by antagonistic strains of Bacillus and Pseudomonas. 17th Iranian Plant Protection Congress; 2006. p. 12.

[89] Behnam S, Ahmadzadeh M, Sharifi Tehrani A, Hedjaroude GA, Farzaneh M. Biological control of Sclerotinia sclerotiorum (Lib) de Bary the causal agent of white mold by Pseudomonas species on canola petals. Commun Agric Appl Biol Sci. 2007;72(4):993-6.
[90] Belimov AA, Safronova VI, Sergeyeva TA, Egorova TN, Matveyeva VA, Tsyganov VE, et al. Characterization of plant growth promoting rhizobacteria isolated from polluted soils and containing 1-aminocyclopropane-1-carboxylate deaminase. Can J Microbiol. 2001;47(7):642-52.

[91] Benítez T, Rincón AM, Limón MC, Codón AC. Biocontrol mechanisms of Trichoderma strains. Int Microbiology. 2004;7:249-60.

[92] Beydaghi M, Panjehkeh N, Rezaei R. Identification fungal causing leaf spot on tomato and biological control by the antagonists isolated from the rhizosphere of tomato in Sistan. Biol Control Pests Plant Dis. 2016;6(1):23-39.

[93] Binandeh N, Safaie N, Khelghatibana F. Antagonistic activity of two Bacillus species against apple white root rot fungus in vitro. 22th Iranian Plant Protection Congress; 2016. p. 349.

[94] Bloemberg GV, Lugtenberg BJ. Molecular basis of plant growth promotion and biocontrol by rhizobacteria. Curr OpPlant Biol. 2001;4:343-50.

[95] Boromand G, Fatemy S, Rezaee S. Evaluation of biocontrol of root knot nematode (Meloidogyne spp.) by Paecilomyces lilacinus fungus. 19th Iranian Plant Protection Congress; 2010. p. 808.

[96] Calvo J, Calvente V, de Orellano ME, Benuzzi D, de Tosetti MIS. Biological control of postharvest spoilage caused by Penicillium expansum and Botrytis cinerea in apple by using the bacterium Rahnella aquatilis. Int J Food Microbiology. 2007;113:251-7.

[97] Chavoshisani M, Jamali S, Taheri H, Khodaparast SA. Bioinhibition of citrus nematode Tylenchulus semipenetrans by antagonistic fungi under greenhouse condition. J Plant Prot. 2013;27(3):376-8.

[98] Chegini S, Behboudi K, Javan-Nikkhah M, Farzaneh M. Study of Trichoderma isolates against mycelial growth and AFB1 produced by Aspergillus flavus on pistachio nuts. Biol Control Pests Plant Dis. 2013;2(2):71-79.

[99] Cook RJ, Baker KF. The Nature and Practice of Biological Control of Plant Pathogens. St Paul MN: American Phytopathological Society; 1983. p. 539.

[100] Costa JM, Loper JE. Characterization of siderophore production by the biological control agent Ente robacter cloacae. MPMI. 1994;7:440-8.

[101] Dadjoo H, Khodakaramyian G, Rooh Razi K. The endophytic bacterium of potato Paenibacillus polymyxa as biocontrol agent of Ralstonia solanacearum. 21th Iranian Plant Protection Congress; 2014. p. 94.

[102] Damadzadeh M, Samavatian H, Ansaripour B, Gowen S. Control of Meloidogyne javanica by Pasteuria penetrans in greenhouse. 12th Iranian Plant Protection Congress; 1996. p. 167.

[103] Danaei M, Baghizadeh A, Pourseyedi S, Amini J, Yaghoobi MM. Biological control of plant fungal diseases using volatile substances of Streptomyces griseus. Eur J Exp Biol. 2014;4(1):334-9.

[104] Davari M, Ezazi R. Study on the effects of four medicinal plant essential oils and two Trichoderma species on biocontrol of grape fruit rot fungi. Biol Control Pests Plant iseasesD. 2016;5(1):1-12.

[105] David BV, Chandrasehar G, Selvam PN. Pseudomonas fluorescens: a plant-growth-promoting rhizobacterium (PGPR) with potential role in biocontrol of pests of crops. 
In Crop improvement through microbial biotechnology. Elsevier; 2018. pp. 221-43.

[106] Delkhah Z, Behboudi K. Production and application of Trichoderma harzianum Tr6 for controlling of damping-off caused by Phytophthora drechsleri and its effect on the growth promotion of cucumber. Biol Control Pests Plant Dis. 2015;3(2):97-104.

[107] Derakhshan A, Safaie N, Alizadeh A. Investigating effect of epiphytic bacteria in biocontrol of wheat head blight on Tagen and Falat cultivars in vivo. 19th Iranian Plant Protection Congress; 2010. p. 840.

[108] Droby S, Cohen L, Daus A, Weiss B, Horev B, Chalutz E, et al. Commercial testing of Aspire: a yeast preparation for the biological control of postharvest decay of citrus. Biol Control. 1998;12(2):97-101.

[109] Duffy BK, Weller DM. Use of Gaeumannomyces graminis var. graminis alone and in combination with fluorescent Pseudomonas spp. to suppress take-all of wheat. Plant Dis. 1995;79:907-11.

[110] Dukare AS, Paul S, Nambi VE, Gupta RK, Singh R, Sharma K, et al. Exploitation of microbial antagonists for the control of postharvest diseases of fruits: a review. Crit Rev Food Sci Nutr. 2019;59(9):1498-513.

[111] Ebrahimi L, Etebarian HR, Aminian HA, Sahebani NA. Biological control of apple blue mold with Metschnikowia pulcherrima and assessment of total phenolic content and peroxidase activity. 20th Iranian Plant Protection Congress; 2012a. p. 298.

[112] Ebrahimi L, Etebarian HR, Aminian HA. Control of apple blue mold with Torulaspora delbrueckii alone and with silicon in storage condition. 20th Iranian Plant Protection Congress; 2012b. p. 306.

[113] Ebrahimi-Zarandi M, Shahidi Bonjar GH, Padasht Dehkaeio F, Ayatollahi Moosavi SA, Aghighi S. Biological control of rice blast by use of Streptomyces spp. 18th Iranian Plant Protection Congress; 2008. p. 351.

[114] Eini S, Behbodi K, Purbabaei AA, Zahed MJ. Biological control of Sclerotinia sclerotiorum the causal agent of cucumber white stem rot by rhizosphere actinobacteria. Biol Control Pests Plant Dis. 2018;7(1):33-45.

[115] Eivazi A, Soleimani MJ, Zafari D. Biological control of tomato stem canker disease caused by Botrytis cinerea using Trichoderma isolates. 19th Iranian Plant Protection Congress; 2010. p. 876.

[116] Emadi A, Eteharian HR, Aminian H, Sahebani N, Alizadeh Aliabadi A. In vitro and in vivo biological control of blue mold of apple fruit by Bacillus subtilis. 19th Iranian Plant Protection Congress; 2010. p. 878.

[117] Engelbrecht G, Horak I, Jansen van Rensburg PJ, Claassens S. Bacillus-based bionematicides: development modes of action and commercialization. Biocontrol Sci Technol. 2018;28(7):629-53.

[118] Etebarian H, Mohammadifar M, Alizadeh H, Zareei SA. Biological control of barley covered smut by bacterial antagonists. Appl Entomology Phytopathology. 2007;74(2):81-91.

[119] Etebarian HR. Evaluation of Trichoderma isolates for biological control of charcoal stem rot in melon caused by Macrophomina phaseolina. J Agric Sci Technol. 2006;8:243-50.
[120] Etminani F, Harighi B. Isolation and identification of endophytic bacteria with plant growth promoting activity and biocontrol potential from wild pistachio trees. Plant Pathol J. 2018;34(3):208.

[121] Fadaei Sh, Shahidi Bonjar GH, Aminaee MM, Negarestani MR. Evaluation of physiological characteristic of some Actinomycetes isolated from agricultural soils of Kerman Fars and Hormozgan Provinces for production of chitinase protease lipase and amylase enzymes. 20th Iranian Plant Protection Congress; 2012. p. 254.

[122] Fallahzadeh-Mamaghani V, Alizadeh Aliabadi A, Shirzad A. Screening of fluorescent pseudomonads based on produc tion of siderophore and induction of plant ethylene production for induction of systemic resistance against wheat bacterial leaf streak. Iran J Plant Prot Sci. 2016;47(2):277-92.

[123] Fallahzadeh-Mamaghani V, Ahmadzadeh M, Sharifi R. Screening systemic resistance-inducing fluorescent pseudomonads for control of bacterial blight of cotton caused by Xanthomonas campestris pv. malvacearum. J Plant Pathol. 2009;91(3):663-7.

[124] Faraji A, Roghaye Hemmati R, Marefat A. Biological control of major fungal causal agent of root and crown rot of bean in Zanjan province with antagonistic bacteria. Iran J Plant Prot Sci. 2015;46(2):317-29.

[125] Farzaneh M, Sharifi-Tehrani A, Ahmadzadeh M, Zad J, Effect of some antagonistic bacteria in the control of Phytophthora cactorum the casual agent of root and crown rot on apple trees. 17th Iranian Plant Protection Congress; 2006. p. 338.

[126] Farzaneh M, Sharifi-Tehrani A, Ahmadzadeh M, Zad J. Biocontrol of Phytophthora cactorum the causal agent of root and crown rot on apple (Malus domestica) by formulated Pseudomonas fluorescens. Commun Agric Appl Biol Sci. 2007;72(4):891-900.

[127] Farzaneh M, Shi ZQ, Ahmadzadeh M, Hu LB, Ghassempour A. Inhibition of the Aspergillus flavus Growth and Aflatoxin B1 contamination on pistachio nut by Fengycin and Surfactinproducing Bacillus subtilis UTBSP1. Plant Pathol J. 2016;32(3):209.

[128] Fatemy S, Ahmadian Yazdi A. Isolation and introduction of Paecilomyces fumosoroseus from beet cyst nematodes, Heterodera schachtii. Sugerbeet. 1997;13(1):63-70.

[129] Fatemy S. Evaluation of Paecilomyces lilacinus as a biocontrol agent of Meloidogyne javanica on tomato. 12th Iranian Plant Protection Congress; 1996. p. 173.

[130] Fedi S, Tola E, Moenne-Loccoz Y, Dowling DN, Smith LM, O'Gara F. Evidence for signaling between the phytopathogenic fungus Pythium ultimum and Pseudomonas fluorescens F113: pultimum represses the expression of genes in Pseudomonas fluorescens F113 resulting in altered ecological fitness. Appl Environ Microbiol. 1997;63:4261-66.

[131] Fernando WGD, Nakkeeran S, Zhang Y. Biosynthesis of antibiotics by PGPR and its relation in biocontrol of plant diseases. In: Siddiqui ZA, editor. PGPR: Biocontrol and Biofertilization Dordrecht (NL). Dordrecht/Netherlands: Springer; 2006. p. 67-109.

[132] Firouzian Bandpey S, Rahimian H. Identification of Pantoea agglomerans and evaluation of its antagonistic activities against Erwinia amylovora the causative agent of fire blight of pome fruits in Mazandaran. 22th Iranian Plant Protection Congress; 2016. p. 315 
[133] Flint ML, Dreistadt SH, Clark Jack K. editors. Natural Enemies Handbook: The Illustrated Guide to Biological Pest Control. University of California Press; 1998.

[134] Forchetti G, Masciarelli O, Alemano S, Alvarez D, Abdala G. Endophytic bacteria in sunflower (Helianthus annuus L.): isolation, characterization, and production of jasmonates and abscisic acid in culture medium. Appl. Microbiol. Biotechnol. 2007;76(5):1145-52.

[135] Foroutan A, Rahimian H, Raiatpanah S, Barary H, Sedaghatfar E, Ramezani $\mathrm{H}$, et al. Effect of Trichoderma harzianum and $T$. viride for control of take -all in Mazandaran. 15th Iranian Plant Protection Congress; 2002. p. 19.

[136] Foroutan A. Evaluation of Trichoderma isolates for biological control of wheat Fusarium foot and root rot. Romanian Agric Res. 2013;30:35-44.

[137] Foroutan A, Rahimian H, Alizadeh AE. Effect of antagonistic bacteria on Fusarium head blight of wheat. Iran J Plant Pathol. 2005;41(3):455-73.

[138] Fotoohiyan Z, Rezaee S, Bonjar GHS, Mohammadi AH, Moradi M. Biocontrol potential of Trichoderma harzianum in controlling wilt disease of pistachio caused by Verticillium dahliae. J Plant Prot Res. 2017;57(2):185-93.

[139] Fotoohiyan Z, Rezaee S, Bonjar GHS, Mohammadi AH, Moradi M. Induction of systemic resistance by Trichoderma harzianum isolates in pistachio plants infected with Verticillium dahliae. J Nuts. 2015;6(2):95-111.

[140] Fravel DR. Role of antibiosis in the biocontrol of plant diseases. Annu Rev Phytopathology. 1988;26:75-91.

[141] Geraldine AM, Lopes FAC, Carvalho DDC, Barbosa ET, Rodrigues AR, Brandão RS, et al. Cell wall-degrading enzymes and parasitism of sclerotia are key factors on field biocontrol of white mold by Trichoderma spp. Biol Control. 2013;67:308-16.

[142] Gerami E, Hassanzadeh N, Abdollahi H, Ghasemi A, Heydari A. Evaluation of some bacterial antagonists for biological control of fire blight disease. J Plant Pathol. 2013;95(1):127-34.

[143] Ghaffarian A, Minassian V, Shahriari D. Biological control of Macrophomina phaseolina the causal agent of charcoal rot disease by Trichoderma spp. 14th Iranian Plant Protection Congress; 2000. p. 103.

[144] Ghafelebashi SS, Jamali F, Ahmadzadeh M. Study biological properties of Pseudomonas fluorescens UTPF68, biocontrol agent against Phytophthora drechsleri. Biol Control Pests Plant Dis. 2014;3(2):105-16.

[145] Ghanbari SH, Zamani-zadeh HR, Sheikholeslami M, Sharifi R. Biological control of sugar beet damping-off caused by Rhizoctonia solani with some commercial and non-commercial isolates of Trichoderma harzianum. 20th Iranian Plant Protection Congress; 2012. p. 305.

[146] Gharaei M, Jamali S, Abbasi S. Effects of biocontrol activity of ascomycetes yeasts isolated from natural resources on grey mold fungus (Botrytis cinerea) using dual culture method. Biol Control Pests Plant Dis. 2018;7(1):1-7.

[147] Ghasemi Sardareh R, Etebarian HR, Vasebi Y. Control of blue mold of orange fruit by Pichia kluyveri and induction of defense responses in flavedo tissue at $20^{\circ} \mathrm{C}$. 20th Iranian Plant Protection Congress; 2012. p. 304.

[148] Ghasemi Sardareh R, Etebarian HR, Sahebani N, Aminian H. Studies on biological control of blue mold in Thomson orange by Pichia guilliermondii. 19th Iranian Plant Protection Congress; 2010. p. 902.
[149] Ghods-Alavi BS, Ahmadzadeh M, Behboudi K, Jamali S. Biocontrol of rhizome soft rot (Pectobacterium carotovorum) on valerian by Pseudomonas spp. under in vitro and greenhouse conditions. J Agric Technol. 2012;8:1913-23.

[150] Gholami M, Khakvar R, Niknam GR, Aliasgar Zad N, Motalleb Azar AR. Biological control of white mold disease of bean (Sclerotinia sclerotiorum) using endophytic bacteria. 20th Iranian Plant Protection Congress; 2012. p. 311.

[151] Gholami M, Khakvar R, Aliasgar Zad N. Application of endophytic bacteria for controlling anthracnose disease (Colletotrichum lindemuthianum) on bean plants. Arch Phytopathol Plant Prot. 2013;46(15):1831-38.

[152] Gholamnejad L, Etebarian HR, Roustaee A, Sahebani NA, Mirzaie M. Biological control of apple blue mold with three isolates Candida membranifaciens. 18th Iranian Plant Protection Congress; 2008, p. 342.

[153] Gholamnejad J, Etebarian HR, Sheikh Beig Goharrizi MA, Nemati A, Naseri Nasab F. Biological control of apples blue mold by two isolates of Saccharomyces cerevisiae in order to reduce the environmental pollution. Ann Military Health Sci Res. 2009;7(3):182-89.

[154] Gholamnejad J, Etebarian H, Naserinasab F. Induction of defense responses and biological control of blue mold of apple fruit (Penicillium expansum) with Rhodotorula mucilaginosa a1quarterly. J Res Plant Pathol. 2011;1(2):45-57.

[155] Gholamnejad J, Etebarian HR, Sahebani NA, Roustaee A. Characterization of biocontrol activity of two yeast strains from Iran against blue mould of apple in order to reduce the environmental pollution. J Int Environ Appl Sci. 2009;4(1):28-36.

[156] Ghorbanpour M, Omidvari M, Abbaszadeh-Dahaji P, Omidvar R, Kariman K. Mechanisms underlying the protective effects of beneficial fungi against plant diseases. Biol Control. 2018;117:147-57.

[157] Godfray HCJ, Beddington JR, Crute IR, Haddad L, Lawrence D, Muir JF. Food security: the challenge of feeding 9 billion people. Science. 2010;327:812-18.

[158] Golamnejad J, Naserinasab F, Etebarian HR. Control of blue mold of apple fruit with Rhodotorula mucilaginosa $\mathrm{A} 1$ and induction of defense responses. 19th Iranian Plant Protection Congress; 2010. p. 885.

[159] Golpayegani S, Zafari D, Khodakaramian G. The biological control of important faba bean root rot agents caused by rhizospheric antagonist bacteria. Iran J Plant Prot Sci. 2010;41(2):283-92.

[160] Golzari H, Panjehkeh N, Salari M, Sedaghati Khoravi E, Rejali F. Effects of mycorrhizal fungi (Glomus mosseae and Glomus intraradices) on root-knot nematode (Meloidogyne javanica) on tomato. Biol Control Pests Plant Dis. 2013;1(2):121-9.

[161] Golzary H, Ahmadzadeh M, Panjekeh N, Salari M, Sedaghati E. Evaluation of Trichoderma harzianum isolates for biological control of Meloidogyne javanica in in vitro. 18th Iranian Plant Protection Congress; 2008a. p. 280.

[162] Golzary H, Ahmadzadeh M, Panjekeh N, Salari M, Sedaghti E. Biological control of Meloidogyne javanica by Iranian strains of fluorescent Pseudomonads in vitro. 18th Iranian Plant Protection Congress; 2008b. p. 378.

[163] Guo L, Rasool A, Li C. Antifungal substrates of bacterial origin and plantdisease management. In: Maheshwari DK, 
editor. Bacteria in Agrobiology: Disease Management. Berlin/Heidelberg: Springer Verlag; 2013. p. 473-85.

[164] Haas D, Défago G. Biological control of soil-borne pathogens by fluorescent Pseudomonads. Nat Rev Microbiology. 2005;3:307-19.

[165] Habibi R, Rahnama K. Morphological and molecular identification of Trichoderma species based on rDNA ITS sequences from cucurbits field of Iran and study their antagonistic properties. 22th Iranian Plant Protection Congress; 2016. p. 324.

[166] Haggag Wafaa M, Abo SA, Sedera. Influence of iron sources and siderophores producing Pseudomonas fluorescens on crown rot disease incidence and seed contamination of peanut with pathogenic Aspergilli Egyptian.

J Phytopathology. 2000;28:1-16.

[167] Haggag WM, Mohamed HAA. Biotechnological aspects of microorganisms used in plant biological control. AmEurasian J. Sustain Agric. 2007;1(1):7-12.

[168] Haghdel M, Taghavi SM, Mohammadi AH. Study of antagonistic effect isolated bacteria of pistachio nuts on toxigenic Aspergillus flavus. 18th Iranian Plant Protection Congress; 2008a. p. 252.

[169] Haghdel M, Taghavi SM, Mohammadi AH. Study of antagonistic effect isolated bacteria of pistachio nuts on toxigenic Aspergillus flavus. 18th Iranian Plant Protection Congress; 2008b. p. 333.

[170] Hajieghrari B, Torabi-Giglou M, Mohammadi MR, Davari M. Biological potential of some Iranian Trichoderma isolates in the control of soil borne plant pathogenic fungi. Afr J Biotechnol. 2008;7(8).

[171] Handelsman J, Stabb K. Biocontrol of soilborne plant pathogens. Plant Cell. 1996;8:1855-69.

[172] Hasani E, Khodakaramian G. Assessment of the antagonistic activity of fluorescent pseudomonads isolated from potato rhizosphere towards Ralstonia solanacearum. 22th Iranian Plant Protection Congress; 2016. p. 274.

[173] Hashemi Alizade SK, Rouhani H, Tarighi S. Study of interaction between mycorrhizal Glomus fasciculatum and Bacillus subtilis on control of common root rot of wheat hay Bipolaris sorokiniana. 19th Iranian Plant Protection Congress; 2010. p. 925.

[174] Hashemi Alizadeh SG, Rouhani H, Tarighi S. study of interaction between mycorrhiza Glomus fasciculatum and Pseudomonas fluorescens on control of common root rot of wheat caused by Bipolaris sorokiniana. J Plant Prot. 2013;27(2):142-8.

[175] Heidari Faroughi S, Etebarian HR, Zamanizadeh HR. Evaluation of Trichoderma isolates for biological control of Phytophthora drechsleri in greenhouse. Entomol Phytopathol. 2004;72(2):113-34.

[176] Heidari F, Olia M. Study on the separate and integrated application of the fungus Trichoderma harzianum i2375 and Vermicompost in Control of Root-knot Nematode Meloidogyne javanica on Tomato. 22th Iranian Plant Protection Congress; 2016. p. 271.

[177] Heidari-Tajabadi F, Ahmadzadeh M, Moinzadeh A, Khezri M. Influence of some culture media on antifungal activity of Pseudomonas fluorescens UTPF61 against the Sclerotinia sclerotiorum. Afr J Agric Res. 2011;6(30):6340-47.
[178] Heidarzadeh N, Baghaee-Ravari S. Application of Bacillus pumilus as a potential biocontrol agent of Fusarium wilt of tomato. Arch Phytopathol Plant Prot. 2015;48(13-16):841-9.

[179] Heidari Faroughi S, Etebarian HR, Zamanizadeh HR. Evaluation of Streptomyces isolates for biological control of cucurbit wilt. 15th Iranian Plant Protection Congress; 2002. p. 110.

[180] Heydari A, Fatahi H, Zamanizadeh H, Hasan ZN, Naraghi L. Investigation on the possibility of using bacterial antagonists for biological control of cotton seedling damping-off in green house. Appl Entomol Phytopathol. 2004;72(1):51-68.

[181] Hojjat Jalali AA, Coosemans J. Antagonistic fungi of sugar beet cyst nematode of Iran. 12th Iranian Plant Protection Congress; 1995. p. 128.

[182] Hosini M, Mehdi Nasr Esfahani MN, Ghorbani M. Antagonistic effects of fungal isolates and two commercial bioproducts in the control of sugar beet cyst nematode Heterodera schachtii. Biocontrol Plant Prot. 2018;5(2):1-12.

[183] Hosseini Haji Abdal M, Rahimian H, Shahriari D, Sahebani N, Lotfi $M$. The evaluation of Trichoderma atroviride and Trichoderma harzianum isolates in biological control of Cantaloup Fusarium wilt disease. 21th Iranian Plant Protection Congress; 2014a. p. 98.

[184] Hosseini Haji Abdal M, Rahimian H, Shahriari D, Sahebani N, Lotfi M. Biological control of Cantaloup Fusarium wilt disease by Bacillus subtilis and investigation of total phenol amount and peroxidase enzyme changes. 21th Iranian Plant Protection Congress; 2014b. p. 95.

[185] Hosseini H, Panjehkeh N, Alaei H. Effect of Glomus mosseae on cucumber damping off caused by Pythium under salinity stress. Biol Control Pests Plant Dis. 2016;5(2):139-49.

[186] Hosseyni H, Alaei H, Panjehkeh N. The possibility of biological control of Pythium aphanidermatum the causal agent of cucumber damping off using Bacillus isolates under saline conditions. 20th Iranian Plant Protection Congress; 2012a. p. 271

[187] Hosseyni H, Alaei H, Panjehkeh N, Rostami F. Evaluation of Trichoderma isolates for biological control of cucumber damping off caused by Pythium aphanidermatum in vitro and in vivo. 20th Iranian Plant Protection Congress; 2012b. p. 258.

[188] Iragi MM, Mostafa M, Rahnama K, Taghinasab M. Evaluation of antagonistic activity of Bacillus subtilis isolates on Ophiostoma novo-ulmi causal agent of "Dutch Elm Disease" in vitro. 18th Iranian Plant Protection Congress; 2008. p. 326.

[189] Iraqi M, Rahnama K. Survey on Bacillus subtilis isolates for biological control of sunflower root rot caused by Macrophomina phaseolina (Tassi). Goid Sci J Agriculture. 2011;34(1):1-11.

[190] Iraqi MM, Rahnama K, Zafari D, Taghinasab M. Investigating biological control of Ophiostoma novo-ulmi causal agent of Dutch Elm Disease by Trichoderma harzianum and $T$. virens in vitro. J Agric Sci Nat Resour. 2007;14(5):178-91.

[191] Izadyar M, Padasht F. Antagonistic activity of some microorganisms against rice sheat blight. 11th Iranian Plant Protection Congress; 1994. p. 65.

[192] Izadyar M, Popushoi I, Rouhani H. Evaluation of antagonistic activity Trichoderma and Gliocladium species on Rhizoctonia 
solani the causal agent of rice sheath blight in vitro. 14th Iranian Plant Protection Congress; 2000a. p. 247.

[193] Izadyar M, Popushoi I, Rouhani H. Evaluation of antagonistic activity of Trichoderma species and Gliocladium virens on Rhizoctonia solani causal agent of rice sheath blight on bean leaf. 14th Iranian Plant Protection Congress; 2000b. p. 35.

[194] Jaemsaeng R, Jantasuriyarat C, Thamchaipenet A. Molecular interaction of 1-aminocyclopropane-1-carboxylate deaminase (ACCD)-producing endophytic Streptomyces sp. GMKU 336 towards salt-stress resistance of Oryza sativa L. cv KDML105. Sci Rep. 2018;8(1):1950.

[195] Jalali S, Panjekeh M, Darvishnia M, Salari M, Salehi A. Biological control of Fusarium oxysporum fsp. lycopersici by antagonistic bacteria Bacillus and Pseudomonas isolated from tomato rhizosphere in Lorestan province. Res Plant Pathol. 2016;4(1):67-78.

[196] Jalali S. Biological control of Fusarium oxysporum fsp. lycopersici using antagonistic agents of tomato rhizosphere (Doctoral dissertation University of Zabol); 2014.

[197] Jamali F, Modarresi M, Bayat F. Biocontrol potential of Pseudomonas fluorescens strains producing 24diacetylphloroglucinol and hydrogen cyanide against tomato Fusarium wilt. Biol Control Pests Plant. 2016;5(2):235-46.

[198] Jamali F, Sharifi-Tehrani A, Okhovat M, Zakeri Z. Study of the effect of some antagonistic bacteria against Fusarium oxysporum the causal agent of chickpea wilt in greenhouse and field condition. 17th Iranian Plant Protection Congress; 2004. p. 139.

[199] Jamdar Z, Mohammadi AH, Mohammadi S, Haghdel M. Study of antagonistic effect of isolated Trichoderma from soils of pistachio gardens on radial growth of Verticillium dahliae the causal agent of Verticillium wilt of pistachio. 20th Iranian Plant Protection Congress, 2012. p. 323.

[200] Jamshidnejad V, Sahebany N, Etebarian HR. Biological control of root-knot nematode, Meloidogyne javanica, by Arthrobotrys oligospora and Paecilomyces lilacinus, and their effects on tomato development. The first national conference on agriculture in difficult environmental conditions, 2012. p. 1-5.

[201] Javadi L, Naeimi S, Rezaei S, Khosravi V. Biological control of Magnaporthe oryzae the causal agent of rice blast disease with native Trichoderma strains in vitro. 20th Iranian Plant Protection Congress; 2012. p. 307.

[202] Javadi L, Naeimi SH, Rezaei S, Vahid K. Biological control of rice blast disease with native Trichoderma isolates. J Biocontrol Plant Prot. 2014;2(1):1-15.

[203] Javanshir Javid K, Mahdiyan S, Behboudi K, Alizadeh H. Biocontrol of cucumber Fusarium root and stem rot disease by Trichoderma isolates. 20th Iranian Plant Protection Congress; 2012. p. 263.

[204] Kahnooji H, Alaei H, Mohammadi AH, Haghdel M. Isolation and identification of Trichoderma species from soil of pistachio orchards in Rafsanjan and their evaluation for biological control of Aspergillus flavus. 20th Iranian Plant Protection Congress; 2012. p. 290.

[205] Karampour F, Okhovat M. Investigation on the effect of some isolates of Trichoderma and Gliocladium on the growth of Fusarium solani at lab conditions. 10th Iranian Plant Protection Congress; 1992. p. 143.
[206] Karimi E, Rouhani H, Zafari DM, Khoda Karamian GH, Taghinasab M. Biological control of vascular wilt disease of carnation caused by Fusarium oxysporum fsp. dianthi by Bacillus and Pseudomonas strains isolated from rhizosphere of carnation. J Sci Technol Agric Nat Resour. 2007;11(41):309-19.

[207] Karimi E, Sadeghi A. Study on optimum growth condition and designing formulation for increasing shelf life of Streptomyces rimosus strain c-(2012) as biocontrol agent. Biol J Microorg. 2015;4(15):109-22.

[208] Karimi E, Rouhani H, Zafari D, Taghinasab M. Investigation on possible reason of reduced antagonistic potential of Trichoderma longibrachiatum chickpea root rot disease under greenhouse conditions. 16th Iranian Plant Protection Congress; 2004a. p. 185.

[209] Karimi E, Rouhani H, Zafari D, Khodakaramian Gh. Antagonistic activity of Bacillus and Pseudomonas fluorescens isolated from carnation rhizosphere against Fusarium oxysporum f.sp. dianthi the causal agent of vascular rot of carnation in Mahallat. 16th Iranian Plant Protection Congress; 2004b. p. 456.

[210] Karimi E, Rouhani H, Zafari D, Khodakaramian Gh, Taghinasab M. Investigation on the antagonistic activity of Bacillus isolates from chickpea rhizosphere against Fusarium oxysporum f.sp. ciceri the causal agent of root rot of chickpea in Kermanshah province. 16th Iranian Plant Protection Congress; 2004c. p. 183.

[211] Karimi E, Safaie N, Shams-Baksh M, Mahmoudi B. Bacillus amyloliquefaciens SB14 from rhizosphere alleviates Rhizoctonia damping-off disease on sugar beet. Microbiol Res. 2016;192:221-30.

[212] Karimik Amini J, Harighi B, Bahrannejad B, Behtoei H. Antagonistic activity of Bacillus and Pseudomonas isolates from the chickpea rhizosphere against Fusarium oxysporum f.sp. ciceri the causal agent of Fusarium wilt disease of chickpea in Kurdistan province. 19th Iranian Plant Protection Congress; 2010. p. 908.

[213] Karimipourfard H, Damadzadeh M. The effect of Pasteuria to control of Meloidogyne spp. on pistachio. 17th Iranian Plant Protection Congress; 2006. p. 375.

[214] Karkhaneh R, MSheikholeslami M, Hojat-Jalali AA, Asadi Sardari A. Study on antagonistic effect of Penicillium spp. associated with females and egg masses of Meloidogyne javanica in vitro. 20th Iranian Plant Protection Congress; 2012. p. 277.

[215] Kasfi K, Taheri P, Jafarpour B, Tarighi S. Biological control of grey mould disease on grape caused by Botrytis cinerea using Trichoderma harzianum and Candida membranifaciens. 22th Iranian Plant Protection Congress; 2016a. p. 387.

[216] Kasfi K, Taheri P, Jafarpour B, Tarighi S. Biological control of Aspergillus niger the causal agent of black rot disease on grape using Trichoderma harzianum and Candida membranifaciens. 22th Iranian Plant Protection Congress; 2016b. p. 386.

[217] Kavari M, Mahdikhani Moghadam E, Rouhani H. Survey on chitinase production by several isolates of Trichoderma and its biological control effect on tomato root-knot nematode Meloidogyne javanica. J Plant Prot. 2015;29(1):123-33.

[218] Kazempour MN. Biological control of Rhizoctonia solani the causal agent of rice sheath blight by antagonistic bacteria in 
greenhouse and field conditions. Plant Pathol J. 2004;3(2):88-96.

[219] Kazemzadeh M, Roustaii A, Padasht F, Khodakaramian Kh. Study of biological control of rice sheath blight caused by Rhizoctonia solani with some antagonistic bacteria in the Guilan Province. J Plant Prot. 2012;26(1):44-54.

[220] Kazemzadeh M, Padasht F, Rostai A. Effects of antibiosis antagonistic bacterial isolated from rice paddy of the Guilan province on the Guilan province on the Rhizoctonia solani causal agent of rice sheath blight. J Agric Sci Nat Resour. 2006;12(6):146-53.

[221] Kermajany Z, Jamali Zavareh A, Fadaei Tehrani A. In vitro inhibitory effects of five strains of Trichoderma on the growth of Fusarium oxysporum f.sp. dianthi. Biol Control Pests Plant Dis. 2017;6(1):121-25.

[222] Keshavarzi S, Behboudi K, Sarpeleh A, Ahmadzade M. Potential of Trichoderma species for biocontrol of root rot and vine decline of Cucumis melo caused by Monosporascus cannonballus. 20th Iranian Plant Protection Congress; 2012a. p. 267.

[223] Keshavarzi S, Behboudi K, Sarpeleh A, Ahmadzade M. Induction of chitinase dependent resistance by Trichoderma virens strain IRAN $1101 \mathrm{C}$ against Monosporascus cannonballus the casual agent of root rot and vine decline of muskmelon. 20th Iranian Plant Protection Congress; 2012b. p. 261.

[224] Khabbaz Jolfaei H, Mohammadi Goltapeh E, Rahimian HA. Isolation screening and evaluation of the efficacy of potentially antagonistic bacteria for the biocontrol of brown blotch disease of the cultivated mushroom Agaricus bisporus. Iran J Plant Pathol. 2005;41(4):543-59.

[225] Khaledi N, Taheri P. Biological control potential of Trichoderma harzianum fungi against soybean charcoal rot agent under experimental and greenhouse condition. 21th Iranian Plant Protection Congress; 2014. p. 74.

[226] Khaledi N, Taheri P. Biocontrol mechanisms of Trichoderma harzianum against soybean charcoal rot caused by Macrophomina phaseolina. J Plant Prot Res. 2016;56(1):21-31.

[227] Khalighi S, Khodakaramian G. Biocontrol of Meloidogyne javanica inducing olive root-knot under green-house conditions and by use of Fluorescent Pseudomonads. Iran J Plant Prot Sci. 2012;43(2):323-32.

[228] Khalili E, Sadravi M, Naeimi SH, Khosravi V. Biological control of rice brown spot with native isolates of three Trichoderma species in greenhouse. 20th Iranian Plant Protection Congress; 2012a. p. 301.

[229] Khalili E, Javed MA, Huyop F, Rayatpanah S, Jamshidi S, Wahab RA. Evaluation of Trichoderma isolates as potential biological control agent against soybean charcoal rot disease caused by Macrophomina phaseolina. Biotechnological Equip. 2016;30(3): 479-88.

[230] Khalili E, Sadravi M, Naeimi S, Khosravi V. Biological control of rice brown spot with native isolates of three Trichoderma species. Braz J Microbiology. 2012b;43(1):297-305.

[231] Khalili E, Sadravi M. Biological control of rice sheath blight pathogen with three Trichoderma species isolates in vitro. 18th Iranian Plant Protection Congress; 2008. p. 334.

[232] Kharazian ZA, Jouzani GS, Aghdasi M, Khorvash M, Zamani M, Mohammadzadeh H. Biocontrol potential of Lactobacillus strains isolated from corn silages against some plant pathogenic fungi. Biol Control. 2017;110: 33-43.

[233] Khazaee FA, Etetsarian HR, Roustaee A, Alizadeh-Aliabadi A. Potential biocontrol of Penicillium expansum in apple with some Pseudomonas fluorescens isolates. 18th Iranian Plant Protection Congress; 2008. p. 352.

[234] Kheiri A, Etebarian HR, Roustae A, Khodakaramian Gh, Aminian H. Study of possibility of biological control of charcoal rot on melon (Macrophomina phaseolina) by Pseudomonas fluorescens isolates. J Agric. 2009;11(1):35-46.

[235] Khezri M, Manafi Shabestari M. Biological control of wheat Take-all by native probiotic. Bacillus subtilis. 22th Iranian Plant Protection Congress; 2016. p. 288.

[236] Khezri M, Ahmadzadeh M, Jouzani GS, Behboudi K, Ahangaran A, Mousivand M, et al. Characterization of some biofilm-forming Bacillus subtilis strains and evaluation of their biocontrol potential against Fusarium culmorum. J Plant Pathol. 2011;373-82.

[237] Khezri S, Ahmadzadeh M, Sharifi R, Ahangaran A. Screening of some isolates of Pseudomonas fluorescens against Sclerotinia sclerotiorum on sunflower. 19th Iranian Plant Protection Congress; 2010. p. 830.

[238] Khodaei M, Hemmati R, Rouhani H, Sarafraz Nikou F. Biological control of Fusarium root rot of bean using native Trichoderma isolates. 20th Iranian Plant Protection Congress; 2012. p. 302.

[239] Khodakaramian A, Heydari A, Balestra GM. Evaluation of Pseudomonads bacterial isolates in biological control of citrus bacterial canker disease. Int J Agric Res. 2008;3(4):268-72.

[240] Khodakaramian G, Zafari D. Identification of fluorescent pseudomonads isolated from potato rhizosphere and assessment of their antagonistic activity towards Pectobacterium carotovorum under field condition. Appl Entomol Phytopathol. 2010;77(2):1-18.

[241] Khodakaramian G. Characterization of fluorescent pseudomonads isolated from citus phyllosphere in southern Iran and evaluation of their antagonistic activity against bacterial inducing citrus canker disease. Iran J Agric Sci. 2004;35(4):911-91.

[242] Khodaygan B, Etebarian HR, Khodakaramian G, Torabi M. Biological control of wheat common bunt (Tilletia laevis L10) by some bacterial antagonist. 16th Iranian Plant Protection Congress; 2004. p. 45.

[243] Khodaygan P, Etebarian HR, Khodakaramian G, Torabi M. Investigation of possibility of biocontrol of common covered smut disease in wheat by several isolates of Pseudomonas. Iran J Agric Sci. 2006;37(4):707-17.

[244] Khomeini K, Daneshjoo R, Nasr MR, Bakhtiar M. Biocontrol disease agents exposed to pathogens of chickpea by different combinations under field condition. Int Scholars J. 2016;2(2):28-32.

[245] Khorasani GA, Alizadeh A, Safaie N. Biological control of Fusarium wilt of potato using antagonistic strains of bacteria. Plant Dis. 2008;44(1):1-21.

[246] Khorasani-Aghazadeh A, Alizadeh A, Safaei N. Biological control of Fusarium oxysporum f.sp. tuberosi using antagonistic mutant and wild type bacteria. 17th Iranian Plant Protection Congress; 2006. p. 218. 
[247] Khosravi M, Abdollahi M, Sadravi M. Effect of Metarhizium anisopliae and Trichoderma harzianum on root knot nematode Meloidogyne javanica. Biol Control Pests Plant. 2015;3(1):67-76.

[248] Khosro-Anjom E, Sharzei A, Sahebani N, Mohammadifar M. Biological control of Fusarium root rot of beans by Trichoderma hamatum and Pseudomonas fluorescens treatments. 22th Iranian Plant Protection Congress; 2016. p. 293.

[249] Kia Sh, Rahnama K. Study on the efficiency of Trichoderma isolates in controlling charcoal rot disease of soybean caused by Macrophomina phaseolina under greenhouse conditions. Biocontrol Plant Prot. 2016;4(1):1-10.

[250] Kloepper JW, Leong J, Teintze M, Schiroth MN. Enhanced plant growth by siderophores produced by plant growth promoting rhizobacteria. Nature. 1980;286:885-86.

[251] Köhl J, Kolnaar R, Ravensberg WJ. Mode of action of microbial biological control agents against plant diseases: relevance beyond efficacy. Front plant Sci. 2019;10:845.

[252] Kubicek CP, Herrera-Estrella A, Seidl-Seiboth V, Martinez DA, Druzhinina IS, Thon M. Comparative genome sequence analysis underscores mycoparasitism as the ancestral life style of Trichoderma. Genome Biol. 2011;12(4):40.

[253] Kumar A, Saini P, Shrivastava JN. Production of peptide antifungal antibiotic and biocontrol activity of Bacillus subtilis. Indian J Exp Biol. 2008;47:57-62.

[254] Lagzian A, Saberi-Riseh R, Khodaygan P, Sedaghati E, Dashti H. Isolation identification and screening for antifungal activity of fluorescent pseudomonads against Gaeumannomyces graminis var. tritici the causal agent of take-all. 20th Iranian Plant Protection Congress; 2012. p. 312.

[255] Lam ST, Gaffney TD. Biological activities of bacteria used in plant pathogen control. In: Chet I. editor. Biotechnology in Plant Disease Control. New York: John Wiley; 1993. p. 291-320.

[256] Leong SA, Expert D. Siderophores in plant pathogen interactions. In: Kosuge T, Nester EW, eds. Plant-Microbe Interactions Molecular and Genetic Perspectives. Vol 3, New York: McGraw-Hill; 1989. p. 62-83.

[257] Loper JE, Buyer JS. Siderophores in microbial interactions on plant surfaces. Mol Plant Microbe Interact. 1991;4:5-13.

[258] López-Mondéjar R, Ros M, Pascual JA. Mycoparasitismrelated genes expression of Trichoderma harzianum isolates to evaluate their efficacy as biological control agent. Biol Control. 2011;56:59-66.

[259] Madloo PB, Behboudi K, Tohidfar M, Jouzani GS, Ahmadzadeh M. Response of some important Iranian wheat cultivars to Fusarium culmorum under genetic diversity of indigenous bio-control agent fluorescent Pseudomonas spp. Aust. J Crop Sci. 2013;7(7):1003.

[260] Maghsodloo R, Ghorbani-Nasrabadi R, Razavi SE, Ebrahimi T. Evaluation of antagonistic activity of Azotobacter isolates on Gaeumannomyces graminis var. tritici causal agent of takeall disease in vitro. 18th Iranian Plant Protection Congress; 2008. p. 389.

[261] Mahdikhani Moghadam E, Rouhani H, Flahi Rastegar M. Biological control of sugar beet cyst forming nematode with Trichoderma under in vitro and greenhouse condition. J Water Soil Sci. 2009;13(48):301-12.

[262] Mahdikhani Moghadam E, Rouhani H. Effect of isolates of Trichoderma harzianum, T. virens and Bacillus subtilis for controlling Heterodera schachtii in field conditions. J Plant Prot. 2011;26(1):75-81.

[263] Mahdizadehnaraghi R, Heydari A, Zamanizadeh HR, Rezaee S, Nikan J. Biological control of garlic (Allium) white rot disease using antagonistic fungi-based bioformulations. J Plant Prot Res. 2015;55(2):136-41.

[264] Majzoob S, Karegar A, Taghavi M, Hamzehzarghani H. Evaluation of rhizobacteria for antagonistic activity against root-knot nematode Meloidogyne javanica on cucumber under greenhouse condition. Iran J Plant Pathol. 2012;48(1):27-9.

[265] Maleki Ziyarati H, Saheban N, Rahnama K. Biological control of root- knot nematode Meloidogyne javanica by Trichoderma harzianum and the study of peroxidase activity changes in tomato. Iran J Plant Prot Sci. 2009;40(1):25-33

[266] Malik RJ, Dixon MH, Bever JD. Mycorrhizal composition can predict foliar pathogen colonization in soybean. Biol Control. 2016;103:46-53.

[267] Maloy OC. Plant Disease Control: Principles and Practice. New York: John Wiley Sons Inc; 1993. p. 346.

[268] Mansoori B. Evaluation of antagonistic effects of Penicillium polonicum on a number of soil-borne of wheat under laboratory and greenhouse condition. 13th Iranian Plant Protection Congress; 1998. p. 51.

[269] Mansoori M, Heydari A, Hassanzadeh N, Rezaee S, Naraghi L. Evaluation of Pseudomonas and Bacillus bacterial antagonists for biological control of cotton Verticillium wilt disease. J Plant Prot Res. 2013;53(2):154-7.

[270] Mansouripour SM, Alizadeh A, Safaie N. Biological control of Sclerotinia stem rot of canola using wild type and derived antibiotic resistant bacterial antagonists. 18th Iranian Plant Protection Congress; 2008. p. 388.

[271] Manulis S, Epstein E, Shafrir H, Lichter A, Barash I. Biosynthesis of indole-3-acetic acid via the indole-3acetamide pathway in Streptomyces spp. Microbiology. 1994;140:1045-50.

[272] Marefat A, Rand Rahimian H. Identity and population dynamics of epiphytic bacteria of wheat in Mazandaran Tehran and Isfahan and preliminary studies on the antagonistic effects of representative strains on biological control of leaf streak caused by Xanthomonas translucens pv. cerealis. 13th Iranian Plant Protection Congress; 1998. p. 58.

[273] Masudi Sh, Shahidi GH. In vitro evaluation of antagonistic activity of Talaromyces flavus against Rosellinia necatrix the causal agent of white root rot disease. 20th Iranian Plant Protection Congress; 2012. p. 257.

[274] Mazzola M, Cook RJ. Effects of fungal root pathogens on the population dynamics of biocontrol strains of fluorescent pseudomonads in the wheat rhizosphere. Appl Environ Microbiology. 1991;57(8):2171-78.

[275] McSpadden BB, Fravel DR. Biological control of plant pathogens: research commercialization and application in the USA. Online. Plant Health Prog. 2002;3(1):1-18.

[276] Mehrabi Koshki M, Zafari DM, Rouhani H, Ghalandar M. Evaluation of effect of Trichoderma isolates mustard flour two biological commercial products in control of take-all disease. Agric Sci. 2007;17(3):197-208.

[277] Mehrabi Koshki M, Zafari D, Sharif Nabi B. Control of wheat common bunt by mustard flour Trichoderma isolates and biological materials. J Water Soil Sci. 2009;13(47):741-8. 
[278] Merat A, Mirhoseini SA, Rohani H. Study on antagonistic effect of Trichoderma spp. from Guilan province on Sclerotinia sclerotiorum causal agent of bud and twig dieback of mulberry trees. 14th Iranian Plant Protection Congress; 2000. p. 336.

[279] Mihajlović M, Rekanović E, Hrustić J, Grahovac M, Tanović B. Methods for management of soilborne plant pathogens. Pestic Fitomed. 2017;32(1):9-24.

[280] Mirhosaini Sa, Izadyar M, Rohani H. Study on the antagonistic activity of Trichoderma and Gliocladium species on Sclerotium rolfsii causal agent of stem rot of groundnut. 13th Iranian Plant Protection Congress; 1998. p. 109.

[281] Mirkhani F, Alaei H, Mohhammadi A, Haghdel M, Kahnougi H. Identification of Trichoderma species isolated from soil of pistachio orchards in Iran and in vitro evaluation for biological control of Phytophthora drechsleri the causal agent of pistachio gummosis. 20th Iranian Plant Protection Congress; 2012. p. 291.

[282] Mirzaie M, Aminian H, Alizadeh A, Rustaee A, Gholamnejad J. The study of biological control of Erwinia amylovora the causal agent of pear fire blight by some antagonistic bacteria in Damavand. 18th Iranian Plant Protection Congress; 2008. p. 373.

[283] Moayedi G, Mostowfizadeh-Ghalamfarsa R. Antagonistic activities of Trichoderma spp. on Phytophthora root rot of sugar beet Iran. Agric Res. 2011;29(2):21-38.

[284] Moazenian S, Aminian H, Etebarian HR, Sahebani N. Biological control of Phaseolus vulgaris damping-off caused by Rhizoctonia solani using Streptomyces microflavus (S6) in greenhouse condition. 20th Iranian Plant Protection Congress; 2012a. p. 299.

[285] Moazenian S, Aminian H, Etebarian HR, Ghasemi A, Sahebani N. Isolation and characterization of Streptomyces microflavus (A3) and evaluation of antagonistic effects against Rhizoctonia solani the causal agent of common bean damping-off in vitro. 20th Iranian Plant Protection Congress; 2012b. p. 289.

[286] Mohammadi K, Etebaian HR, Rahimian H, Ghalandar M. Biological control of wheat (Bipolaris sorokiniana) by antagonistic bacteria isolated from wheat rhizosphere. 16th Iranian Plant Protection Congress; 2004. p. 37.

[287] Mohammadi K, Etebarian H, Rahimian H, Ghalandar M. Biological control of common root rot of wheat by antagonistic bacteria isolated from wheat rhizosphere. Iran J Plant Pathol. 2005;41(3):383-402.

[288] Mohammadi P, Kotan R, Tozlu E. The investigation of citrus green mold biological control with Penicillium digitatum agent by antagonistic bacteria. 21th Iranian Plant Protection Congress; 2014. p. 44.

[289] Mohammadi S, Ghanbari L. In vitro Antagonistic Mechanisms of Trichoderma spp. and Talaromyces flavus to Control Gaeumannomyces graminis var. tritici the causal agent of wheat take-all disease. Turkish J Agric-Food Sci Technol. 2015;3(8):629-34.

[290] Mohammadi S, Mansoori B, Zamani-Zahed HR, Heydari A. Biological control of Rhizoctonia solani the causal agent of wet root of chickpea in greenhouse conditions. 16th Iranian Plant Protection Congress; 2004. p. 189.

[291] Mokhtari S, Navaz-allah Sahebani NA, Etebarian HR. Biological control of root-knot nematode (Meloidogyne javanica) by Pseudomonas fluorescens CHAO and
Trichoderma harzianum $\mathrm{BI}$ in tomato. Biol Control Pests Plant Dis. 2015;3(2):117-26.

[292] Mokhtari S, Montazeri R, Sahebani N, Etebarian HR. Study of Biological control and systemic induction of polyphenol oxidase and catalase enzymes activity in tomato plant infected with root-knot nematode by Pseudomonas fluorescens CHAO antagonist. 18th Iranian Plant Protection Congress; 2008. p. 262.

[293] Montakhabi MK, Rahimian H, Falahati Rastegar M, Jafarpour $B$. in vitro investigation on biocontrol of Xanthomonas axonopodis pv. citri cause of citrus bacterial canker by citrus antagonistic bacteria. J Plant Prot. 2010;24(4):368-76.

[294] Montazernia B, Rahnama K, Barari H, Naeemi Sh. Evaluation of Trichoderma spp. isolated from soybean field against of Macrophomina phaseolina the causal agent of charcoal rot disease. 18th Iranian Plant Protection Congress; 2008. p. 379.

[295] Mostofizadeh-Ghalamfarsa R, Banihashemi Z, Taghavi SM. Antagonistic mechanisms of wheat rhizosphere fluorescens Pseudomonads and their inhibition on root pathogenic Fusarium species in Fars province. 15th Iranian Plant Protection Congress; 2002. p. 25.

[296] Motamedi H, Zahedi E, Abadi AZM. Optimizing conditions for the production of antifungal agents using the native Bacillus cereus SB15 Feyz. J Kashan Univ Med Sci. 2017;21(1): 9-18.

[297] Mousavi Mirak SS. The evaluation of inhibitory effect of in sugar beet rhizosphere antagonistic bacteria on the growth of Cercospora beticola fungi the causal agent of sugar beet cercospora leaf spot. 21th Iranian Plant Protection Congress; 2014. p. 48.

[298] Mousavi SA, Rahimiyan H, Zohour E, NasrollaH-Nejad S. Investigation of antagonistic effects of some strains Pseudomonas fluorescens on Clavibacter michiganensis subsp. michiganensis in vitro. 18th Iranian Plant Protection Congress; 2008a. p. 371.

[299] Mousavi SA, Rahimiyan H, Zohour E, NasrollaH-Nejad S. Investigation of antagonistic effects of some strains of Pseudomonas fluorescens on Pseudomonas syringae pv. tomato in vitro. 18th Iranian Plant Protection Congress; 2008b. p. 370.

[300] Naeimi S, Okhovvat SM, Javan-Nikkhah M, Vágvölgyi C, Khosravi V, Kredics L. Biological control of Rhizoctonia solani AG1-1A the causal agent of rice sheath blight with Trichoderma strains. Phytopathol Mediterr. 2010;49(3):287-300.

[301] Naeimi Sh, Zare R. Evaluation of indigenous Trichoderma spp. isolates in biological control of Botrytis cinerea the causal agent of strawberry gray mold disease. J Biocontrol Plant Prot. 2013;2(2):55-74.

[302] Naghed H, Sadravi M, Kazemi S. Biological control of chickpea blight with some isolates of three species of Trichoderma. Biol Control Pests Plant Dis. 2016;5(1):123-7.

[303] Naher L, Yusuf UK, Ismail A, Hossain K. Trichoderma spp.: a biocontrol agent for sustainable management of plant diseases. Pak J Botany. 2014;46(4):1489-93.

[304] Najmeh A, Dostmorad Za, Mansoureh M. Combination of Trichoderma species and Bradyrhizobium japonicum in 
control of Phytophthora sojae and soybean growth. J Crop Prot. 2012;1(1):67-79.

[305] Naraghi L, Heydari A, Afshari Azad H, Sharifi K. Antagonistic effects of Talaromyces flavus on some soil-borne pathogens of potato tomato and greenhouse cucumber. 20th Iranian Plant Protection Congress; 2012a. p. 278.

[306] Naraghi L, Heydari A, Karimi Roozbehani A, Ershad J. Isolation of Talaromyces flavus from cotton fields in Gorgan area and investigation of its antagonistic effects against Verticillium dahliae causal agent of cotton wilt. 14th Iranian Plant Protection Congress; 2000. p. 275.

[307] Naraghi L, Heydari A, Rezaee S, Razavi M. Biological control of wilt disease caused by Verticillium albo-atrum in potato tomato and greenhouse cucumber by Talaromyces flavus. 20th Iranian Plant Protection Congress; 2012b. p. 297.

[308] Naraghi L, Heydari A, Rezaee M, Razavi M, Jahanifar H. Biological control of tomato Verticillium wilt disease by Talaromyces flavus. 19th Iranian Plant Protection Congress; 2010. p. 920.

[309] Naserinasab F, Saheban N, Etebarian HR. Biological control of root knot nematode of tomato Meloidogyne javanica with Trichoderma harzianum $\mathrm{BI}$ and salicylic acid in greenhouse and an investigation of their effect on induction of phenolic compounds and total flavonoids on tomato. Iran J Plant Prot Sci. 2012;43(1):121-31.

[310] Nasir Hussein A, Abbasi S, Sharifi R, Jamali S. The effect of biocontrol agents consortia against Rhizoctonia root rot of common bean Phaseolus vulgaris. J Crop Prot. 2018;7(1):73-85.

[311] Nasiri M, Soleimani MJ, Zafari D. Study on possibility of using Trichoderma isolates on biocontrol of potato brown spot caused by Alternaria alternata. 20th Iranian Plant Protection Congress; 2012. p. 270.

[312] Nasrolah Nejad F, Rahnama K. Study of antagonistic effects of Bacillus bacterium on Sclerotinia sclerotiorum the causal agent of stem rot disease in canola. 18th Iranian Plant Protection Congress; 2008. p. 360.

[313] Nasrolah Nejad F, Rahnama K, Zafari D, Sadravi M, Nasrolah Nejad S, Vakili Zaraj Z. Study of antagonistic assessment of Trichoderma species on the causal agent of white stem rot of canola. J Agric Sci Nat Resour. 2009;16(1b):1-11.

[314] Nasrollahi Omran A, Beighy Firooz Jaei F, Sangi M. Biological control of green and blue mold agents in oranges by citrus fruit epiphytic microbes in north of Iran. Plant Prot J. 2011;3(4):377-91.

[315] Nazari F, Momeni H, Rabani Nasab H. Antagonistic effects of Pseudomonas putida strains P5 and P13 formulated in biological fertilizers against Rhizoctonia solani (sugar beet root rot and seedling damping off) and Fusarium oxysporum f sp tuberosi (Fusarium dry rot of potato). 20th Iranian Plant Protection Congress; 2012. p. 269.

[316] Nazari F, Safaie N, Soltani BM, Shams-Bakhsh M, Sharifi M. Study of flavonoids produced by Bacillus subtilis due to its biocontrol effect on Agrobacterium tumefaciens in tobacco plants. 22th Iranian Plant Protection Congress; 2016. p. 272.

[317] Nazerian E, Javadi S, Mirabolfathi M, Mohamadalian Y. Study on possibility of biocontrol on ornamental plants root rot caused by Phytophthora sp. 18th Iranian Plant Protection Congress; 2008. p. 358.
[318] Nega A. Review on concepts in biological control of plant pathogens. J Biol Agri Healthc. 2014;4(27):33-54.

[319] Niknejad Kazempour M, Pedramfar H, Elahinia SA. Effect of certain fungicides and isolates of antagonistic fungi on Rhizoctonia solani the causal agent of rice sheath blight. J Water Soil Sci. 2002;6(4):151-58.

[320] Niknejad K, Sharifi-Tehrani A, Okhovat M. Effect of antag onistic fungi Trichoderma spp. on the control of Fusarium wilt of tomato caused Fusarium oxysporum f.sp. lycopersici under greenhouse conditions. Iran J Agric Sci. 2000;31(1):31-37.

[321] Niknejad-Kazempour M, Pedramfar H, Elahinia SA. Effect of some fungicides and certain isolates antagonistic fungi to control rice sheath blight caused by Rhizoctonia solani under in vitro and greenhouse conditions. 14th Iranian Plant Protection Congress; 2000. p. 248.

[322] Niknejad-Kazempour M. Biological control of Rhizoctonia solani the causal agent of rice sheath blight with Pseudomonas fluorescens in greenhouse and field conditions. 16th Iranian Plant Protection Congress; 2004a. p. 88.

[323] Niknejad-Kazempour M, Anvary M, Elahinia E. Biological control of Fusarium moniliform the casual agent of collar and root rot of rice by antagonistic bacteria. 16th Iranian Plant Protection Congress; 2004b. p. 87.

[324] Niknejad-Kazempour M, hamran E, Merat A. Biological control of the causal agents of root rot of mulberry by antagonistic bacteria. 16th Iranian Plant Protection Congress; 2006. p. 347.

[325] Ningaraju TM. Cloning and characterization of chitinase gene/s from native isolates of Msc thesis Serratia marcescens. Dharwad: UAS; 2006. p. 144.

[326] Noorizadeh S, Golmohammadi M, Jamali S. Biological control of important citrus pathogenic fungi by some isolated actinomycetes from citrus rhizosphere. 20th Iranian Plant Protection Congress; 2012. p. 303.

[327] Norouzi K, Khara J, Ghosta Y. Effects of three Glomus species as biocontrol agents against Verticillium-induced wilt in cotton. J Plant Prot Res. 2009;49(2):185-9.

[328] Norouzian SJ, Etebarian HR, Khodakaramian G, Torabi M, Karimi N. Biological control of crown rot of wheat with Pseudomonas fluorescens, Bacillus subtilis and Streptomyces sp. 23th Iranian Plant Protection Congress; 2018. p. 877.

[329] Norouzian SJ, Etebarian HR, Khodakaramian G, Torabi M. Isolation and selection bacterial antagonists for biological control of Fusarium graminearum. 15th Iranian Plant Protection Congress; 2002. p. 179.

[330] Nosrati S. Investigation on The Ability of Trichoderma spp. existent in the soil of cucumber greenhouses of Yazd province to control Fusarium wilt agent in vitro condition. Biol Control Pests Plant Dis. 2018;7(1):99-102.

[331] Nourozian J, Etebarian HR, Khodakaramian G. Biological control of Fusarium graminearum on wheat by antagonistic bacteria Songklanakarin. J Sci Technol. 2006;28(1):29-38.

[332] Ojaghian SMR, Zafari D, Khodakaramian G. Biological control of Sclerotinia sclerotiorum the causal agent of potato white mold by different Trichoderma spp. and Coniothyrium minitans. J Agric Sci Sustain Prod. 2010;20(1):107-19.

[333] Ojaghian MR, Zafari D, Khodakaramian Gh. Biological control of Sclerotinia sclerotiorum the causal agent of potato white 
mold in Hamedan province. 18th Iranian Plant Protection Congress; 2008. p. 345.

[334] Okhovat M. In vitro antagonistic effects of Trichoderma spp. on several soil-borne plant pathogenic fungi. J Sci Islamic Repub Iran. 1997;8(2):86-95.

[335] Okhovat M, Zafari DM, Karimi-Roosbahani AR, Rohani. Evaluation of antagonistic effects of Trichoderma on Colletotrichum coccodes isolated from potato. 11th Iranian Plant Protection Congress; 1994. p. 149.

[336] Okhowat M, Karampour F. Effect of some isolates of antagonistic fungi on the control of chickpea black root rot caused by Fusarium solani under greenhouse condition. Iran J Agric Sci. 1996;27(2):37-43.

[337] Olanrewaju OS, Babalola 00. Streptomyces: implications and interactions in plant growth promotion. Appl Microbiol Biotechnol. 2019;103(3):1179-88.

[338] Omidi Nasab M, Khodakaramian G. Inhibitation of alfalfa endophytic bacteria against Clavibacter michiganensis subsp. insidiosus causal agent of wilt disease in in vitro and greenhouse conditions. Biocontrol Plant Prot. 2017;5(1):1-13.

[339] Ommati F, Khavaziand K, Akhyani A. A study on effect of Fluorescent Pseudomonads in controlling Fusarium wilt of potato in Semnan province. 18th Iranian Plant Protection Congress; 2008. p. 295.

[340] Ommati F, Zaker. In vitro and greenhouse evaluations of Trichoderma isolates for biological control of potato wilt disease (Fusarium solani). Arch Phytopathology Plant Protect. 2012;45(14):1715-23.

[341] Ommati F, Zaker M, Mohammadi A. Biological control of Fusarium wilt of potato (Fusarium oxysporum f. sp. tuberosi) by Trichoderma isolates under field condition and their effect on yield. J Crop Prot. 2013;2(4):435-42.

[342] Omrani Kh, Minassian V, Farokhnejad EJ. Biological control of Sclerotinia sclerotiorum (Lib) de Bary the causal agent of aubergine white mold. 14th Iranian Plant Protection Congress; 2000. p. 97.

[343] Oostendorp M, Sikora RA. Seed treatment with antagonistic rhizobacteria for the suppression of Heterodera schachtii early root infection of sugar beet. Rev de nematologie. 1989;12:77-83.

[344] Padasht Dehkaei F, Mansouri Jajaei SH, Rouhani H. Effects of paddy soil antagonistic microorganisms of Guilan on the causal agent of rice bakanae disease. J Water Soil Sci. 2004;8(1):213-21.

[345] Padasht DF, Izadyar M. Study On the biological control of rice blast disease in the field condition. J Agric Sci Nat Resour. 2007;13(6):84-92.

[346] Padasht-Dehkaei F, Popushoi I, Izadyar M, Khodakaramian G. Biological control of rice blast disease in the field conditions. 16th Iranian Plant Protection Congress; 2004. p. 106.

[347] Pakdaman BS, Goltapeh EM, Soltani BM, Talebi AA, Nadepoor M, Joanna SK, et al. Toward the quantification of confrontation (Dual Culture) test: a case study on the biological control of Pythium aphanidermatum with Trichoderma asperelloides. J Biofertil Biopesticides. 2013;4(2):137-41.

[348] Pakniat M, Banihashemi Z. Biological control of root knot nematode (Meloidogyne javanica) by Paecilomyces lilacinus on tomato. 15th Iranian Plant Protection Congress; 2002. p. 107.

[349] Pal KK, McSpadden GB. Biological Control of Plant Pathogens. The Plant Health Instructor; 2006.

[350] Palaniyandi SA, Damodharan K, Yang SH, Suh JW. Streptomyces sp. strain PGPA39 alleviates salt stress and promotes growth of 'Micro Tom'tomato plants. J Appl Microbiology. 2014;117(3):766-73.

[351] Palizi P, Goltapeh E, Pourjam E, Safaie N. Potential of oyster mushrooms for the biocontrol of sugar beet nematode (Heterodera schachtii). J Plant Prot Res. 2009;49(1):27-34.

[352] Panjehkeh N, Saberyan A, Afshari Azad H, Salari M. Biological control of Phoma lingam the causal agent of rapeseed blackleg by Trichoderma and Bacillus subtilis isolates. Iran J Plant Pathol. 2011;47(1):19-30.

[353] Parveen S, Wani AH, Bhat MY, Koka JA. Biological control of postharvest fungal rots of rosaceous fruits using microbial antagonists and plant extracts. Czech Mycology. 2016;98(1):41-66.

[354] Patten CL, Glick BR. Role of Pseudomonas putida indoleacetic acid in development of the host plant root system. Appl Environ Microbiology. 2002;68(8):3795-801.

[355] Peighami-Ashnaei S, Sharifi-Tehrani A, Ahmadzadeh M, Behboudi K. Interaction of different media on production and biocontrol efficacy of Pseudomonas fluorescens P-35 and Bacillus subtilis B-3 against grey mould of apple. J Plant Pathol. 2009a;65-70.

[356] Peighami-Ashnaei S, Sharifi-Tehrani A, Ahmadzadeh M, Behboudi K. Screening of Pseudomonas and Bacillus isolates for potential biocontrol of the damping-off of bean (Phaseolus coccineus). Commun Agric Appl Biol Sci. 2009b;74(3):745-8.

[357] Peighamy-Ashnaei S, Sharifi-Tehrani A, Ahmadzadeh M, Behboudi K. Effect of carbon and nitrogen sources on growth and biological efficacy of Pseudomonas fluorescens and Bacillus subtilis against Rhizoctonia solani the causal agent of bean damping-off. Commun Agric Appl Biol Sci. 2007;72(4):951-6.

[358] Peyghami E, Babadoost M. Studying biological control of common and dwarf bunts of wheat. 12th Iranian Plant Protection Congress; 1996. p. 32.

[359] Peyghami E, Nishabouri MR. Studying biological control of cucumber Fusarium wilt by Trichoderma harzianum Rifai. 13th Iranian Plant Protection Congress; 1998. p. 178.

[360] Peyghami E. Antagonistic effects of several isolates of Trichoderma on fungi causing onion root rot East Azarbaidjan Province Iran. J Agric Sci. 2001;32:747-55.

[361] Pourabdullah Sh, Binesh H. Biological control of rice sheat blight with antagonistic fungi. 11th Iranian Plant Protection Congress; 1994. p. 68.

[362] Pourmehdi Alamdarlou R, Zaman Mirabadi A, Fakharian S. Antagonistic effect of Coniothyrium minitans on the sclerotia of Sclerotinia sclerotiourum in Mazandran province. 17th Iranian Plant Protection Congress; 2006. p. 469.

[363] Raaijmakers JM, Mazzola M. Diversity and natural functions of antibiotics produced by beneficial and plant pathogenic bacteria. Annu Rev phytopathology. 2012;50:403-24.

[364] Raeesi H, Djavaheri M, Taghavi SM. Biocontrol effect of Trichoderma species on disease severity of Magnaporthe grisea. 20th Iranian Plant Protection Congress; 2012a. p. 250.

[365] Raeesi H, Djavaheri M, Taghavi SM. Biocontrol activity of $T$. harzianum against Botrytis cinerea in laboratory and 
greenhouse conditions. 20th Iranian Plant Protection Congress; 2012b. p. 266.

[366] Rahanandeh H, Moshaiedy M. Potency evaluation of Pseudomonas aeruginosa and Pseudomonas fluorescens as biocontrol agents for root-knot nematodes in Iran. Int J Biosci. 2014;12:222-8.

[367] Rahanandeh H, Khodakaramian G, Hassanzadeh N, Seraji A, Asghari SM. Evaluation of antagonistic Pseudomonas against root lesion nematode of tea. Int J Biosci. 2013;3(3):32-40.

[368] Rahanandeh H, Khodakaramian G, Hassanzadeh N, Seraji A, Asghari SM, Tarang AR. Inhibition of tea root lesion nematode Pratylenchus loosi by rhizosphere bacteria. Online J Manag Syst. 2012;2(4):243-50.

[369] Rahnama K, Cooke RC. Evaluation of mycoparasitism effect on oospores and sporangia of Pythium ultimum by Pythium oligandrum.13th Iranian Plant Protection Congress; 1998. p. 302.

[370] Ramadan EM, AbdelHafez AA, Hassan EA, Saber FM. Plant growth promoting rhizobacteria and their potential for biocontrol of phytopathogens. Afr J Microbiol Res. 2016;10:486-504.

[371] Ramezani H. Biological control of root-rot of eggplant caused by Macrophomina phaseolina American-Eurasian. J Agric Environ Sci Dubai. 2008;4:218-20.

[372] Ramezani-Baghmishezad M, Sharifi-Tehrani A, Rohani H, Zakeri Z. Study on the effect of some antagonistic bacteria against Fusarium oxysporum the causal agent of basal and root rot in greenhouse and field conditions. 16th Iranian Plant Protection Congress; 2004. p. 239.

[373] Ranjbar Chaharborj S, Shirzad A, Arzanlou M. Evaluation of the biocontrol ability of Pichia membranaefaciens yeast against Aspergillus tubingensis and Penicillium crustosum causing bunch rot disease in grapes. Biol Control Pests Plant Dis. 2016;5(1):97-110.

[374] Ranjbar Sistani S, Behboudi K, Sharifi Tehrani A, Razavi M, Ghasemi A. Biological control of common root rot of wheat by fluorescent pseudomonads isolated from wheat rhizosphere. 19th Iranian Plant Protection Congress; 2010. p. 841.

[375] Reddy KRK, Jyothi G, Sowjanya Ch, Kusumanjali K, Malathi N, Subramaniam G. Editors. Plant Growth-Promoting Actinomycetes: mass production delivery systems and commercialization in plant growth promoting Actinobacteria. Singapore: Springer; 2016. p. 287-98.

[376] Rezaei R, Alizadeh HR, Azadvar M, Salari K. Evaluation of Bacillus spp. isolates for biological control of Pythium aphanidermatum causal agent of cucumber damping-off. 22th Iranian Plant Protection Congress; 2016. p. 351.

[377] Roodgar E, Foroutan A, Khosravi V, Eskandar IA, Naeimi Sh. Study on possibility of biological control of rice bakanae disease with Trichoderma isolates in Mazandaran province. 19th Iranian Plant Protection Congress; 2010. p. 844.

[378] Roohabadi I, Rowhani H, Hemati Kakhki A, Mahdikhani Moghadam E. The in vitro evaluation of Trichoderma isolates for biological control of Bipolaris australiensis and Botrytis cinerea the causal agents of saffron corm rot. 20th Iranian Plant Protection Congress; 2012. p. 260.

[379] Rostami SH, Maleki M, Shahriyari D, Farzaneh M. Investigation of the effect of Bacillus sp. antagonistic isolates on biological control of Sclerotinia sclerotiorum cucumber stem rot in vitro. 20th Iranian Plant Protection Congress; 2012. p. 310.
[380] Rouhani H, Safari M. Study on antagonistic effect of Aspergillus niger on Pythium butleri. 13th Iranian Plant Protection Congress; 1998. p. 301.

[381] Saberi-Riseh R, Fathi F. Biocontrol of Fusarium oxysporum in cucumber by some antagonist bacteria under drought stress. J Crop Prot. 2018;7(4):375-85.

[382] Saberi-Riseh R, Sharifi-Tehrani A, Hejaroud GH, Mohammadi M. Antagonistic effects of several bacteria on Phytophthora citrophthora the causal agent of gummosis (root and crown rot) of pistachio. 16th Iranian Plant Protection Congress; 2004. p. 381.

[383] Sadeghi B, Hatami N. Evaluation of antifungal activity of Streptomyces isolates against cucumber Fusarium rot. 20th Iranian Plant Protection Congress; 2012. p. 296.

[384] Sadeghi B. Evaluation of Streptomyces isolates for biological control of Phytophthora parasitica the causal agent of citrus root rot. 20th Iranian Plant Protection Congress; 2012. p. 253.

[385] Sadeghi B, Hatami N. Screening biological activities of soilborne Streptomyces sp. against several phytopathogenic fungi. Arch Phytopathol Plant Prot. 2014;47(8):954-8.

[386] Safaee D, Heydari A, Hesan A, Younesi H. Investigation of the possibility of biological control of sugar beet seedling damping-off and root rot disease in the field condition in Kermanshah province using Trichoderma harzianum and $T$. viride. 18th Iranian Plant Protection Congress; 2008. p. 308.

[387] Safari Asl E, Rouhani H, Falahati Rastegar M. Study of antagonistic mechanisms of Bacillus spp. in biocontrol of cucumber root and foot rot caused by Pythium aphanidermatum in the Tonekabon fields. 19th Iranian Plant Protection Congress; 2010. p. 871.

[388] Safari Motlagh MR, Mohammadian S. Biological control of rice brown spot disease caused by Bipolaris victoriae by some fungal isolates in the greenhouse and in vitro conditions. Biocontrol Plant Prot. 2016;3(2):11-25.

[389] Safdarpour F, Khodakaramian G. Assessment of biocontrol ability of some tomato rhizosphere Bacillus spp. towards the causal agent of Verticillium wilts disease. 22th Iranian Plant Protection Congress; 2016. p. 303.

[390] Sajadi S, Hasan ZN, Bahrami M, Khosravi V. A possible approach to biocontrol of rice sheath blight with some antagonistic bacteria. J Agric Sci. 2006;12(1):201-213.

[391] Sajadi SA, Asemi H. Evaluation of biological control potential Trichoderma species against of tobacco collar rot in Mazandaran province. N Find Agriculture. 2008;2(3):253-70.

[392] Sajjadi A, Hasanzadeh N, Bahrami M, Khosravi V. Studies the effects of some antagonistic bacteria against rice sheat blight on seed germination percentage and different rice growth stages. 16th Iranian Plant Protection Congress; 2004. p. 103.

[393] Salari M, Hajian-Shahri M, RohaniH Farrokhi F, Ravan S. Biological control of Rhizoctonia solani (AG4) damping-off of sugar beet with Pythium oligandrum. 18th Iranian Plant Protection Congress; 2008a. p. 312.

[394] Salari M, Salehi Jouzani Gh, Panjeke N, Mohamadipour M, Mousivand M. Evaluation of biocontrol potential Bacillus subtilis strains producing surfactin against Citrus anthracnose. 18th Iranian Plant Protection Congress; 2008b. p. 250.

[395] Salari M, Shahidi Bonjar GH, Sadeghi B, Panjeke N, Aminnaii MM, Shakery T. Investigation biological control two strains of antifungal actinomycetes against Phytophthora 
parasitica and $P$. citrophthora in vitro and in vivo. Cond J Plant Prot. 2011;24(4):437-44.

[396] Salehpour M, Etebarian HR, Roustaii MA, Khodakaramian Gh, Aminian H. Biological control of Bipolaris sorokiniana causal agent of common root rot of wheat by Trichoderma spp. and Streptomyces spp. 16th Iranian Plant Protection Congress; 2004. p. 55.

[397] Samavat S, Heydari A, Zamanizadeh HR, Rezaee S, Aliabadi AA. A comparison between Pseudomonas aureofaciens (chlororaphis) and $P$. fluorescens in biological control of cotton seedling damping-off disease. J Plant Prot Res. 2014;54(2):115-21.

[398] Sanei SJ, Ghobadi A. Interaction of antagonistic and pathogens in biological control of soybean root rot. 12th Iranian Plant Protection Congress; 1996. p. 112.

[399] Sarani SA, Sharifi TA, Ahmadzadeh M, Javan NM. Biological control of canola rhizoctonia damping off by application of Burkholderia cepacia. Plant Prot (Sci J Agriculture). 2010;32(2):1-14.

[400] Sarani SH, Sharifi Tehrani A, Ahmadzadeh M, Javan Nikkhah M. Application of Fluorescent Pseudomonads in biological control of Rhizoctonia solani causal agent of Colza. JWSS-Isfahan Univ Technol. 2008a; 11(42):261-70.

[401] Sarani ShA, Sharifi Tehrani A, Ahmadzadeh M, Javan Nikkhah M. The study of correlation between antifungal metabolites production of antagonistic bacteria and biological control of Rhizoctonia solani the causal agent of canola damping-off. 18th Iranian Plant Protection Congress; 2008b. p. 314.

[402] Saravanakumar DA, Ciavorella D, Spadaro A, Garibaldi A, Gullino ML. Metschnikowia pulcherrima strain MACH1 out competes Botrytis cinerea, Alternaria alternata and Penicillium expansum in apples through iron depletion Postharvest. Postharvest Biol Technol. 2008;49:121-28.

[403] Sedaghatfar A, Hassanzadeh N, Heydari A, Foroutan AR. Suppression of Take-all disease of wheat by bacterial isolates of in Pseudomonas spp. greenhouse condition. 15th Iranian Plant Protection Congress; 2002. p. 17.

[404] Selselehzakeri Sh, Akhavansepahi A, Rezapanah MR. An investigation on antifungal activity and compounds of Bacillus subtilis against some plant pathogenic fungi. 18th Iranian Plant Protection Congress; 2008. p. 299.

[405] Shahbazi H, Behboudi K, Nikkhah MJ, Ahmadzadeh M. Detection of hcnAB and phID genes in fluorescent pseudomonads biological control agent of Fusarium graminearum and studying their ability to ectorhizosphere colonization of wheat. Biol Control Pests Plant Dis. 2015;4(2):143-55.

[406] Shahid S, Khan MR. Biological control of root-rot on mungbean plants incited by Macrophomina phaseolina through microbial antagonists. Plant Pathol J. 2016;15(2):27-39.

[407] Shahidi Bonjar GH, Aghighi S. Chitinolytic and microsclerostatic activity of Iranian strains of Streptomyces plicatus and Frankia sp. on olive isolate of Verticillium dahliae. Biotechnology. 2005;4(2):108-13.

[408] Shahidi Bonjar GH, Zamanian S, Aghighi S, Rahimian H, Masoumi H, Hoseini Pour A, et al. Antibacterial activity of Streptomyces coralus strain 63 and S. plicatus strain 101 against Ralstonia solanacearum and Pectobacterium carotovorum sub.sp. carotovorum. 17th Iranian Plant Protection Congress; 2006. p. 467.
[409] Shahiri Tabarestani M, Flahati Rastegar M, Jafarpour B, Rohani H. Biological control of sugar beet Rhizoctonia root rot by Trichoderma, Gliocladium and Bacillus subtilis in in-vitro and invivo. 14th Iranian Plant Protection Congress; 2000. p. 65.

[410] Shahiri TM, Falahati RM, Jafarpour B, Rouhani H. Investigation of antagonistic effect of Bacillus subtilis on biological control of sugar beet damping-off disease. J Sugarbeet. 2005;20(2):161-74.

[411] Shahriari D, Naraghi L, Sarpeleh A, Hydrae A, Afshari Azad H. Decrease in the incidence of cucumber Fusarium wilt in Varamin greenhouses using Talaromyces flavus. 22th Iranian Plant Protection Congress; 2016. p. 270.

[412] Shahriary D, Okhovat M, Rohani H. Biological control of Pythium ultimum the causal agent of chickpea seed-rot and damping-off by antagonistic fungi. 12th Iranian Plant Protection Congress; 1996. p. 147.

[413] Shams M, Shahnavaz B. Evaluation of antimicrobial activity some of marine Streptomyces sp. against three plant pathogens. Biol Control Pests Plant Dis. 2017;6(1):73-82.

[414] Sharifi-Tehrani A, Ahmadzadeh M, Sarani S, Farzaneh M. Powder formulation of Burkholderia cepacia for control of rape seed damping-off caused by Rhizoctonia solani. Commun Agric Appl Biol Sci. 2007;72(2):129-36.

[415] Sharify A, Sharzei A, Ramshini HA. Isolation and identification and evaluation of biological control potential of Trichoderma citrinoviride isolates against root and crown rot of wheat. 22th Iranian Plant Protection Congress; 2016a. p. 362.

[416] Sharify A, Sharzei A, Ramshini HA. Isolation and identification and evaluation of biological control potential of Trichoderma asperellum isolates against root and crown rot of wheat. 22th Iranian Plant Protection Congress; 2016b. p. 369.

[417] Shetab-Booshehri SM, Zad J, Hejaroud GHA, Okhovat M, Farokhinezhad $R$. The effects of several fungicides and antagonistic fungi (Trichoderma spp.) on Mauginiella scaettae Cav the causal agent of date palm inflorescence rot (Khamej). 13th Iranian Plant Protection Congress; 1998. p. 227.

[418] Shirazi K, NasrEsfahani M, Atabaki N, Mohsenzade Kermani A. Study of antagonistic effects of some fungi isolates and bioproducts in controlling sugar beet cyst nematode in the greenhouse. 22th Iranian Plant Protection Congress; 2016. p. 388.

[419] Sikora RA. Management of the antagonistic potential in agricultural ecosystems for the biological control of plant parasitic nematodes. Annu Rev Phytopathology. 1992;30:245-70.

[420] Sindhu SS, Sehrawat A, Sharma R, Dahiya A. Biopesticides: use of rhizosphere bacteria for biological control of plant pathogens. Def Life Sci J. 2016;1(2):135-48.

[421] Sindhu SS, Rakshiya YS, Sahu G. Biological control of soil borne plant pathogens with rhizosphere bacteria. Pest Technol. 2009;3:10-21.

[422] Soharabi M, Mohammadi H, Mohammadi AH. Effects of two arbuscular mycorrhizal fungi Glomus mossae and Glomus intraradices on pea root rot disease caused by Fusarium solani f.sp. pisi under greenhouse conditions. Biol Control Pests Plant Dis. 2014;2(2):129-37.

[423] Soltani H, Zafari D, Rouhani H. A study on biological control of the crown root and tuber fungal diseases of potato by Trichoderma harzianum under in-vivo and field condition in Hamadan. Agric Res. 2006;5(3):13-25. 
[424] Soltanzadeh M, Soltani Nejad M, Shahidi Bonjar GH. Application of soil-borne actinomycetes for biological control against Fusarium wilt of chickpea (Cicer arietinum) caused by Fusarium solani f.sp. pisi. J Phytopathology. 2016;164(11-12):967-78.

[425] Soofi E, Safaie N, Shahbazi S. Evaluation of antagonistic properties of Trichoderma viride mutants against some fungal plant pathogens. 20th Iranian Plant Protection Congress; 2012. p. 259.

[426] Spadaro D, Gullino ML. State of the art and future prospects of the biological control of postharvest fruit diseases. Int J Food Microbiology. 2004;91(2):185-94.

[427] Sziderics AH, Rasche F, Trognitz F, Sessitsch A, Wilhelm E. Bacterial endophytes contribute to abiotic stress adaptation in pepper plants (Capsicum annuum L.). Can J Microbiology. 2007;53(11):1195-202.

[428] Tabarrraie M, Amini J, Harighi B, Shahriari D. Biological control of damping-off disease of cantaloupe with fluorescent pseudomonades bacteria in greenhouse conditions. 19th Iranian Plant Protection Congress; 2010. p. 812.

[429] Tabe Bordbar E, Etebarian HR, Sahebany N, Rohani H. Control of blue mold of apple fruit by Trichoderma virens (T8) and inoculation of defence responses at $20^{\circ} \mathrm{C}$. 18th Iranian Plant Protection Congress; 2008a. p. 251.

[430] Tabe-Bordbar F, Etebarian HR, Sahebany N, Rohani H. Biological control of apple blue mold Penicillium solitum by Trichoderma isolates.18th Iranian Plant Protection Congress; 2008b. p. 324.

[431] Taghinasab M, Rouhani H, Khodakaramian Gh, Karimi E. Evaluation of antagonistic activity of Trichoderma spp., Pseudomonas fluorescens and Bacillus subtilis on Pythium ultimum the causal agent of cucumber dampin-off. 16th Iranian Plant Protection Congress; 2004. p. 258.

[432] Taheri H, Minassian V, Farrokhinegad R. Investigation on the possibility of biological and chemical control of citrus branch wilt decline and death disease. 14th Iranian Plant Protection Congress; 2000. p. 325.

[433] Tajalipour S, Hassanzadeh N, Khabbaz Jolfaee H, Heydari A, Ghasemi A. Biological control of mushroom brown blotch disease using antagonistic bacteria. Biocontrol Sci Technol. 2014;24(4):473-84.

[434] Tajalipour Sh, Hassanzadeh N, Heydari A, Khabbaz Jolfaee H. Biological control of brown blotch disease of white button mushroom (Agaricus bisporus) by some antagonistic bacteria. 20th Iranian Plant Protection Congress; 2012. p. 300.

[435] Talibi I, Boubaker H, Boudyach EH, Ait Ben Aoumar A. Alternative methods for the control of postharvest citrus diseases. J Appl Microbiology. 2014;117(1):1-17.

[436] Tanha S, Bayat F, Jamali F, Saeidi Zadeh AA. Evaluation of Pseudomonas fluorescens strains for biological control of root-knot nematode in some tomato cultivars. J Biocontrol Plant Prot. 2016;3(2):27-39.

[437] Tashi-Oshnoei F, Harighi B, Abdollahzadeh J. Isolation and identification of endophytic bacteria with plant growth promoting and biocontrol potential from oak trees. For Pathol. 2017;47(5):12360.

[438] Toghueoa RMK, Ekea P, Gonzálezb IZ, de Aldanab BRV, Nanaa LW, Boyoma FF. Biocontrol and growth enhancement potential of two endophytic Trichoderma spp. from Terminalia catappa against the causative agent of Common Bean Root Rot (Fusarium solani). Biol Control. 2016;96:8-20.
[439] Turatto MF, Dourado FDS, Zilli JE, Botelho GR. Environmental microbiology: control potential of Meloidogyne javanica and Ditylenchus spp. Using fluorescent Pseudomonas and Bacillus spp. Braz J Microbiology. 2017;49(1):54-8.

[440] Ulloa-Ogaz AL, Muñoz-Castellanos LN, NevárezMoorillón GV. Biocontrol of phytopathogens: antibiotic production as mechanism of control the battle against microbial pathogens: basic science technological advances and educational programs. Spain: Formatex research center; 2015. p. 305-9.

[441] Vafaie A, Behboudi B, Jafarie A. Effect of Streptomyces isolates from tomato rhizosphere on Fusarium oxysporum f.sp. radicis lycopersici. 23th Iranian Plant Protection Congress; 2018. p. 874.

[442] Vasebi Y, Alizadeh A, Safaie N. Pantoea agglomerans ENA1 as a biocontrol agent of Macrophomina phaseolina and growth enhancer of soybean. J Crop Prot. 2015;4(1):43-57.

[443] Vasebi Y, Dehnad AR. Evaluation of antifungal potential of Streptomyces isolates based on molecular identification of chitinase-encoding gene. 20th Iranian Plant Protection Congress; 2012. p. 272.

[444] Vasebi Y, Safaie N, Alizadeh A. Biological control of soybean charcoal root rot disease using bacterial and fungal antagonists in vitro and greenhouse condition. J Crop Prot. 2013;2(2):139-50.

[445] Vinale F, Sivasithamparam K, Ghisalberti EL, Woo SL, Nigro M, Marra R, et al. Trichoderma secondary metabolites active on plants and fungal pathogens. Open Mycology J. 2014;8(Suppl-1):127-39.

[446] Vorholt JA. Microbial life in the phyllosphere. Nat Rev Microbiol. 2012;10:828-40.

[447] Vos CM, De Cremer K, Cammue BPA, De Coninck B. The toolbox of Trichoderma spp. in the biocontrol of Botrytis cinerea disease. Mol Plant Pathol. 2015;16:400-12.

[448] Wisniewski M, Biles C, Droby S, McLaughlin R, Wilson C, Chalutz E. Mode of action of the postharvest biocontrol yeast Pichia guilliermondii I characterization of attachment to Botrytis cinerea. Physiol Mol Plant Pathol. 1991;39(4):245-58.

[449] Yahyavi Azad A, Seraji A, Ali Akbar HJ, Safaei Chaeikar S. The effect of several antagonistic fungi isolate on biological control of tea root lesion nematode (Pratylenchus loosi). Biol Control Pests Plant Dis. 2018;7(1):21-32.

[450] Yahyavi Azad A, Seraji A, Hojjat Jalali AA, Jamali S. Isolation of antagonistic fungi from tea plantation and study of their impact on tea root lesion nematode Pratylenchus loosi in laboratory. Biocontrol Plant Prot. 2017;5(1):81-91.

[451] Yousefi H, Sahebani N, Mirabolfathy M, Faravardeh L, Mahdavi V. The effect of Bacillus subtilis on cucumber root and stem rot caused by Fusarium oxysporum f.sp. radiciscucumerinum. 19th Iranian Plant Protection Congress; 2010. p. 926.

[452] Yousefi H, Hassanzadeh N, Behboudi K, Firouzjahi FB. Identification and determination of characteristics of endophytes from rice plants and their role in biocontrol of bacterial blight caused by Xanthomonas oryzae pv. oryzae. Hellenic Plant Prot J. 2018;11(1):19-33.

[453] Zafari D, Koushki MM, Bazgir E. Biocontrol evaluation of wheat take-all disease by Trichoderma screened isolates. Afr J Biotechnol. 2008;7(20):3650-56. 
[454] Zafari D, Rouhani H, Okhovat M, Hejaroud GhA. Biological control of Phytophthora erythroseptica by Trichoderma spp. 11th Iranian Plant Protection Congress; 1994. p. 156.

[455] Zahed MJ, Behbudi K. Assessment of Streptomyces isolates of tomato rhizosphere for biocontrol of Fusarium oxysporum f.sp. radicis-lycopersici. Biol Control Pests Plant Dis. 2017;6(2):173-85.

[456] Zahed MJ, Behbudi K. Biological control of Sclerotinia sclerotiorum (Lib) De Bary cause the cucumber white stem rot by rhizospheric Actinobacteria. Biol Control Pests Plant Dis. 2018;7(1):33-45.

[457] Zamani M, Sharifi TA, Ahmadzadeh M, Ali ZAAA, Farzaneh M. Biological Control of green mold of orange caused by Penicillium digitatum with bacterium Pantoea aglomerans. Iran J Agric Sci (J Agriculture). 2008a;39(2):345-52.

[458] Zamani M, Tehrani AS, Ahmadzadeh M, Behboodi K, Hosseininaveh V. Biological control of Penicillium digitatum on oranges using Pseudomonas spp. either alone or in combination with hot sodium bicarbonate dipping. Aust Plant Pathol. 2008b;37(6):605-8.

[459] Zamani M, Sharifi-Tehrani A, Ahmadzadeh M, AlizadehAliabadi A. Biological control of citrus green mold using integrated application of some isolates of Trichoderma sp., Pseudomonas fluorescens and Bacillus subtilis under cold storage. 18th Iranian Plant Protection Congress; 2008c. p. 296.
[460] Zangoei E, Etebarian HR, Sahebani N. Biological control of apple gray mold by mixtures of Bacillus subtilis and yeast isolates. Afr J Food Sci. 2014;8(3):155-63.

[461] Zanguei E, Etebarian HR, Sahebani N, Alizadeh A. Improving biocontrol of gray mold disease of apple using a mixture of yeast isolates. Iran J Plant Prot Sci. 2010;41(2):361-72.

[462] Zebarjad A, Sharifi-Tehrani A, Hejaroud GHA, Mohammadi M. A study on the effect of several antagonistic bacteria on control of soybean damping-off disease caused by Phytophthora sojae. Iran J Agric Sci (J Agriculture). 2006;37(4):671-86.

[463] Zendehdel N, Hasanzadeh N, Beiki Firouzjahi N, Naeimi S. Isolation of tomato endophytic bacteria and evaluation of their biocontrol potential against Verticillium dahliae. 23th Iranian Plant Protection Congress; 2018. p. 880.

[464] Zeynadini-Riseh A, Mahdikhani-Moghadam E, Rouhani H, Moradi M, Saberi-Riseh R, Mohammadi A. Effect of some probiotic bacteria as biocontrol agents of Meloidogyne incognita and evaluation of biochemical changes of plant defense enzymes on two cultivars of Pistachio. J Agric Sci Technol. 2018;20(1):179-91.

[465] Ziarati HM, Roustaee A, Sahebani N, Etebarian HR, Aminian H. Study of biological control of root-knot nematode Meloidogyne javanica (Trube) Chitwood in tomato by Trichoderma harzianum Rifai in greenhouse and quantitative changes of phenolic compounds in plant. Seed Plant Prod J. 2009;25(3):261-74. 